\title{
Additional Period and Site Class Maps for the 2014 National Seismic Hazard Model for the Conterminous United States
}

Open-File Report 2018-1111 



\section{Additional Period and Site Class Maps for the 2014 National Seismic Hazard Model for the Conterminous United States}

By Allison M. Shumway, Mark D. Petersen, Peter M. Powers, and Sanaz Rezaeian

Open-File Report 2018-1111 


\title{
U.S. Department of the Interior \\ RYAN K. ZINKE, Secretary
}

\author{
U.S. Geological Survey \\ James F. Reilly II, Director
}

U.S. Geological Survey, Reston, Virginia: 2018

For more information on the USGS - the Federal source for science about the Earth, its natural and living resources, natural hazards, and the environment-visit https://www.usgs.gov or call 1-888-ASK-USGS.

For an overview of USGS information products, including maps, imagery, and publications,

visit https://store.usgs.gov.

Any use of trade, firm, or product names is for descriptive purposes only and does not imply endorsement by the U.S. Government.

Although this information product, for the most part, is in the public domain, it also may contain copyrighted materials as noted in the text. Permission to reproduce copyrighted items must be secured from the copyright owner.

Suggested citation:

Shumway, A.M., Petersen, M.D., Powers, P.M., and Rezaeian, S., 2018, Additional period and site class maps for the 2014 National Seismic Hazard Model for the conterminous United States: U.S. Geological Survey Open-File Report 2018-1111, 46 p., https://doi.org/10.3133/ofr20181111.

ISSN 2331-1258 (online) 


\section{Contents}

Abstract

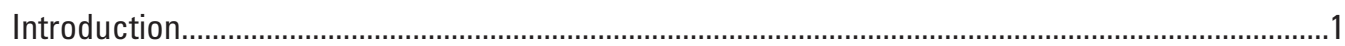

Additional Period and Site Class Maps for the 2014 National Seismic Hazard Model for the Conterminous United States..................................................................................................

Selecting Additional Periods and Site Classes.....................................................................

Selecting $V_{S 30}$ Values to Define Site Classes........................................................................

Review of Ground Motion Model Selection Criteria and Selection of Updated Suites of Weighted Ground Motion Models ..................................................................................

Ground Motion Magnitude-Distance Scaling Relation Plots .............................................

Updated Seismic Hazard Curves and Probabilistic Ground Motion Maps ..............................14

Effect of Updated Suites of Weighted Ground Motion Models on Hazard for Peak Ground Acceleration, 0.2, and 1.0 Second Spectral Accelerations ....................14

Hazard Curves and Uniform Hazard Response Spectra ..........................................................26

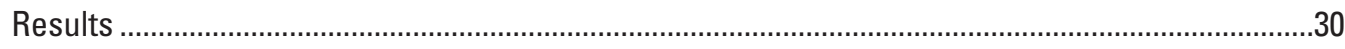

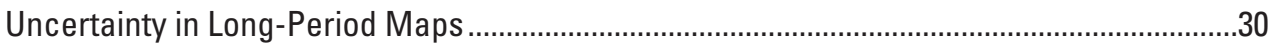

Future Updates of the National Seismic Hazard Model for the Conterminous United States........30

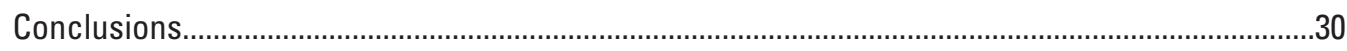

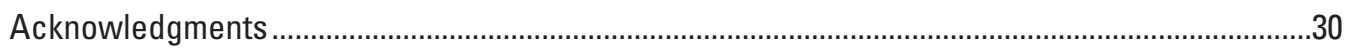

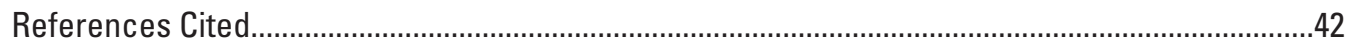

Appendix 1. Maps and Data Available for the 2014 National Seismic Hazard Model for the

Conterminous United States...........................................................................................4

\section{Figures}

1. Central and eastern United States ground motion model magnitude-distance scaling plots for 2.0 second spectral acceleration

2. Western United States ground motion model magnitude-distance scaling plots for 5.0 second spectral acceleration.

3. Subduction interface ground motion model magnitude-distance scaling plots for moment magnitude 8.5

4. Subduction intraslab ground motion model magnitude-distance scaling plots for moment magnitude 7

5. Hazard, difference, and ratio maps calculated for the 2014 National Seismic Hazard Model.

6. Site in the Pacific Northwest in which a deaggregation was performed for peak ground acceleration hazard at 2 percent in 50-year probability of exceedance for the National Earthquake Hazards Reduction Program site class boundary B/C.

7. Summary figure showing 2,5 , and 10 percent probabilities of exceedance in 50 years uniform hazard response spectra plots and select hazard curves for Memphis, Tennesse; Salt Lake City, Utah; Seattle, Washington; and Los Angeles, California...

8. Hazard, difference, and ratio maps for peak ground acceleration and various second spectral accelerations for 2 percent in 50-year probability of exceedance for the National Earthquake Hazards Reduction Program site class boundary B/C. 


\section{Tables}

1. Periods and site classes used for calculations in this report ..............................................2

2. Simplified version of table 20.3-1 in ASCE 7-16.................................................................

3. The 2014 National Seismic Hazard Model original suites of weighted ground motion models, and the updated suites of weighted ground motion models used for calculations in this report.

1.1 List of probabilistic ground motion hazard maps, gridded ground motion data, and seismic hazard curve data available for the 2014 National Seismic

Hazard Model

\section{Abbreviations}

\begin{tabular}{|c|c|}
\hline ASCE & American Society of Civil Engineers \\
\hline BSSC & Building Seismic Safety Council \\
\hline CEUS & central and eastern United States \\
\hline CSZ & Cascadia subduction zone \\
\hline$f$ & $\begin{array}{l}\text { frequency; the number of occurrences of a repeating event per unit of time. } \\
\text { International System of Units is the hertz }(\mathrm{Hz})\end{array}$ \\
\hline g & gravitational acceleration constant equal to 9.81 meters per second squared \\
\hline GMM & ground motion model \\
\hline \multicolumn{2}{|c|}{ Ground motion models for stable continental earthquakes: } \\
\hline A08' & Atkinson (2008), Atkinson and Boore (2011) \\
\hline $\mathrm{AB} 06^{\prime}$ & Atkinson and Boore $(2006,2011)$ \\
\hline $\mathrm{CO3}$ & Campbell (2003) \\
\hline F96 & Frankel and others (1996) \\
\hline S02 & Silva and others (2002) \\
\hline P11 & Pezeshk and others (2011) \\
\hline T02 & Toro and others (1997), Toro (2002) \\
\hline TP05 & Tavakoli and Pezeshk (2005) \\
\hline S01 & Somerville and others (2001) \\
\hline \multicolumn{2}{|c|}{ Ground motion models for active crustal earthquakes: } \\
\hline ASK14 & Abrahamson and others (2014) \\
\hline BSSA14 & Boore and others (2014) \\
\hline CB14 & Campbell and Bozorgnia (2014) \\
\hline CY14 & Chiou and Youngs (2014) \\
\hline 114 & Idriss (2014) \\
\hline
\end{tabular}


Ground motion models for subduction interface and intraslab earthquakes:

AB03 Atkinson and Boore (2003)

AM09 Atkinson and Macias (2009)

BCHydro12 Abrahamson and others (2016)

Zhao06 Zhao and others (2006)

Ground Motion Intensity Measures:

PGA peak ground acceleration

SA spectral acceleration(s)

Mw moment magnitude, or $\mathrm{M}$

NEHRP National Earthquake Hazards Reduction Program

NGA-West2 Next Generation Attenuation Relationships for western United States, version 2, 2014 (ground motion models)

NSHM National Seismic Hazard Model

NSHMP National Seismic Hazard Model Project

PNW Pacific Northwest

Project 17 Building Seismic Safety Council (BSSC) led working group that proposes rules for design maps to support the U.S. Geological Survey (USGS) in developing the next generation of hazard maps

RLME repeated large magnitude earthquakes

$\mathrm{T} \quad$ period; the time needed for one complete cycle of vibration to pass a given point. International System of Units is the second (s)

UHRS uniform hazard response spectra; response spectra having the same probability of exceedance in a specified span of time at all frequencies

USGS U.S. Geological Survey

$\mathrm{V}_{\mathrm{S} 30} \quad$ Time-averaged shear wave velocity in the upper 30 meters, used to define National Earthquake Hazards Reduction Program (NEHRP) A, B, C, D, and E site classes. NEHRP site class $A$ is defined as $V_{S 30}=2,000$ meters per second, the site class boundary between $A$ and $B$ is defined as $V_{S 30}=1,500$ meters per second, site class $B$ is defined as $V_{S 30}=1,080$ meters per second, the site class boundary between $B$ and $C$ is defined as $V_{S 30}=760$ meters per second, site class $C$ is defined as $V_{S 30}=530$ meters per second, the site class boundary between $C$ and $D$ is defined as $V_{S 30}=365$ meters per second, site class $D$ is defined as $V_{S 30}=260$ meters per second, the site class boundary between $D$ and $E$ is defined as $V_{S 30}=185$ meters per second, and site class $E$ is defined as $V_{S 30}=150$ meters per second, which are uniformly applied in maps in this report

WUS western United States 



\title{
Additional Period and Site Class Maps for the 2014 National Seismic Hazard Model for the Conterminous United States
}

\author{
By Allison M. Shumway, Mark D. Petersen, Peter M. Powers, and Sanaz Rezaeian
}

\section{Abstract}

The 2014 update of the U.S. Geological Survey (USGS) National Seismic Hazard Model (NSHM) for the conterminous United States (2014 NSHM; Petersen and others, 2014, 2015) included probabilistic ground motion maps for 2 percent and 10 percent probabilities of exceedance in 50 years, derived from seismic hazard curves for peak ground acceleration (PGA) and 0.2 and 1.0 second spectral accelerations (SAs) with 5 percent damping for the National Earthquake Hazards Reduction Program (NEHRP) site class boundary B/C (time-averaged shear wave velocity in the upper 30 meters $\left[\mathrm{V}_{\mathrm{S} 30}\right]=760$ meters per second $[\mathrm{m} / \mathrm{s}])$. We now provide uniform NEHRP site class maps for 2, 5, and 10 percent probabilities of exceedance in 50 years derived from hazard curves for additional spectral periods. For the central and eastern United States (CEUS) and western United States (WUS), hazard curves and maps for PGA, 0.1, 0.2, 0.3, 0.5, 1.0, and 2.0 second SAs are now available. The WUS additionally includes hazard curves and maps for $0.75,3.0,4.0$, and 5.0 second SAs. The use of region-specific suites of weighted ground motion models (GMMs) in the 2014 NSHM precluded the calculation of ground motions for a uniform set of periods and site classes for the conterminous United States. At the time of the development of the 2014 NSHM, there was no consensus in the CEUS on an appropriate site-amplification model to use; therefore, we calculated hazard curves and maps for NEHRP site class A, for which most stable continental GMMs were originally developed, based on simulations for hard rock site conditions $\left(\mathrm{V}_{\mathrm{S} 30}=2,000 \mathrm{~m} / \mathrm{s}\right)$. In the WUS, however, the active crustal Next Generation Attenuation Relationships for the WUS (NGA-West2 GMMs) and subduction GMMs allow amplification of ground motions based on site class (defined by $\mathrm{V}_{\mathrm{S30}}$ ); so we calculated hazard curves and maps for NEHRP site classes $\mathrm{B}\left(\mathrm{V}_{\mathrm{S} 30}=1,080 \mathrm{~m} / \mathrm{s}\right), \mathrm{C}\left(\mathrm{V}_{\mathrm{S} 30}=530 \mathrm{~m} / \mathrm{s}\right), \mathrm{D}\left(\mathrm{V}_{\mathrm{S} 30}=260 \mathrm{~m} / \mathrm{s}\right)$, and $\mathrm{E}\left(\mathrm{V}_{\mathrm{S} 30}=150 \mathrm{~m} / \mathrm{s}\right)$ and site class boundaries $\mathrm{A} / \mathrm{B}\left(\mathrm{V}_{\mathrm{s} 30}=1,500 \mathrm{~m} / \mathrm{s}\right), \mathrm{B} / \mathrm{C}\left(\mathrm{V}_{\mathrm{S} 30}=760 \mathrm{~m} / \mathrm{s}\right), \mathrm{C} / \mathrm{D}\left(\mathrm{V}_{\mathrm{s} 30}=365 \mathrm{~m} / \mathrm{s}\right)$, and $\mathrm{D} / \mathrm{E}\left(\mathrm{V}_{\mathrm{s} 30}=185 \mathrm{~m} / \mathrm{s}\right)$. The $2014 \mathrm{NSHM}$ introduced a set of criteria for selecting GMMs for use in the NSHMs. When calculating additional period and site class maps, we verified whether the 2014 NSHM original suites of GMMs satisfied these ground motion selection criteria at all additional periods and site classes using GMM magnitude-distance scaling relation plots. Results of our analysis show that certain GMMs give unrealistic results at longer periods, distances, and softer soils in the WUS. In these rare instances, the GMM was removed from the original suite of GMMs (for all periods and site classes) and the weights of the remaining GMMs in the suite were renormalized. Ratio maps show these updated suites of weighted GMMs result in probabilistic ground motion changes of less than 10 percent in the WUS at PGA, as well as 0.2 and 1.0 second SAs, except in the Pacific Northwest, where differences as much as 20 percent are seen. Hazard curves and uniform hazard response spectra at test sites across the conterminous United States were produced to verify that results were reasonable. The additional period and site class maps, and the hazard curves from which they were derived, are available for download from the USGS ScienceBase Catalog.

\section{Introduction}

The U.S. Geological Survey (USGS) National Seismic Hazard Model Project (NSHMP) is responsible for developing seismic hazard models and producing maps for the conterminous United States, as well as for Alaska, Hawaii, and permanently inhabited U.S. territories (Puerto Rico and the U.S. Virgin Islands, Guam and the Northern Mariana Islands, and American Samoa). Approximately every 6 years, the NSHMP updates the National Seismic Hazard Model (NSHM) for the conterminous United States, calculates seismic hazard curves, and releases a set of probabilistic ground motion maps. These maps provide the basis for many policies regarding earthquakes, including seismic-design regulations for buildings, bridges, highways, railroads, and other structures. The maps are used in the building codes (Building Seismic Safety Council [BSSC], 2010) to provide variation 
in expected or potential seismic loads at sites across the conterminous United States. The NSHMP seismic hazard assessments also affect insurance rate structures, governmental disaster management and mitigation strategies, planning and seismic safety applications, and many site-specific engineering analyses by industries and governments (Petersen and others, 2014, 2015).

In 2014, the NSHMP updated the NSHM for the conterminous United States (Petersen and others, 2014, 2015, hereinafter referred to as "2014 NSHM") and released a limited number of probabilistic ground motion maps. In the 2008 release of the NSHM for the conterminous United States (Petersen and others, 2008, hereinafter referred to as "2008 NSHM"), maps were produced for an expanded set of spectral periods and uniform National Earthquake Hazards Reduction Program (NEHRP) site classes (https://earthquake.usgs.gov/hazards/hazmaps/conterminous/2008/maps-rev3.php). This report presents details on how the additional period and site class maps for the 2014 NSHM were developed.

In this report, we present probabilistic ground motion maps for 2, 5, and 10 percent probabilities of exceedance in 50 years, derived from seismic hazard curves for peak ground acceleration (PGA), 0.1, 0.2, 0.3, 0.5, 1.0, and 2.0 second spectral accelerations (SAs) in the central and eastern United States (CEUS; this includes uniform NEHRP site class A and site class boundary B/C maps) and for PGA, 0.1, 0.2, 0.3, 0.5, 0.75, 1.0, 2.0, 3.0, 4.0, and 5.0 second SAs in the western United States (WUS; this includes uniform NEHRP site classes B, C, D, and E, and site class boundaries A/B, B/C, C/D, and D/E maps) using the 2014 NSHM. We show hazard, difference, and ratio maps comparing the effect of updated suites of weighted ground motion models (GMMs) on hazard for PGA, as well as 0.2 and 1.0 second SAs. We also show hazard, difference, and ratio maps comparing the 2014 NSHM additional period and site class maps with the 2008 NSHM maps, excluding site class E and site class boundary A/B, which were not produced for the 2008 NSHM. The additional period and site class maps presented in this report are available for download from the USGS ScienceBase Catalog (Shumway, 2018).

\section{Additional Period and Site Class Maps for the 2014 National Seismic Hazard Model for the Conterminous United States}

\section{Selecting Additional Periods and Site Classes}

The first step in producing additional spectral period and site class maps for the 2014 NSHM was to select a set of periods and site classes. For consistency and comparison purposes, we used the same set of periods and site classes as those used to calculate hazard curves and produce maps using the 2008 NSHM. In addition, we included NEHRP site class E and site class boundary A/B maps in the WUS, since our ultimate goal is to provide a selection of periods and site classes that reasonably represent the full range of a design response spectrum. The extended set of periods and site classes used to calculate hazard curves and produce ground motion maps for the 2014 NSHM are listed in table 1.

Table 1. Periods and site classes used for calculations in this report.

[T, period; NEHRP, National Earthquake Hazards Reduction Program; $\mathrm{V}_{\mathrm{S} 30}$, shear wave velocity in the upper 30 meters; m/s, meters per second; PGA, peak ground acceleration]

\begin{tabular}{|c|c|c|}
\hline & Central and eastern United States ${ }^{1}$ & Western United States ${ }^{2}$ \\
\hline Periods (T) & PGA, 0.1, 0.2, 0.3, 0.5, 1.0, and 2.0 seconds & $\begin{array}{l}\text { PGA, } 0.1,0.2,0.3,0.5,0.75,1.0,2.0,3.0,4.0 \text {, } \\
\text { and } 5.0 \text { seconds }\end{array}$ \\
\hline $\begin{array}{l}\text { NEHRP } \\
\text { site } \\
\text { classes } \\
\left(\mathrm{V}_{\mathrm{S} 30}\right)^{3}\end{array}$ & $\begin{array}{l}\text { A (hard rock, } 2,000 \mathrm{~m} / \mathrm{s} \text { ), and B/C (firm rock, } 760 \\
\mathrm{~m} / \mathrm{s} \text { ) }\end{array}$ & $\begin{array}{l}\text { A/B (1,500 m/s), B (rock; } 1,080 \mathrm{~m} / \mathrm{s}), \mathrm{B} / \mathrm{C} \text { (firm rock; } 760 \mathrm{~m} / \mathrm{s}), \mathrm{C} \\
\text { (very dense soil and soft rock; } 530 \mathrm{~m} / \mathrm{s}), \mathrm{C} / \mathrm{D}(365 \mathrm{~m} / \mathrm{s}), \mathrm{D} \text { (stiff soil; } \\
260 \mathrm{~m} / \mathrm{s}), \mathrm{D} / \mathrm{E}(185 \mathrm{~m} / \mathrm{s}) \text {, and } \mathrm{E} \text { (soft clay and soil; } 150 \mathrm{~m} / \mathrm{s}) \text {. }\end{array}$ \\
\hline
\end{tabular}

\footnotetext{
${ }^{1}$ For the central and eastern United States, calculations for seven periods and two site classes were performed. Absence of an appropriate site-amplification model for the central and eastern United States precluded the calculation of additional site classes. The ground motion model applicability ranges of periods in the central and eastern United States precluded the calculation of longer periods.

${ }^{2}$ For the western United States calculations for 11 periods and 8 site classes were performed.

${ }^{3}$ The National Earthquake Hazards Reduction Program site class definitions are from table 20.3-1 of the American Society of Civil Engineers [ASCE] ASCE 7-16 (American Society of Civil Engineers, 2017) and presented in a simplified version here as table 2.
} 
The selection of periods and site classes is restricted by the applicability range of the GMMs used in the 2014 NSHM. In the CEUS, most of the stable continental GMMs are only applicable up to 2.0 seconds. In the WUS, the active crustal GMMs (NGA-West2 GMMs) are applicable up to 10.0 seconds; however, we used a cutoff of 5.0 seconds for consistency with the maximum period of the suite of subduction GMMs. At the time of the development of the 2014 NSHM, there was no consensus on an appropriate site-amplification model in the CEUS. GMMs lack a site term and we only calculated maps for site class A (in other words, hard rock $\left.\left[\mathrm{V}_{\mathrm{S} 30}=2,000 \mathrm{~m} / \mathrm{s}\right]\right)$, for which the suite of 2014 NSHM CEUS GMMs were originally developed based on simulations on hard rock, and for NEHRP site class boundary B/C (firm rock $\left[\mathrm{V}_{\mathrm{S} 30}=760 \mathrm{~m} / \mathrm{s}\right]$ ) by applying amplification factors (see Petersen and others, 2014). In the WUS, however, the active crustal GMMs (NGA-West2 GMMs) and subduction GMMs accept a site term (or $\mathrm{V}_{\text {s30 }}$ ) as an input parameter; therefore, we calculated hazard curves and provide maps for rock and softer sites (see table 1).

\section{Selecting $\mathrm{V}_{\mathrm{s} 30}$ Values to Define Site Classes}

For the 2008 NSHM, we used the following set of $\mathrm{V}_{\mathrm{S30}}$ values to represent the NEHRP site classes and site class boundaries: A=2,000 m/s, B=1,150 m/s, B/C=760 m/s, C=537 m/s, C/D=360 m/s, D=259 m/s, and D/E=180 m/s. These values were estimated using the site class boundary definitions in the corresponding NEHRP and ASCE 7 publications (Building Seismic Safety Council, 2010), where the $\mathrm{V}_{\mathrm{s} 30}$ values for site class boundaries A/B, B/C, C/D, and D/E are defined respectively as 5,000 ft/s, 2,500 ft/s, 1,200 ft/s, and $600 \mathrm{ft} / \mathrm{s}$ (see table 2). For development of future building code documents (for example, NEHRP and ASCE 7), the BSSC Project 17 is considering using the USGS NSHM for additional periods and site classes. As a result, for the 2014 NSHM, we worked directly with the BSSC Project 17 committee to estimate the $\mathrm{V}_{\mathrm{s} 30}$ values for all site classes and their boundaries. The results are slightly different from the values used in 2008 , but they will be more consistent with the future building code documents that are expected to define $\mathrm{V}_{\mathrm{S30}}$ for site class centers as well as site class boundaries.

To determine $\mathrm{V}_{\mathrm{S} 30}$ values for 2014 NSHM, we started with the definition of site class boundaries listed in table 20.3-1 of the American Society of Civil Engineers [ASCE] ASCE 7-16 (American Society of Civil Engineers, 2017) (presented in a simplified version here as table 2). To define the center of a site class, we determined the geometric mean (owing to the logarithmic dependence of GMMs on $\mathrm{V}_{\mathrm{S} 30}$ ) of the boundary $\mathrm{V}_{\mathrm{S} 30}$ values, converted feet per second ( $\mathrm{ft} / \mathrm{s}$ ) to $\mathrm{m} / \mathrm{s}$, and rounded to the nearest 100 and the nearest 5 for values above and below 1,100 m/s (reference rock), respectively. For example, for site class C, we calculated the geometric mean of 2,500 ft/s and 1,200 ft/s, which is $\sim 1,732 \mathrm{ft} / \mathrm{s}$. We then converted this value from ft/s to m/s, which is $\sim 527.9 \mathrm{~m} / \mathrm{s}(1 \mathrm{ft}=0.3048 \mathrm{~m})$. Finally, we rounded this value to the nearest 5 (as the value is below $1,100 \mathrm{~m} / \mathrm{s}$ ) to get a final value of $530 \mathrm{~m} / \mathrm{s}$ to define site class $\mathrm{C}$. The $\mathrm{V}_{\mathrm{S} 30}$ values we used to calculate hazard curves and produce ground motion maps for the 2014 NSHM are listed in table 2.

Table 2. Simplified version of table 20.3-1 in ASCE 7-16 (Building Seismic Safety Council, 2017).

[ft/s, feet per second]

\begin{tabular}{ll}
\hline \multicolumn{1}{c}{ Site class } & \multicolumn{1}{c}{$\mathbf{V}_{\mathbf{s} 30}(\mathbf{f t} / \mathbf{s})$} \\
\hline A. Hard rock & $>5,000$ \\
\hline B. Rock & 2,500 to 5,000 \\
\hline C. Very dense soil and soft rock & 1,200 to 2,500 \\
\hline D. Stiff soil & 600 to 1,200 \\
\hline E. Soft clay soil & $<600$ \\
\hline
\end{tabular}

\section{Review of Ground Motion Model Selection Criteria and Selection of Updated Suites of Weighted Ground Motion Models}

In the 2014 NSHM, the NSHMP defined a set of GMM selection criteria used for selecting GMMs (see p. 109-110 of Petersen and others, 2014; see p. S61-S62 of Rezaeian and others, 2015). The GMM selection criteria relevant to this discussion are as follows:

- Basic - The GMM must provide, at a minimum, equations for the median and aleatory uncertainty of the horizontal component for PGA, 0.2, and 1.0 second SAs. The GMM must be applicable to one of the tectonic regions relevant to the United States.

- Magnitude—The GMM must have magnitude dependence. The magnitude applied must be based on moment magnitude (M). The model must be applicable or reasonably extrapolated to a magnitude range of 5.0 to 8.2 for shallow crustal earthquakes in the WUS and 4.7 to 8.2 for stable continental earthquakes in the CEUS. The GMMs for subduction earthquakes should be applicable or reasonably extrapolated to a magnitude range of 5.0 to 8.0 for intraslab earthquakes and 8.0 to 9.3 for interface earthquakes. 
- Distance-The GMM must have distance dependence. Distance should be measured from the rupture source or from the surface projection of the rupture source. The GMM should be applicable or reasonably extrapolated to a distance of 300 kilometers $(\mathrm{km})$ for shallow crustal and subduction intraslab earthquakes, and 1,000 km for stable continental and subduction interface earthquakes.

- Site Conditions-GMMs must include a term for $\mathrm{V}_{\mathrm{S} 30}$ or be accompanied by other relations (for example, amplification values) that transfer their equations from a $V_{530}$ of $760 \mathrm{~m} / \mathrm{s}$ to soil conditions. For use in softer soil hazard maps, GMMs should account for nonlinear soil effects.

The original ground motion maps released with the 2014 NSHM included only three periods (PGA, 0.2, and 1.0 seconds) and one site class (NEHRP site class boundary B/C, $\mathrm{V}_{\mathrm{s} 30}=760 \mathrm{~m} / \mathrm{s}$ ). For these periods and site class, the original suites of GMMs met the GMM selection criteria. For the additional periods and site classes shown in table 1, the original suites of GMMs needed to be checked to verify that they met these GMM selection criteria at these additional periods and site classes. This was verified by looking at GMM magnitude-distance scaling relation plots to see how median ground motions behaved at longer periods and softer soils.

\section{Ground Motion Magnitude-Distance Scaling Relation Plots}

The 2014 NSHM originally incorporated suites of nine GMMs for the CEUS stable continental earthquake sources, five GMMs for the WUS active crustal (NGA-West 2 GMMs) earthquake sources, and four GMMs for the WUS subduction interface and intraslab earthquake sources (see table 3). For each original suite of GMMs used in the 2014 NSHM, ground motion magnitude-distance scaling relation plots were produced to verify that median ground motions were realistic, and that each GMM met the selection criteria for the set of additional period and site classes shown in table 1.

For the nine original CEUS GMMs, median ground motions for distances ranging from 5 to 1,000 km were examined for the seven periods and two site classes shown in table 1, and for five magnitudes (M 5, 6, 7, 7.5, and 8). Plots for 2.0 second SA are shown in figure 1. All nine GMMs met the basic, magnitude, distance, and site conditions GMM selection criteria: they are valid for the set of CEUS periods shown in table 1, have a magnitude and distance dependence, are applicable (or can be reasonably extrapolated) to a magnitude range of 4.7 to 8.2 and distance of $1,000 \mathrm{~km}$, and have available amplification factors for a $\mathrm{V}_{\mathrm{S} 30}$ of $760 \mathrm{~m} / \mathrm{s}$.

For the five original WUS GMMs (in other words, NGA-West2 GMMs), median ground motions for distances ranging from 0 to $300 \mathrm{~km}$ were examined for the 11 periods and 8 site classes shown in table 1, and for 5 magnitudes (M 5, 6, 7, 7.5, and 8). Plots for 5.0 second SA are shown in figure 2. Four of the five GMMs (in other words, Abrahamson and others [2014], Boore and others [2014], Campbell and Bozorgnia [2014], and Chiou and Youngs [2014]) met the basic, magnitude, and distance GMM selection criteria: they are valid for the set of WUS periods shown in table 1, have a magnitude and distance dependence, and are applicable (or could be reasonably extrapolated), to a magnitude range of 5.0 to 8.2 and distance of $300 \mathrm{~km}$. The Idriss (2014) GMM (hereinafter referred to as "I14") is not valid for distances past $150 \mathrm{~km}$ and could not be reasonably extrapolated (see fig. 2B). All five GMMs met the site conditions GMM selection criteria, as they all include a term for $\mathrm{V}_{\mathrm{S} 30}$ and account for nonlinear soil effects. However, I14 is only valid for $\mathrm{V}_{\mathrm{S} 30} \geq 450 \mathrm{~m} / \mathrm{s}$, and therefore, not valid for site classes $\mathrm{D}$ and $\mathrm{E}$, or site class boundaries C/D and D/E. Because I14 cannot be reasonably extrapolated to $300 \mathrm{~km}$ and is not valid at all site classes shown in table 1, we removed I14 from the original suite of GMMs (for all periods and site classes) and renormalize the weights of the remaining four GMMs (see table 3), so the updated suite of weighted GMMs used to calculate additional period and site class hazard curves and maps were consistent.

For the four original subduction interface GMMs, median ground motions for distances ranging from 0 to $1,000 \mathrm{~km}$ were examined for the 11 periods and 8 site classes shown in table 1, and for 5 magnitudes (M 7, 7.5, 8, 8.5, and 9). Plots for 3.0 and 5.0 second SAs are shown in figure 3. All four GMMs met the basic, magnitude, and distance GMM selection criteria. However, the Atkinson and Boore (2003) Global GMM (hereinafter referred to as "AB03-Global”) is not applicable for periods above 3.0 seconds, and we were unable to reasonably extrapolate the GMM to longer periods. For periods above 1.0 second and distances greater than $\sim 100 \mathrm{~km}, \mathrm{AB} 03$-Global ground motions decayed too slowly with distance (fig. 3). After discussions with the GMM first author, we removed AB03-Global from the original suite of GMMs and renormalize the weights of the remaining three GMMs (see table 3), so the updated suite of weighted GMMs used to calculate additional period and site class hazard curves and maps were consistent.

For the four original subduction intraslab GMMs, median ground motions for distances ranging from 0 to $300 \mathrm{~km}$ were examined for the 11 periods and 8 site classes shown in table 1, and for 5 magnitudes (M 6.5, 7, 7.5, 8, and 8.5). Plots for 3.0 and 5.0 second SAs are shown in figure 4. All four GMMs met the basic, magnitude, and distance GMM selection criteria. However, the Atkinson and Boore (2003) Cascadia GMM (hereinafter referred to as "AB03-Cascadia”) and AB03-Global GMM are not applicable for periods above 3.0 seconds, and we were unable to reasonably extrapolate them to longer periods. After discussions with the GMM first author, we removed AB03-Cascadia and AB03-Global GMMs from the original suite of GMMs and renormalized the weights of the remaining two GMMs (see table 3), so the updated suite of weighted GMMs used to calculate additional period and site class hazard curves were consistent. 
Table 3. The 2014 National Seismic Hazard Model original suites of weighted ground motion models, and the updated suites of weighted ground motion models used for calculations in this report (modified from Rezaeian and others, 2015).

[CEUS, central and eastern United States; WUS, western United States; RLME, repeated large magnitude earthquakes; km, kilometer; GMM, ground motion model; NSHM, National Seismic Hazard Model]

\begin{tabular}{|c|c|c|c|}
\hline Ground motion model suites & Abbreviation & $\begin{array}{l}\text { Original weight (Petersen } \\
\text { and others, 2014, 2015) }\end{array}$ & Updated weight ${ }^{1}$ \\
\hline \multicolumn{4}{|c|}{ CEUS stable continental GMMs } \\
\hline & & \multicolumn{2}{|c|}{ RLME/Grid/>500 km } \\
\hline Atkinson and Boore $(2006,2011)$ & AB06' & $0.22 / 0.25 / 0.30$ & \\
\hline Atkinson (2008), Atkinson and Boore (2011) & AB08' & 0.08/0.08/0.00 & \\
\hline Campbell (2003) & $\mathrm{C} 03$ & $0.11 / 0.13 / 0.17$ & \\
\hline Frankel and others (1996) & F96 & $0.06 / 0.06 / 0.16$ & Same GMMs \\
\hline Pezeshk and others (2011) & P11 & $0.15 / 0.16 / 0.20$ & and weights \\
\hline Silva and others (2002) & S02 & 0.06/0.06/0.00 & as used in \\
\hline Somerville and others (2001) & S01 & 0.10/0.00/0.00 & 2014 NSHM \\
\hline Tavakoli and Pezeshk (2005) & TP05 & $0.11 / 0.13 / 0.17$ & \\
\hline Toro and others (1997), Toro (2002) & T02 & $0.11 / 0.13 / 0.00$ & \\
\hline \multicolumn{4}{|c|}{ Western United States active crustal ground motion models (NGA-West2) } \\
\hline Abrahamson and others (2014) & ASK14 & 0.22 & 0.25 \\
\hline Boore and others (2014) & BSSA14 & 0.22 & 0.25 \\
\hline Campbell and Bozorgnia (2014) & CB14 & 0.22 & 0.25 \\
\hline Chiou and Youngs (2014) & CY14 & 0.22 & 0.25 \\
\hline Idriss (2014) & I14 & 0.12 & 0.00 \\
\hline \multicolumn{4}{|c|}{ Western United States subduction interface ground motion models } \\
\hline Atkinson and Boore (2003) - Global Model & AB03 - Global & 0.10 & 0.00 \\
\hline Atkinson and Macias (2009) & AM09 & 0.30 & 0.33 \\
\hline BC Hydro (Abrahamson and others, 2016) & BCHydro12 & 0.30 & 0.34 \\
\hline Zhao and others (2006) & Zhao06 & 0.30 & 0.33 \\
\hline \multicolumn{4}{|c|}{ Western United States subduction intraslab ground motion models } \\
\hline Atkinson and Boore (2003) - Cascadia Model & AB03 - Cascadia & 0.1665 & 0.00 \\
\hline Atkinson and Boore (2003) - Global Model & AB03 - Global & 0.1665 & 0.00 \\
\hline BC Hydro (Abrahamson and others, 2016) & BCHydro12 & 0.333 & 0.50 \\
\hline Zhao and others (2006) & Zhao06 & 0.334 & 0.50 \\
\hline
\end{tabular}


Figure 1. Central and eastern United States ground motion model (GMM) magnitude-distance scaling plots for 2.0 second spectral acceleration; $(A)$ moment magnitude (M) 5.0 and (B) $\mathbf{M} 8.0$ for the National Earthquake Hazards Reduction Program site class $A$ (shear wave velocity in the upper 30 meters $\left[\mathrm{V}_{\mathrm{S} 30}\right]=2,000$ meters per second $[\mathrm{m} / \mathrm{s}])$, and $(C) \mathbf{M} 5.0$ and $(D) \mathbf{M} 8.0$ for site class B $\left(\mathrm{V}_{\mathrm{s} 30}=760 \mathrm{~m} / \mathrm{s}\right)$. zTop, depth to top of rupture (kilometers); zHyp, hypocentral depth (kilometers). See table 3 for GMM abbreviations.
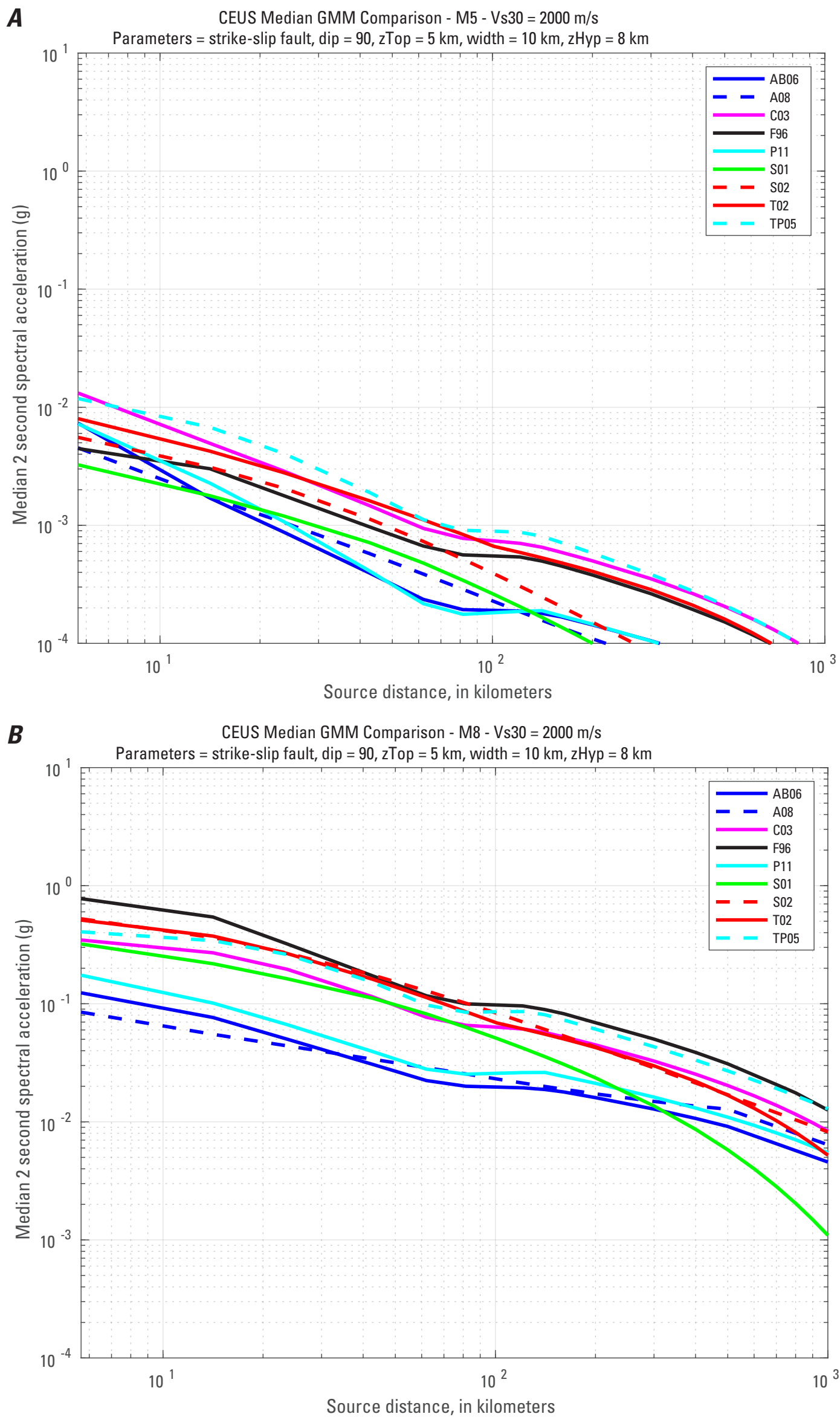
Figure 1. Central and eastern United States ground motion model (GMM) magnitude-distance scaling plots for 2.0 second spectral acceleration; $(A)$ moment magnitude (M) 5.0 and (B) $\mathbf{M} 8.0$ for the National Earthquake Hazards Reduction Program site class $A$ (shear wave velocity in the upper 30 meters $\left[\mathrm{V}_{\mathrm{S} 30}\right]=2,000$ meters per second $[\mathrm{m} / \mathrm{s}])$, and $(C)$ M 5.0 and (D) $\mathbf{M} 8.0$ for site class B $\left(V_{\mathrm{S} 30}=760 \mathrm{~m} / \mathrm{s}\right) . z T o p$, depth to top of rupture (kilometers); zHyp, hypocentral depth (kilometers). See table 3 for GMM abbreviations. -Continued
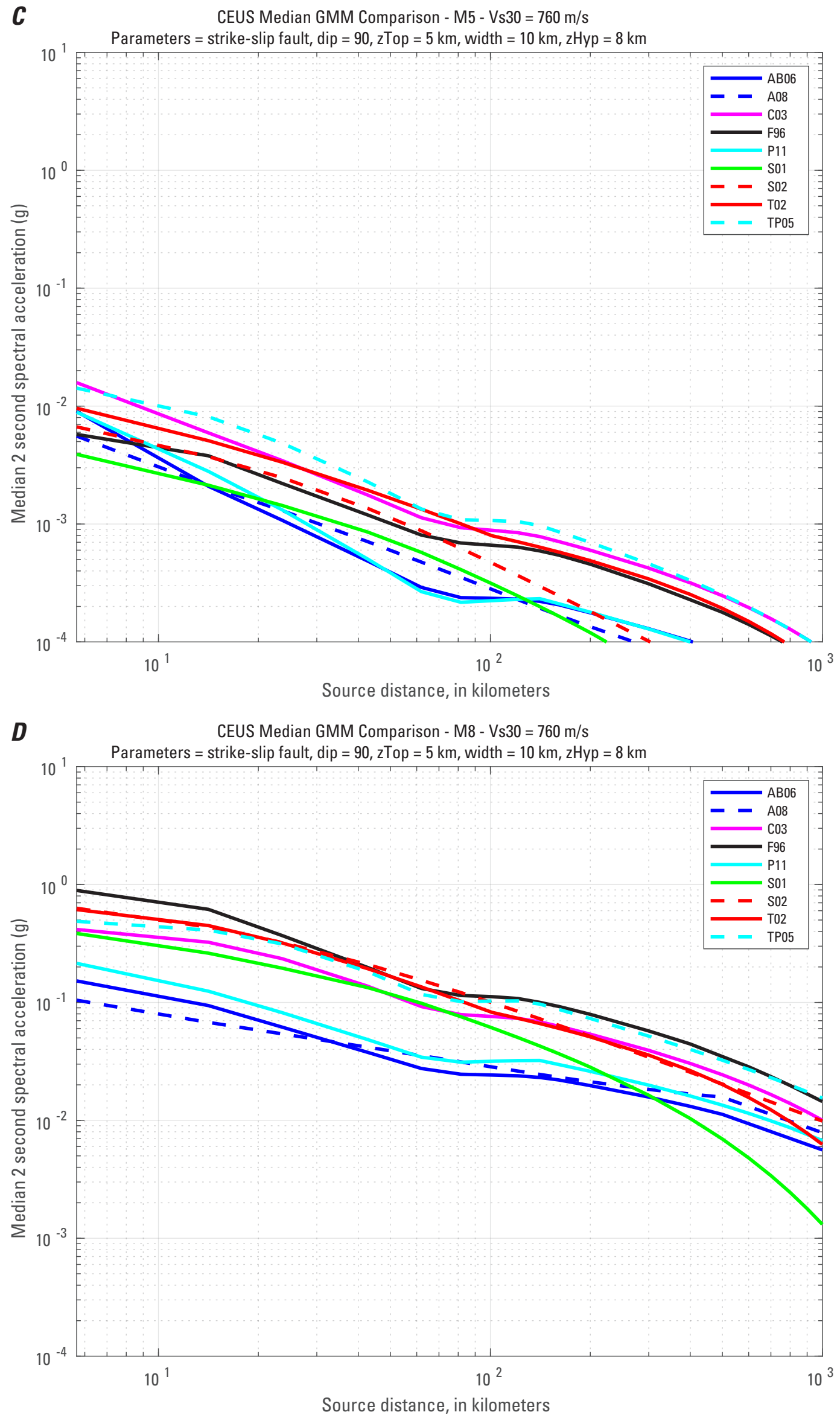
Figure 2. Western Unite States ground motion moc (GMM) magnitude-distanı scaling plots for 5.0 secon spectral acceleration; (A) moment magnitude (M) 5.0 and $(B) \mathbf{M} 8.0$ for the National Earthquake Hazards Reduction Progı site class B (shear wave velocity in the upper $30 \mathrm{me}$ $\left[\mathrm{V}_{S 30}\right]=1,080$ meters per second $[\mathrm{m} / \mathrm{s}])$, and $(C) \mathbf{M}$ ? and $(D) \mathbf{M} 8.0$ for site clas: $D\left(V_{s 30}=260 \mathrm{~m} / \mathrm{s}\right)$. Note that the Idriss (2014) (I14) ground motion model is $\mathrm{nc}$ valid for site class $D$, and therefore, is not shown in those plots. zTop, depth to top of rupture (kilometers) zHyp, hypocentral depth (kilometers). See table $3 \mathrm{fi}$ GMM abbreviations.
A NGA-W2 Median GMM Comparison - M5 - Vs30 $=1080 \mathrm{~m} / \mathrm{s}$

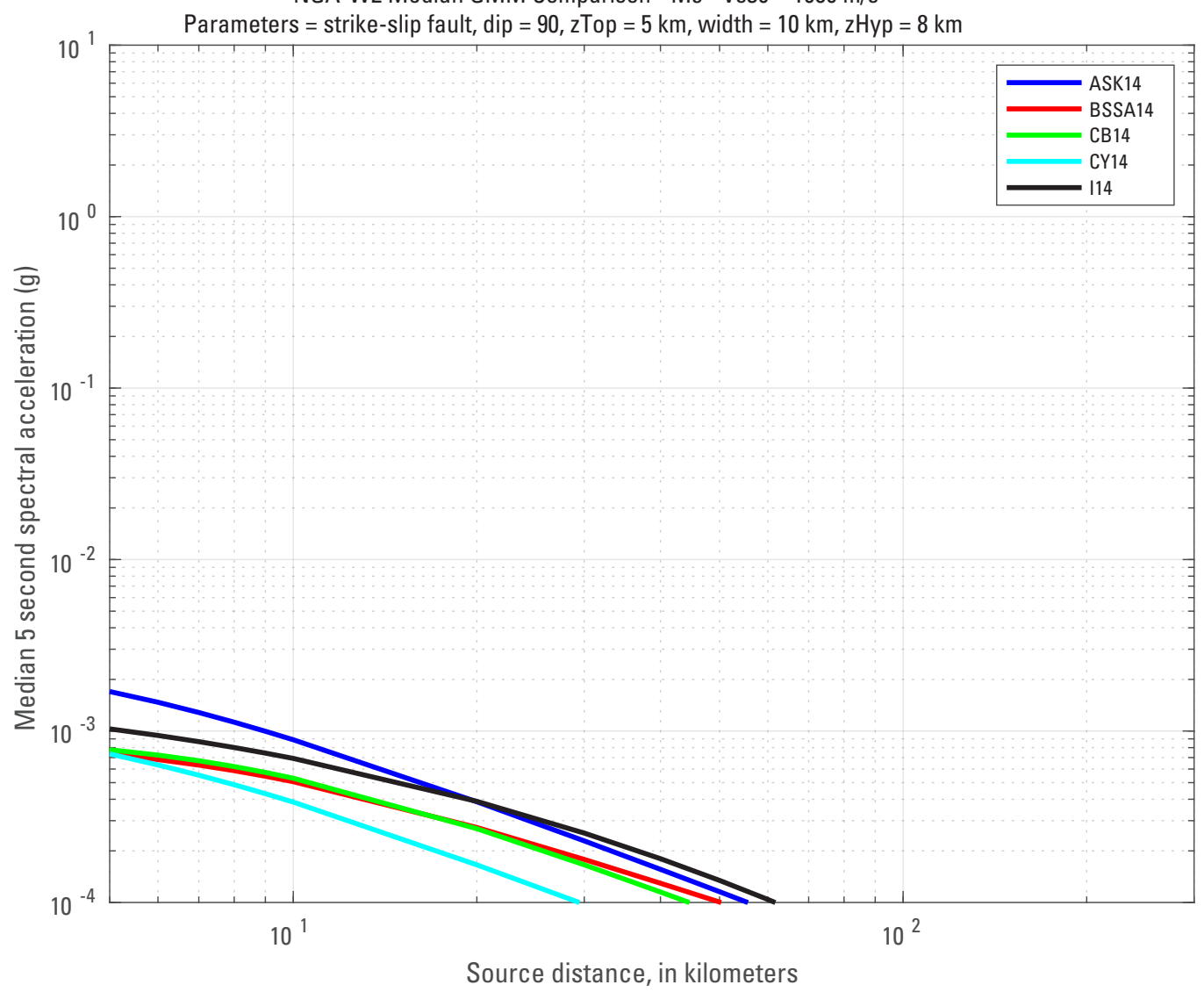

B NGA-W2 Median GMM Comparison - M8 - Vs30 $=1080 \mathrm{~m} / \mathrm{s}$

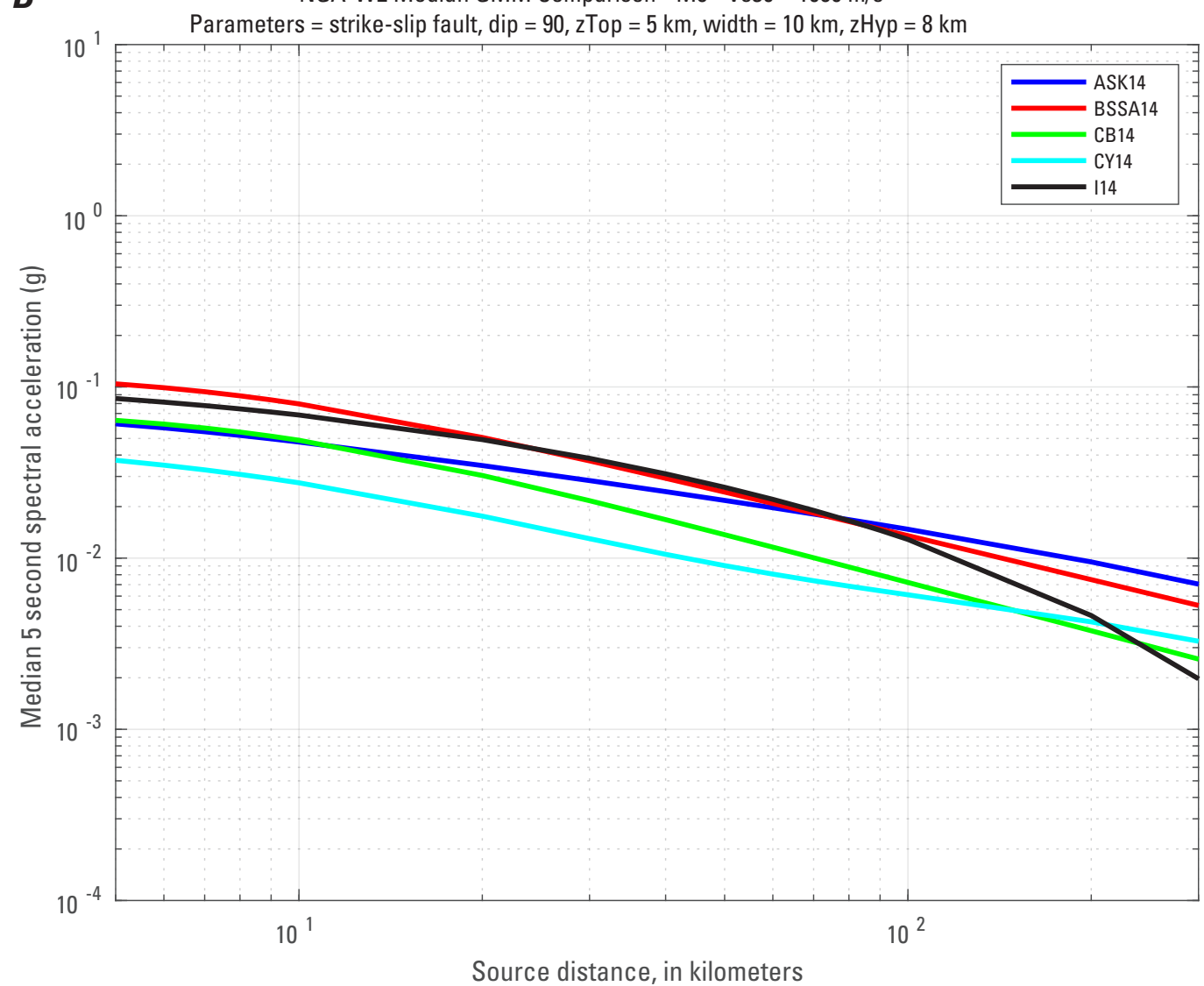


Figure 2. Western United States ground motion mod (GMM) magnitude-distanc scaling plots for 5.0 secon spectral acceleration; (A) moment magnitude (M) 5.0 and (B) M 8.0 for the National Earthquake Hazards Reduction Progr site class $B$ (shear wave velocity in the upper $30 \mathrm{me}$ $\left[\mathrm{V}_{\mathrm{S} 30}\right]=1,080$ meters per second $[\mathrm{m} / \mathrm{s}])$, and $(C) \mathbf{M} 5$ and $(D) \mathbf{M} 8.0$ for site class $D\left(V_{S 30}=260 \mathrm{~m} / \mathrm{s}\right)$. Note that the Idriss (2014) (I14) ground motion model is $\mathrm{nc}$ valid for site class $D$, and therefore, is not shown in those plots. zTop, depth to top of rupture (kilometers) zHyp, hypocentral depth (kilometers). See table $3 \mathrm{fc}$ GMM abbreviations.

-Continued

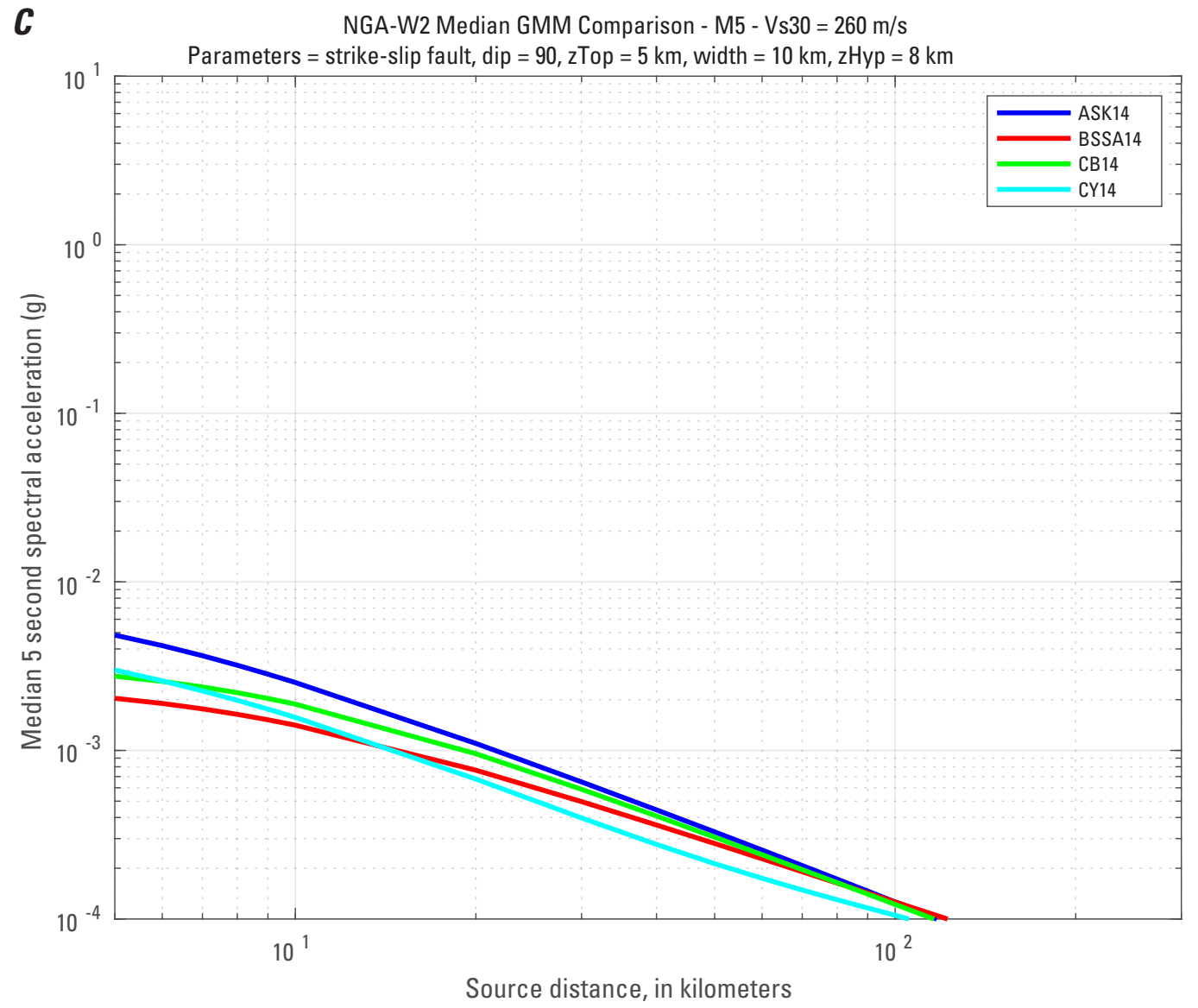

D NGA-W2 Median GMM Comparison - M8 - Vs30 $=260 \mathrm{~m} / \mathrm{s}$

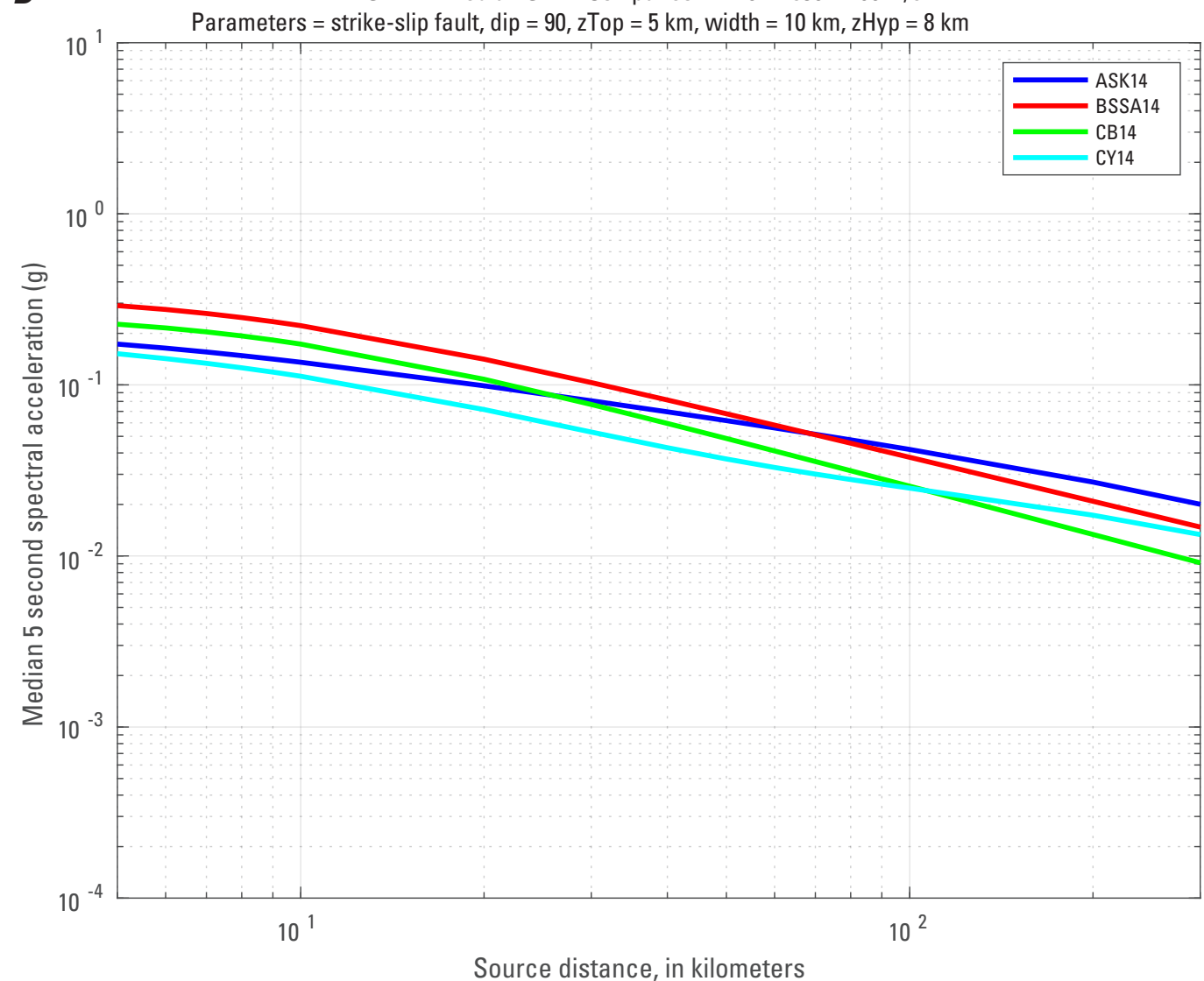


Figure 3.

Subduction interface ground motion model (GMM)

magnitude-distance scaling plots for moment magnitude (M) 8.5; (A) 3.0 second spectral acceleration (SA) for the National Earthquake Hazards Reduction Program (NEHRP) site class $B$ (shear wave velocity in the upper 30 meters $\left[\mathrm{V}_{\mathrm{S} 30}\right]=1,080$ meters per seconc $[\mathrm{m} / \mathrm{s}]),(B) 3.0$ second SA for site class $D\left(V_{S 30}=260 \mathrm{~m} / \mathrm{s}\right)$, (C) 5.0 second SA for site class $B\left(V_{S 30}=1,080 \mathrm{~m} / \mathrm{s}\right)$, and (D) 5.0 second $\mathrm{SA}$ for site class D ( $\left.\mathrm{V}_{S 30}=260 \mathrm{~m} / \mathrm{s}\right)$. Note that the Atkinson and Boore (2003) ground motion model (AB03-Global) is not valid for periods greater than 3.0 seconds, and therefore, is not shown in the 5.0 second plots. zTop, depth to top of rupture (kilometers); zHyp, hypocentral depth (kilometers). See table 3 for GMM abbreviations.
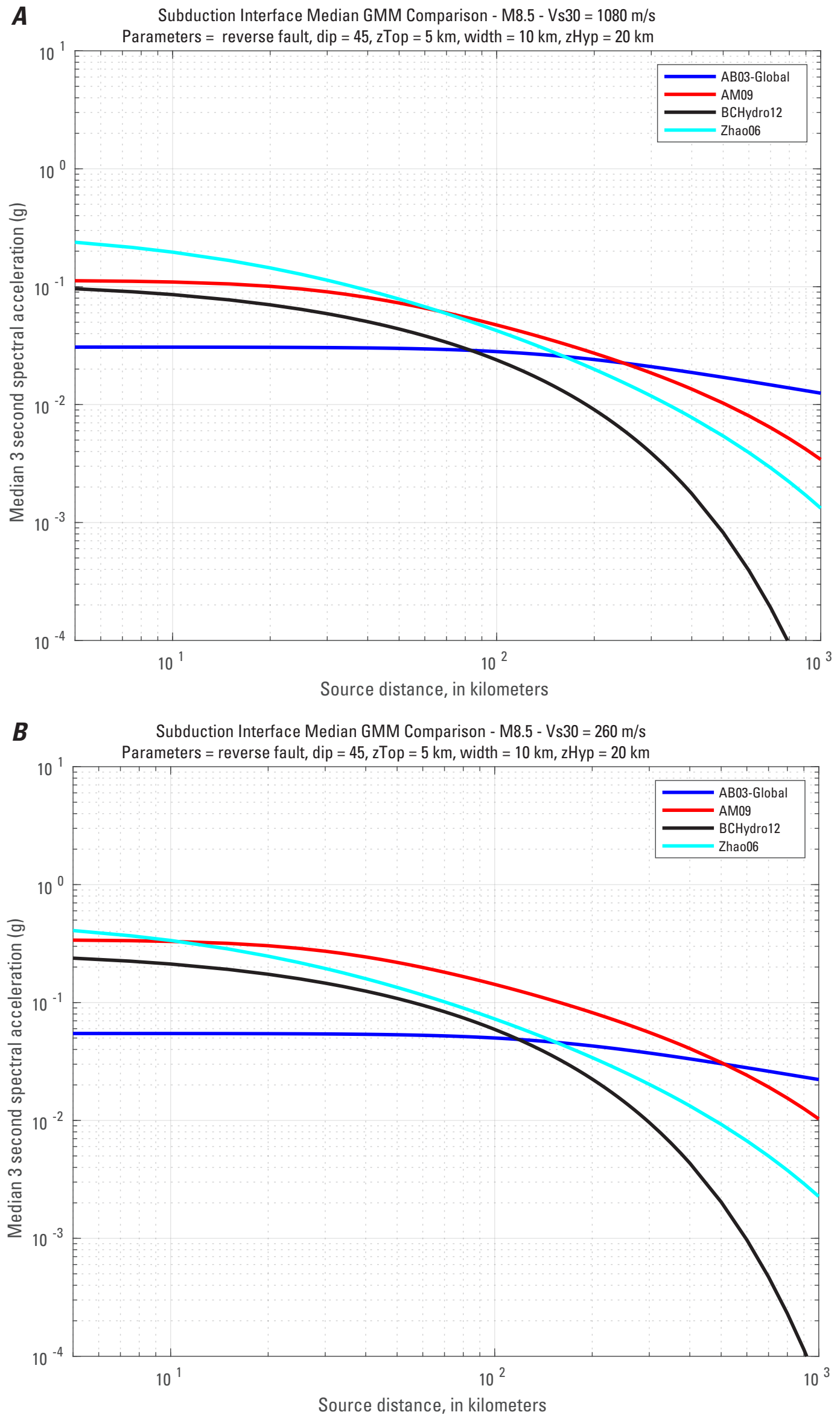
Figure 3.

Subduction interface ground motion model (GMM) magnitude-distance scaling plots for moment magnitude (M) 8.5 ; (A) 3.0 second spectral acceleration (SA) for the National Earthquake Hazards Reduction Program (NEHRP) site class $B$ (shear wave velocity in the upper 30 meters $\left[\mathrm{V}_{S 30}\right]=1,080$ meters per second $[\mathrm{m} / \mathrm{s}]),(B) 3.0$ second $S A$ for site class $D\left(V_{S 30}=260 \mathrm{~m} / \mathrm{s}\right)$, (C) 5.0 second SA for site class $B\left(V_{\mathrm{S} 30}=1,080 \mathrm{~m} / \mathrm{s}\right)$, and (D) 5.0 second SA for site class $D\left(V_{S 30}=260 \mathrm{~m} / \mathrm{s}\right)$. Note that the Atkinson and Boore (2003) ground motion model (AB03-Global) is not valid for periods greater than 3.0 seconds, and therefore, is not shown in the 5.0 second plots. zTop, depth to top of rupture (kilometers); zHyp, hypocentral depth (kilometers). See table 3 for GMM abbreviations. -Continued
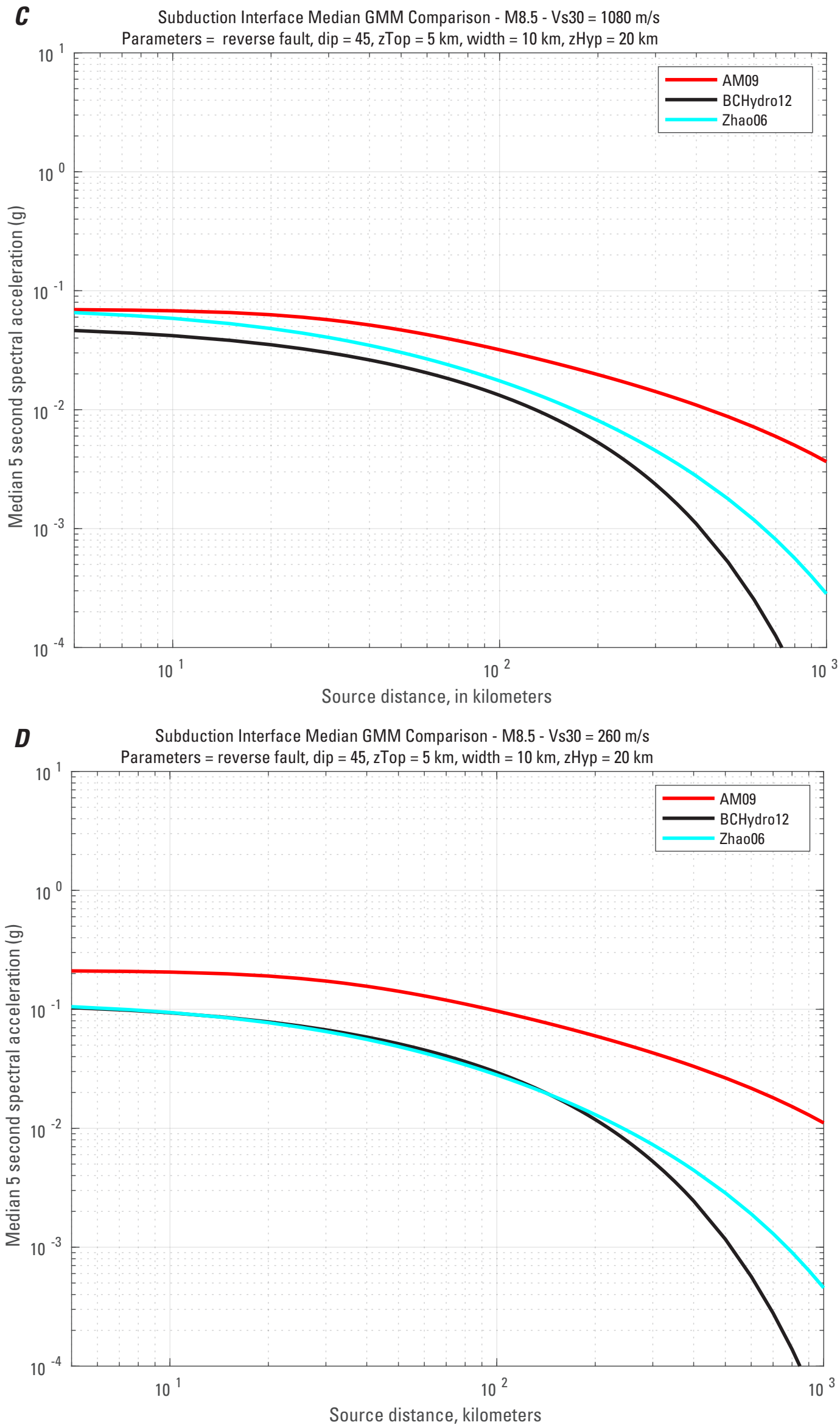


\section{Additional Period and Site Class Maps for the 2014 National Seismic Hazard Model for the Conterminous United States}

Figure 4.

Subduction intraslab grour motion model (GMM)

magnitude-distance scalir plots for moment magnitud (M) $7 ;(A) 3.0$ second spectr acceleration (SA) for the National Earthquake Hazar Reduction Program (NEHR site class $B$ (shear wave velocity in the upper 30 met $\left[\mathrm{V}_{\mathrm{S} 0}\right]=1,080$ meters per secc $[\mathrm{m} / \mathrm{s}]),(B) 3.0$ second $\mathrm{SA} \mathrm{fc}_{\mathrm{f}}$ site class $D\left(V_{S 30}=260 \mathrm{~m} / \mathrm{s}\right)$, (C) 5.0 second SA for site class $B\left(V_{S 30}=1,080 \mathrm{~m} / \mathrm{s}\right)$, and $(D) 5.0$ second $S A$ for site class $D\left(V_{S 30}=260 \mathrm{~m} / \mathrm{s}\right)$. Note that the Atkinson anc Boore (2003) ground motio model (AB03-Global and AB03-Cascadia) is not vali for periods greater than 3.0 seconds, and therefore, not shown in the 5.0 secor plots. zTop, depth to top of rupture (kilometers); zHyp, hypocentral depth. See tab for GMM abbreviations.
A Subduction Intraslab Median GMM Comparison - M7 - Vs30 $=1080 \mathrm{~m} / \mathrm{s}$

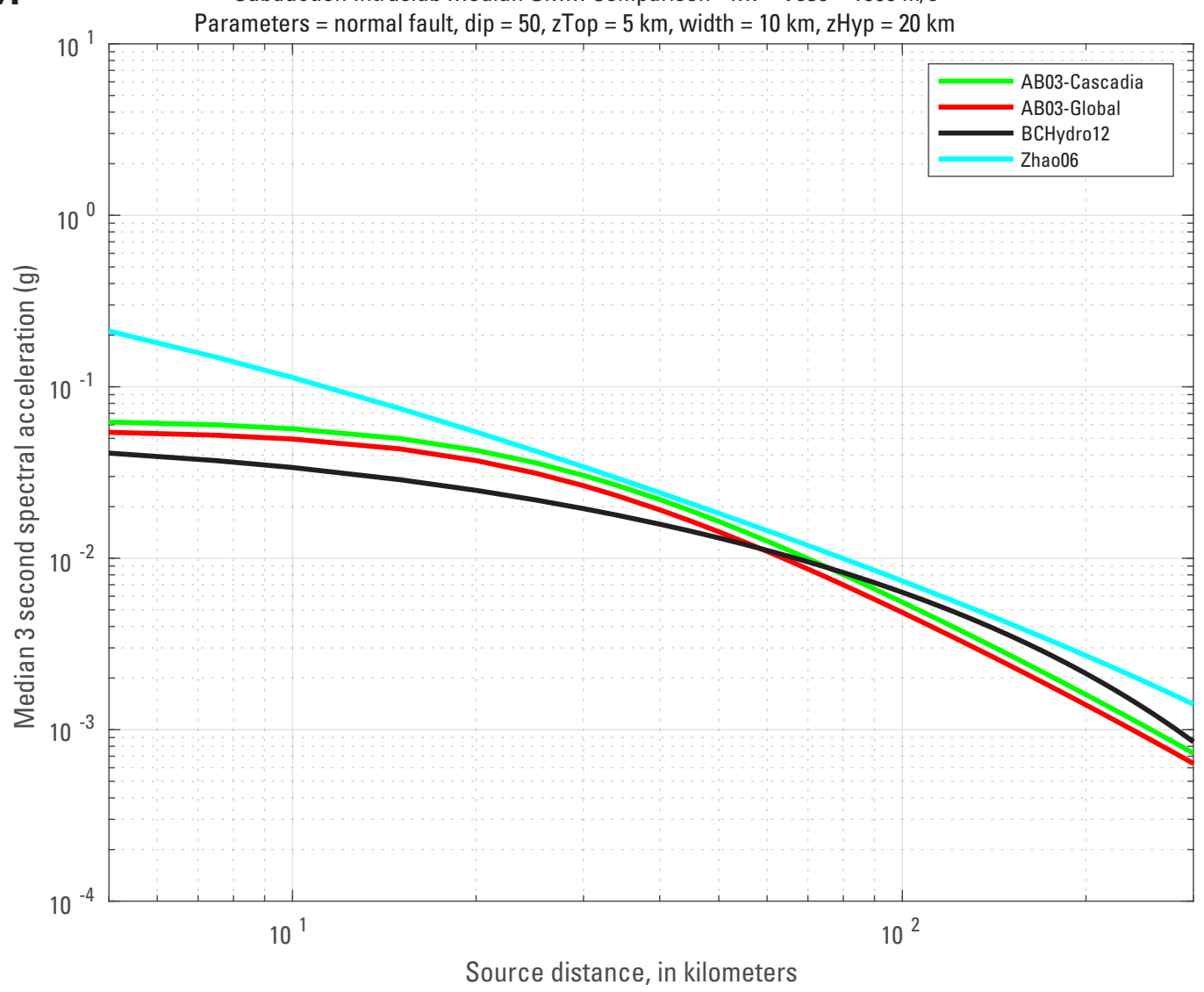

B Subduction Intraslab Median GMM Comparison - M7 - Vs30 $=260 \mathrm{~m} / \mathrm{s}$

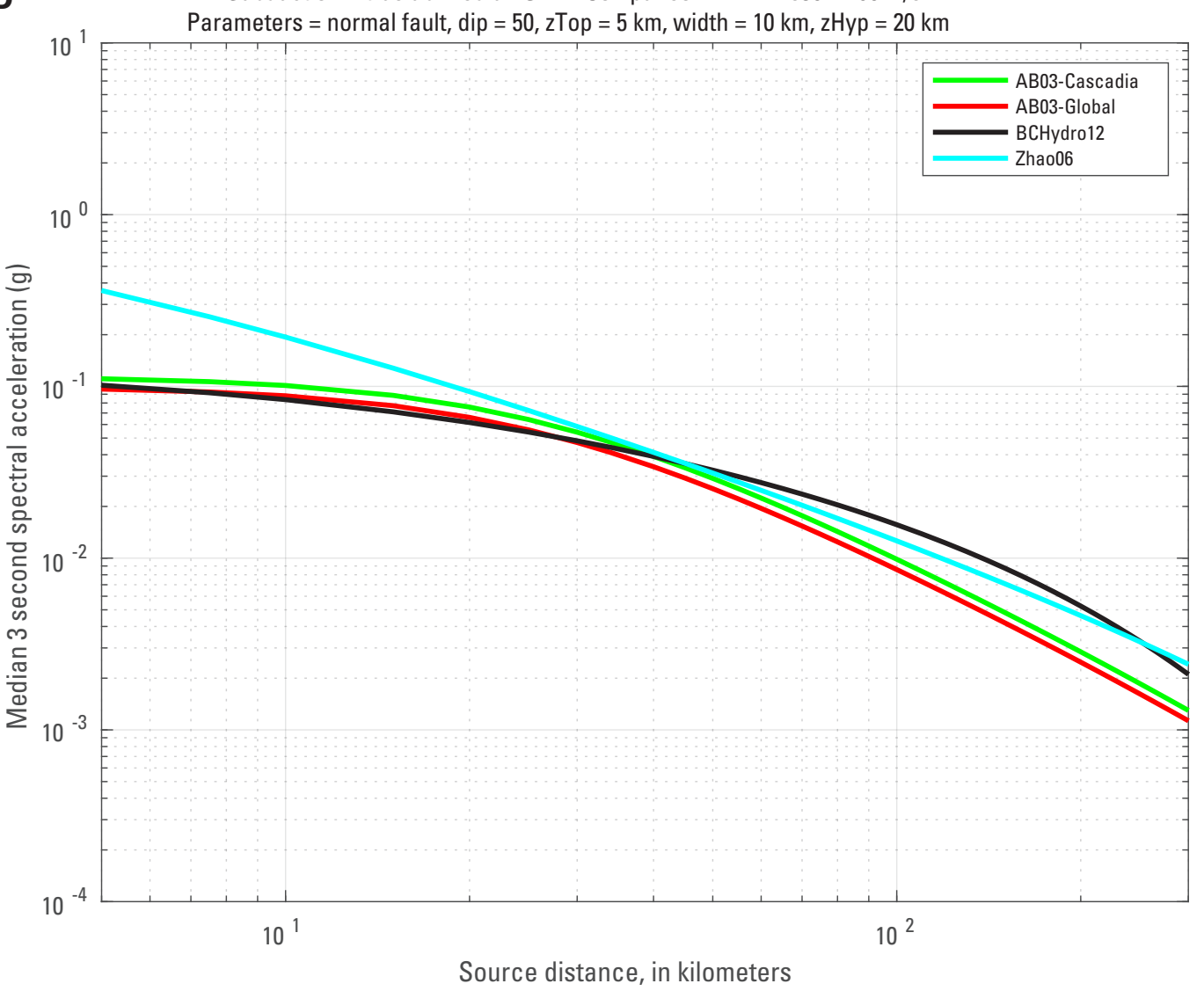


Figure 4.

Subduction intraslab groun motion model (GMM) magnitude-distance scalir plots for moment magnitud (M) 7; (A) 3.0 second spectr acceleration (SA) for the National Earthquake Hazar Reduction Program (NEHR) site class $B$ (shear wave velocity in the upper 30 met $\left[\mathrm{V}_{\mathrm{S} 30}\right]=1,080$ meters per secc $[\mathrm{m} / \mathrm{s}]),(B) 3.0$ second SA fc site class $D\left(V_{S 30}=260 \mathrm{~m} / \mathrm{s}\right)$, (C) 5.0 second SA for site class $B\left(V_{S 30}=1,080 \mathrm{~m} / \mathrm{s}\right)$, and $(D) 5.0$ second $S A$ for site class $D\left(V_{S 30}=260 \mathrm{~m} / \mathrm{s}\right)$. Note that the Atkinson anc Boore (2003) ground motio model (AB03-Global and AB03-Cascadia) is not vali for periods greater than 3.0 seconds, and therefore, not shown in the 5.0 secor plots. zTop, depth to top of rupture (kilometers); zHyp, hypocentral depth. See tab for GMM abbreviations. -Continued
C Subduction Intraslab Median GMM Comparison - M7 - Vs $30=1080 \mathrm{~m} / \mathrm{s}$
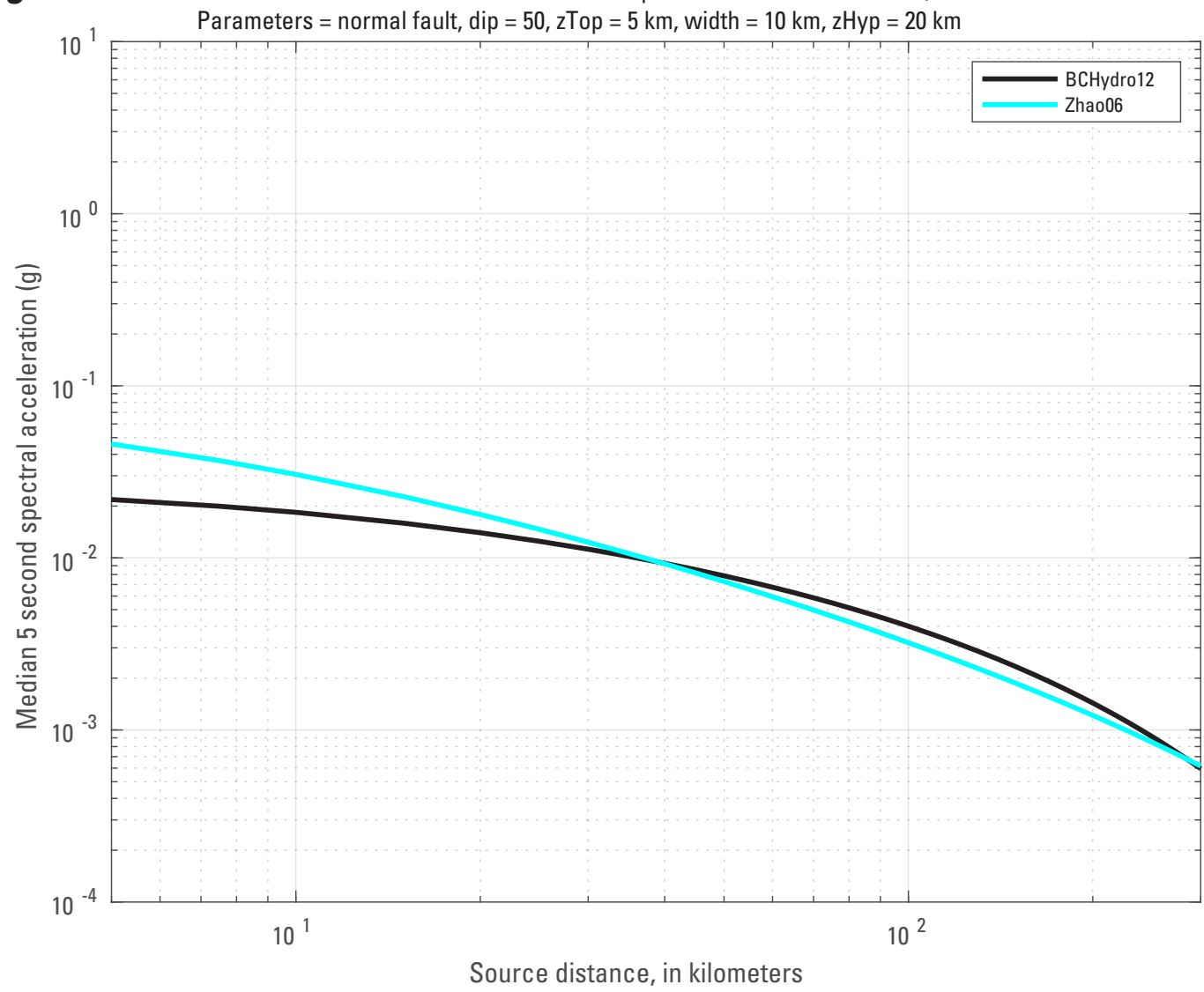

D Subduction Intraslab Median GMM Comparison - M7 - Vs30 $=260 \mathrm{~m} / \mathrm{s}$ Parameters $=$ normal fault, dip $=50, z T o p=5 \mathrm{~km}$, width $=10 \mathrm{~km}, \mathrm{zHyp}=20 \mathrm{~km}$

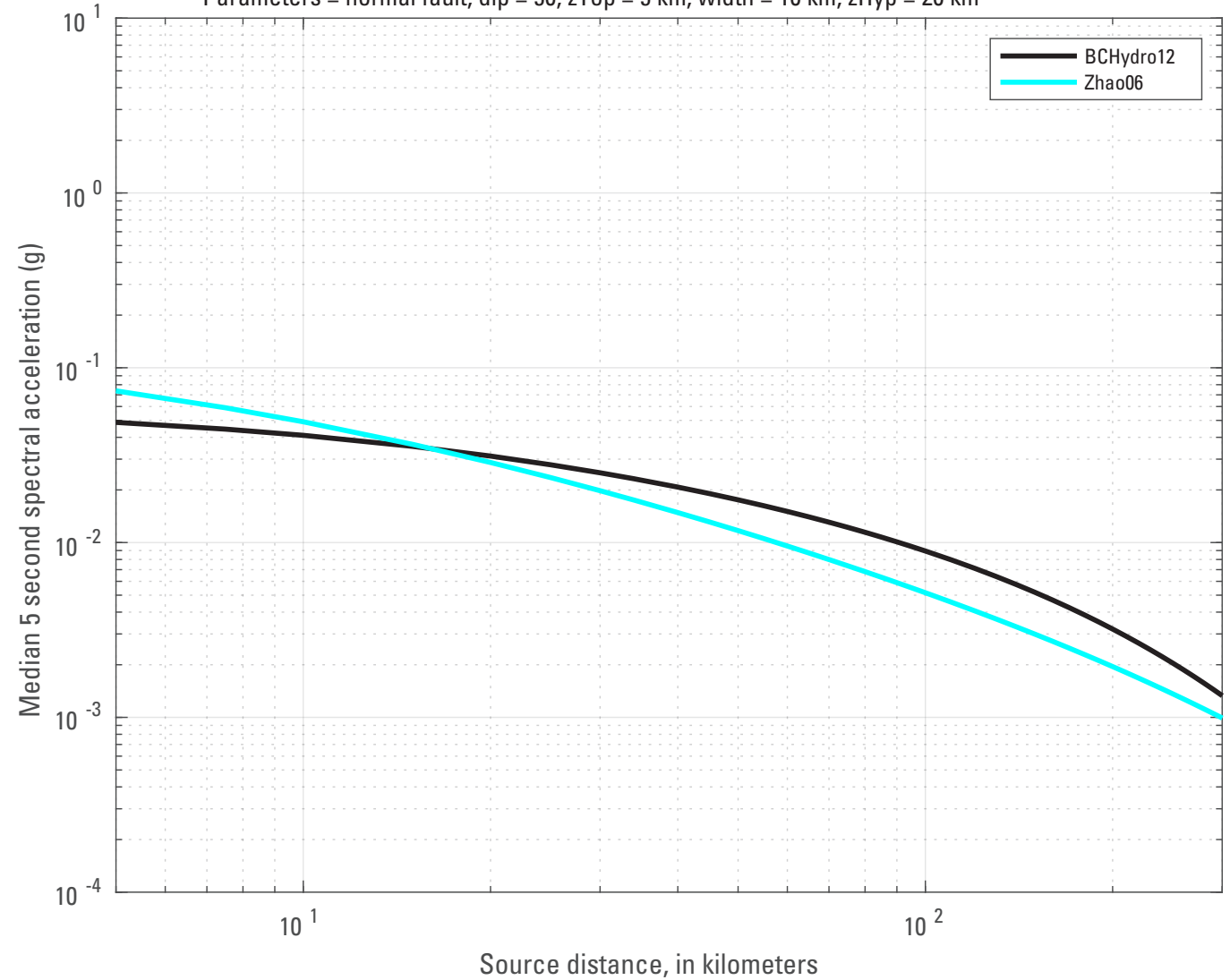




\section{Updated Seismic Hazard Curves and Probabilistic Ground Motion Maps}

Using the 2014 NSHM, but with updated suites of weighted GMMs, seismic hazard curves were calculated for the set of periods and site classes listed in table 1. Probabilistic ground motion maps were produced for 2, 5, and 10 percent probabilities of exceedance in 50 years. For consistency, we also updated the original PGA, 0.2, and 1.0 second hazard curves and maps released with the 2014 NSHM using these updated suites of weighted GMMs.

\section{Effect of Updated Suites of Weighted Ground Motion Models on Hazard for Peak Ground Acceleration, 0.2 , and 1.0 Second Spectral Accelerations}

Figure $5 A-I$ presents hazard, difference, and ratio maps showing the change in probabilistic ground motions for PGA, 0.2 , and 1.0 second SAs for 2, 5, and 10 percent probabilities of exceedance in 50 years for NEHRP site class boundary B/C $\left(\mathrm{V}_{\mathrm{s} 30}=760 \mathrm{~m} / \mathrm{s}\right)$ when hazard is calculated using the 2014 NSHM with the updated suites of weighted GMMs listed in table 3 (see Updated Weight column) compared to the original suites of weighted GMMs, also listed in table 3 (see Original Weight column). The difference and ratio maps show the effect of removing I14 from the WUS suite of crustal GMMs, AB03-Global from the subduction interface suite of GMMs, and AB03-Global and AB03-Cascadia from the subduction intraslab suite of GMMs, and the renormalization of weights of the remaining GMMs.

As no changes were made to the original suite of weighted CEUS GMMs, there is no change in hazard in the CEUS. The removal of 14 resulted in very small changes to hazard (less than 5 percent in California and the interior Pacific Northwest [PNW]). The removal of AB03-Global and AB03-Cascadia GMMs resulted in an increase in hazard (as much as 20 percent) in the PNW.

The UHT was used to perform a deaggregation of PGA hazard at 2 percent in 50-year probability of exceedance for a site in the PNW (fig. 6A). The dataset used by the UHT was the 2014 NSHM with the original suite of weighted GMMs. The results indicated that the highest contributors to total mean hazard at the site were from the Cascadia Subduction Zone (CSZ) interface (in other words, CSZ megathrust source $\sim 75 \mathrm{~km}$ from the site) and intraslab (in other words, intraslab source $\sim 30-90 \mathrm{~km}$ from the site) sources, and local gridded sources (fig. 6B). A PGA subduction interface ground motion magnitude-distance scaling relation plot for magnitude 9 is shown in figure $6 C$. At a distance of $\sim 75 \mathrm{~km}, \mathrm{AB} 03$-Global has lower ground motions than AM09, the Zhao and others (2006) GMM (hereinafter referred to as “Zhao06”), and the Abrahamson and others (2016) GMM (hereinafter referred to as "BCHydro12"). Removing the AB03-Global GMM, and renormalizing the weights of the remaining GMMs, most likely does not result in a significant increase in hazard for interface sources (as AB03-Global only received a weight of 0.1 in the original suite of weighted GMMs and indicates low ground motions for this source). When looking at a PGA subduction intraslab ground motion magnitude-distance scaling relation plot for magnitude 7 (fig. 6D), AB03-Cascadia and AB03-Global have 2.5 times lower ground motions than Zha06 and BCHydro12. In the original suite of weighted GMMs, AB03-Cascadia and AB03-Global have a combined weight was 0.333. When these GMMs are removed and the weights of Zhao06 and BCHydro12 are renormalized, all the weight is now on the two highest ground motions, resulting in as much as a 20 percent increase in hazard seen in the PNW (seen in fig. 4). 
$\boldsymbol{A}$

Comparison of PGA Total Mean Hazard from the USGS 2014 NSHM

Updated Suite of 2014 NSHM GMMs vs. Original Suite of 2014 NSHM GMMs

$2 \%$ in 50 Years Probability of Exceedance, NEHRP Site Class Boundary B/C (Vs30 $=760 \mathrm{~m} / \mathrm{s}$ )

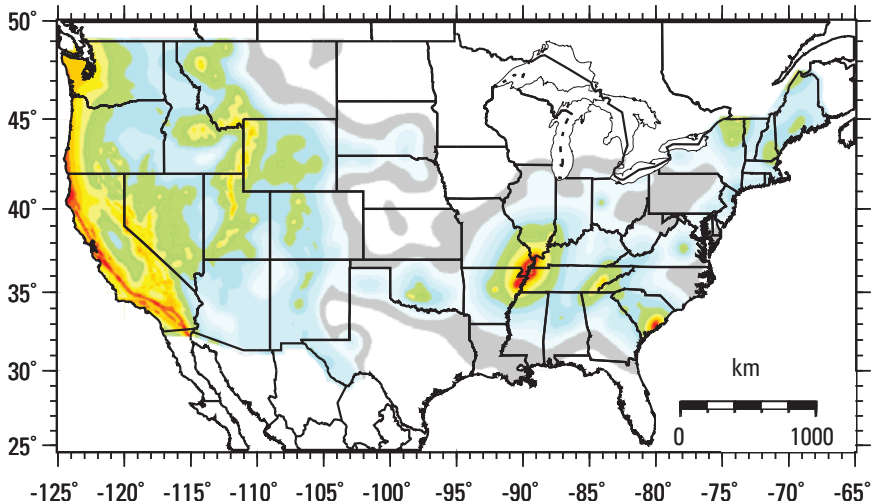

Updated Suite of 2014 NSHM GMMs (map 1)

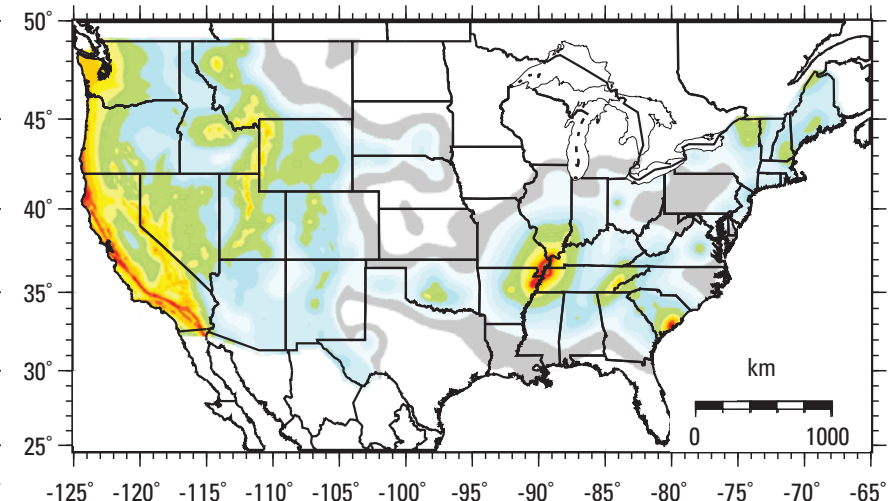

Original Suite of 2014 NSHM GMMs (map 2)

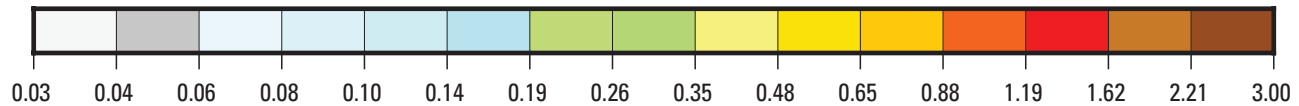

Peak Ground Acceleration (g)

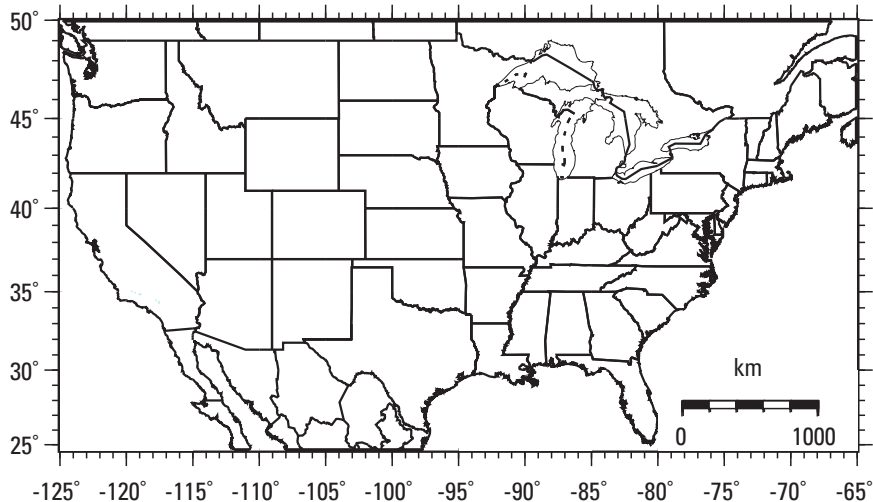

(map 1) - (map 2)

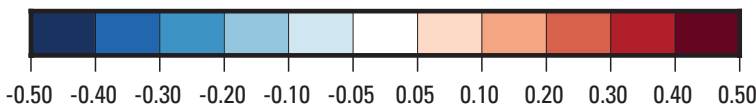

Difference

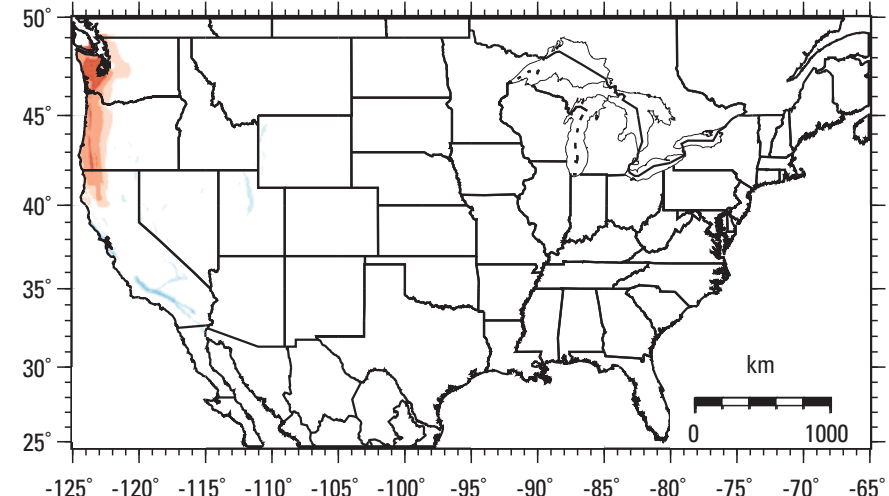

(map 1) / (map 2)

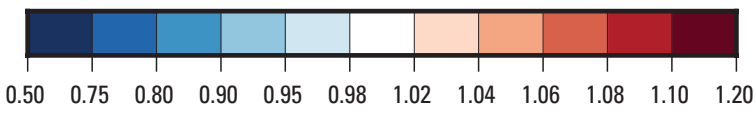

Ratio

Figure 5. Hazard, difference, and ratio maps calculated for the 2014 National Seismic Hazard Model (Petersen and others, 2014, 2015), showing the change in hazard between the updated suite of weighted ground motion models presented in table 3 and the original suite of weighted GMMs, also presented in table 3. For 2 percent in 50 -year probability of exceedance $(A)$ peak ground acceleration (PGA), $(B) 0.2$ second, and $(C) 1.0$ second; for 5 percent in 50-year probability of exceedance $(D)$ PGA, $(E) 0.2$ second, and $(F) 1.0$ second; for 10 percent in 50-year probability of exceedance $(G)$ PGA, $(H) 0.2$ second, and $(/) 1.0$ second for the National Earthquake Hazards Reduction Program site class boundary B/C (time-averaged shear wave velocity in the upper 30 meters $\left[\mathrm{V}_{S 30}\right]=760$ meters per second). 


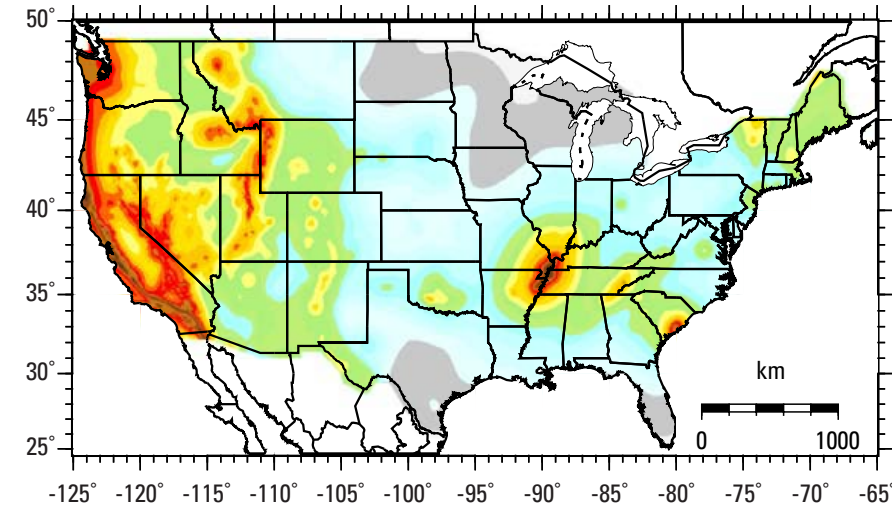

Updated Suite of 2014 GMMs (map 1)

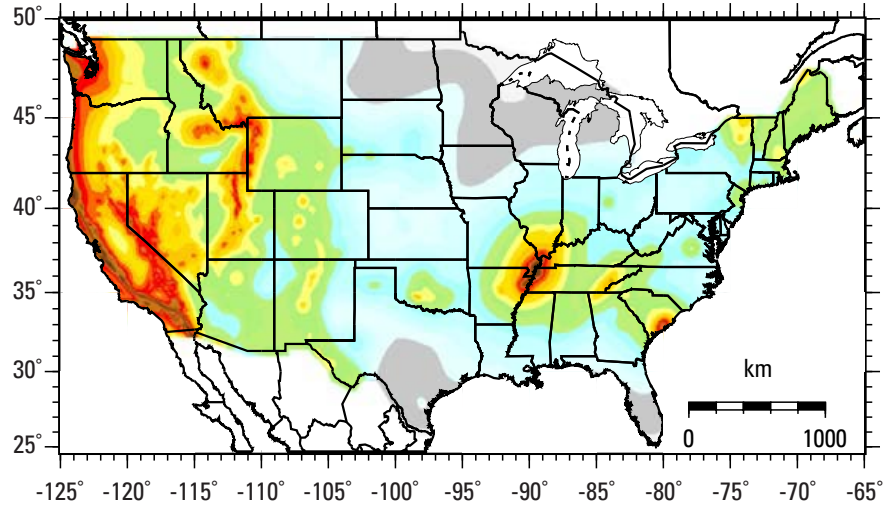

Original Suite of 2014 GMMs (map 2)

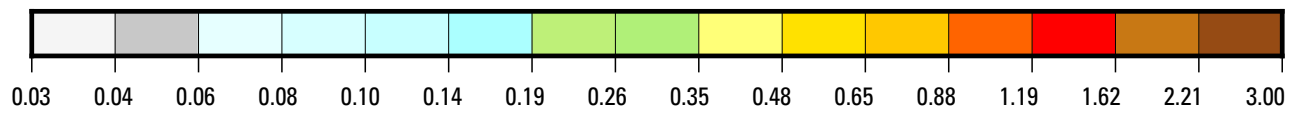

0.2 Second Spectral Acceleration (g)

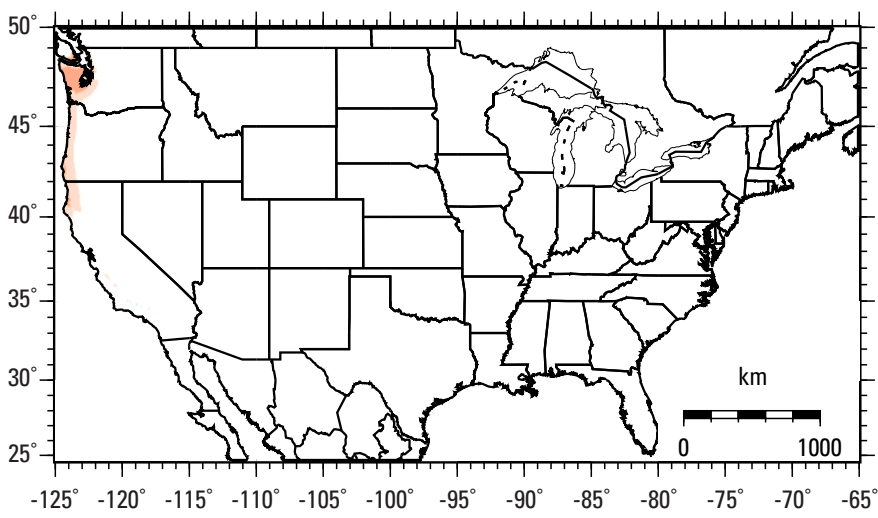

(map 1) - (map 2)

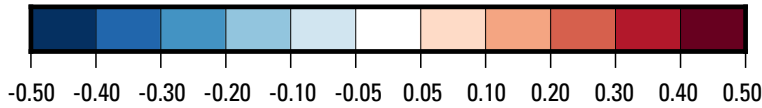

Difference
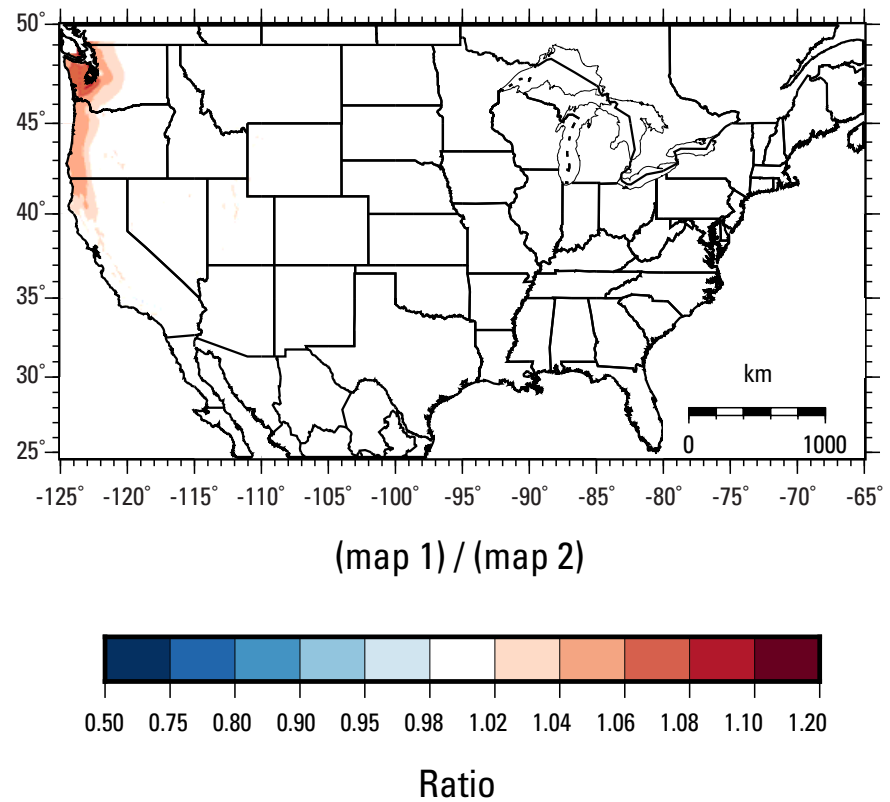

Figure 5. Hazard, difference, and ratio maps calculated for the 2014 National Seismic Hazard Model (Petersen and others, 2014, 2015), showing the change in hazard between the updated suite of weighted ground motion models presented in table 3 and the original suite of weighted GMMs, also presented in table 3. For 2 percent in 50-year probability of exceedance $(A)$ peak ground acceleration (PGA), $(B) 0.2$ second, and $(C) 1.0$ second; for 5 percent in 50-year probability of exceedance $(D)$ PGA, $(E) 0.2$ second, and $(F) 1.0$ second; for 10 percent in 50-year probability of exceedance $(G)$ PGA, $(H) 0.2$ second, and $(/) 1.0$ second for the National Earthquake Hazards Reduction Program site class boundary $B / C$ (time-averaged shear wave velocity in the upper 30 meters $\left[V_{S 30}\right]=760$ meters per second). - Continued 
C

Comparison of 1 Second Total Mean Hazard from the USGS 2014 NSHM

Updated Suite of 2014 NSHM GMMs vs. Original Suite of 2014 NSHM GMMs

$2 \%$ in 50 Years Probability of Exceedance, NEHRP Site Class Boundary B/C (Vs30 =760 m/s)

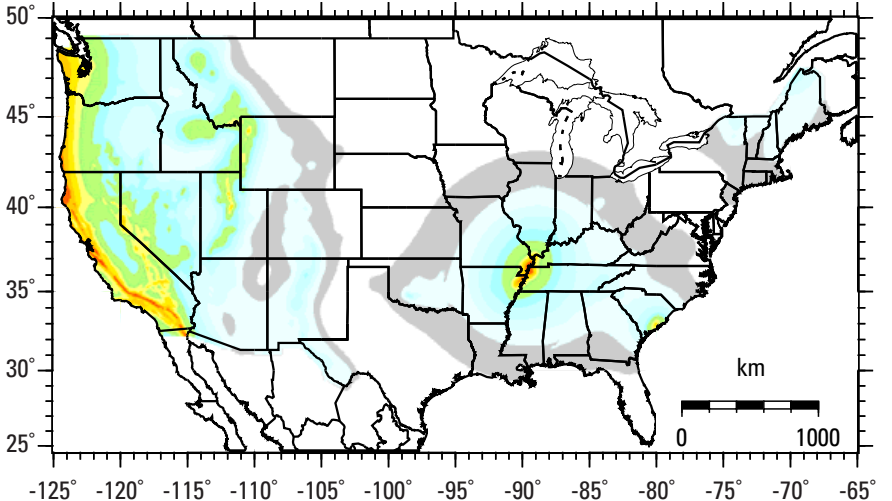

Updated Suite of 2014 GMMs (map 1)

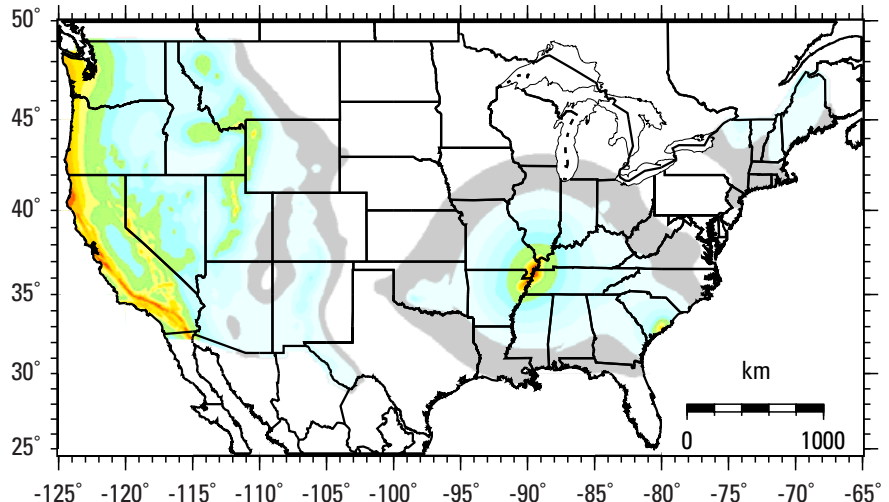

Original Suite of 2014 GMMs (map 2)

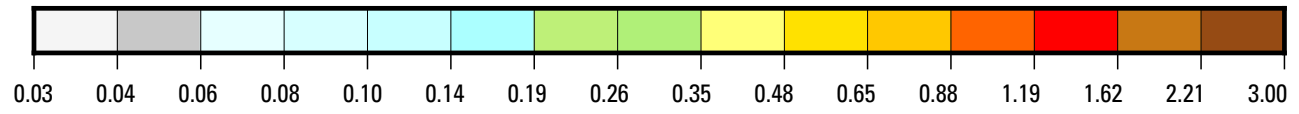

1 Second Spectral Acceleration (g)

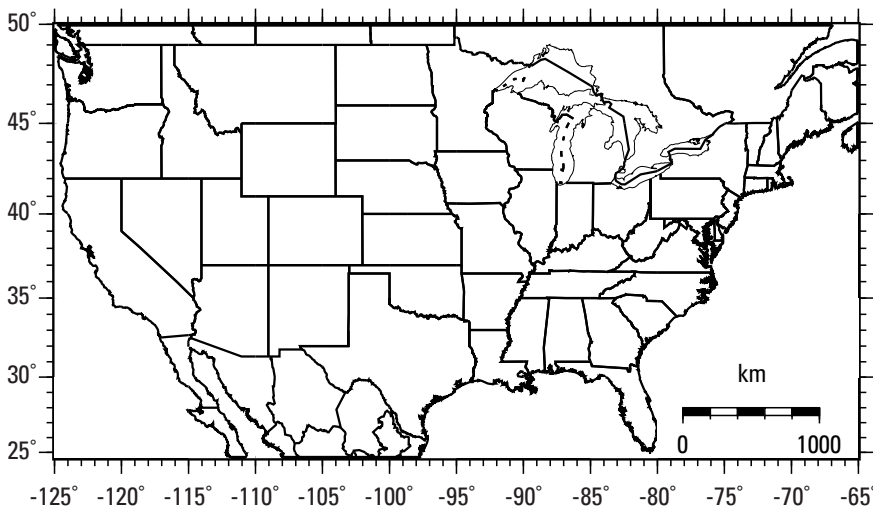

(map 1) - (map 2)

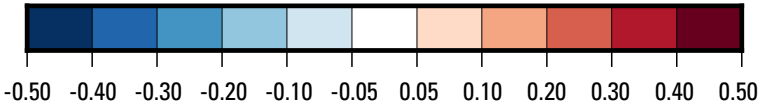

Difference

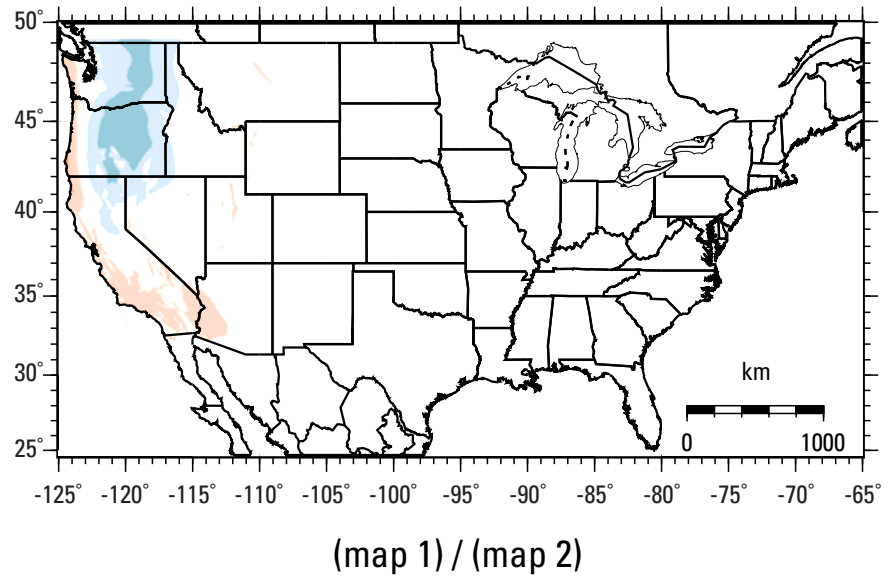

$\begin{array}{llllllllllll}0.50 & 0.75 & 0.80 & 0.90 & 0.95 & 0.98 & 1.02 & 1.04 & 1.06 & 1.08 & 1.10 & 1.20\end{array}$

Ratio

Figure 5. Hazard, difference, and ratio maps calculated for the 2014 National Seismic Hazard Model (Petersen and others, 2014, 2015), showing the change in hazard between the updated suite of weighted ground motion models presented in table 3 and the original suite of weighted GMMs, also presented in table 3. For 2 percent in 50 -year probability of exceedance $(A)$ peak ground acceleration (PGA), $(B) 0.2$ second, and $(C) 1.0$ second; for 5 percent in 50-year probability of exceedance $(D)$ PGA, $(E) 0.2$ second, and $(F) 1.0$ second; for 10 percent in 50-year probability of exceedance $(G)$ PGA, $(H) 0.2$ second, and $(/) 1.0$ second for the National Earthquake Hazards Reduction Program site class boundary $\mathrm{B} / \mathrm{C}$ (time-averaged shear wave velocity in the upper 30 meters $\left[\mathrm{V}_{\mathrm{S} 30}\right]=760$ meters per second).-Continued 
D

Comparison of PGA Total Mean Hazard from the USGS 2014 NSHM Updated Suite of 2014 NSHM GMMs vs. Original Suite of 2014 NSHM GMMs $5 \%$ in 50 Years Probability of Exceedance, NEHRP Site Class Boundary B/C (Vs30 = $760 \mathrm{~m} / \mathrm{s})$

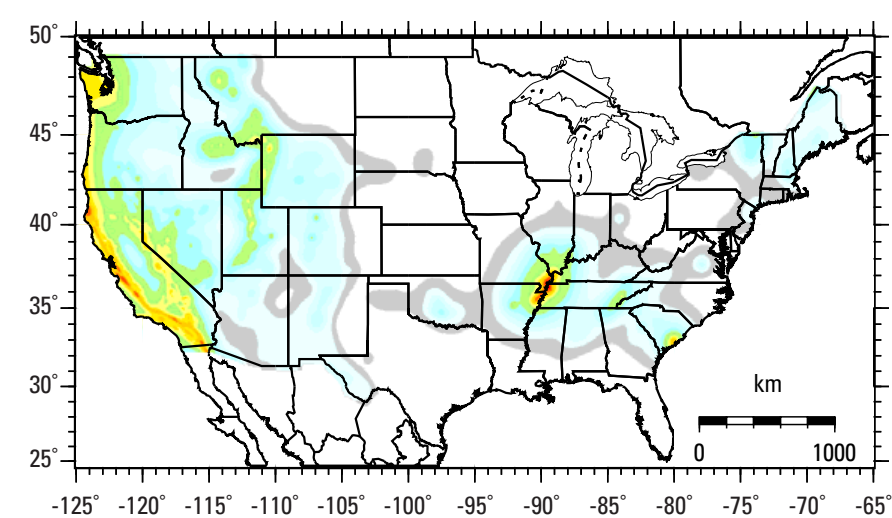

Updated Suite of 2014 GMMs (map 1)

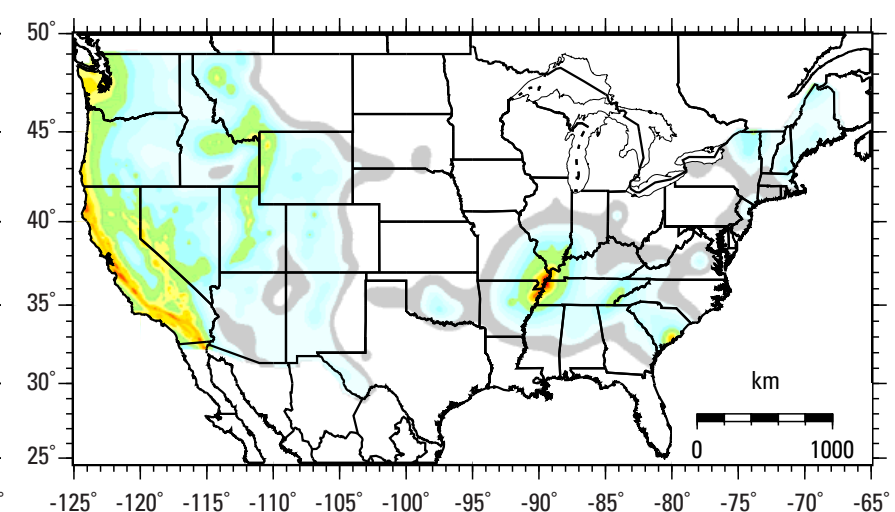

Original Suite of 2014 GMMs (map 2)

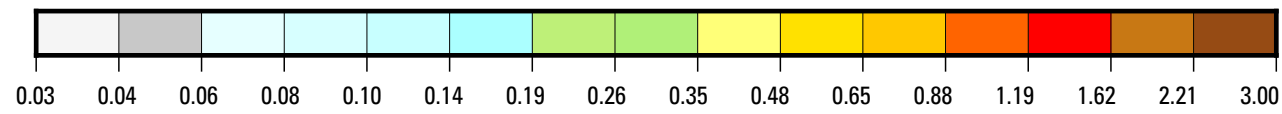

Peak Ground Acceleration (g)

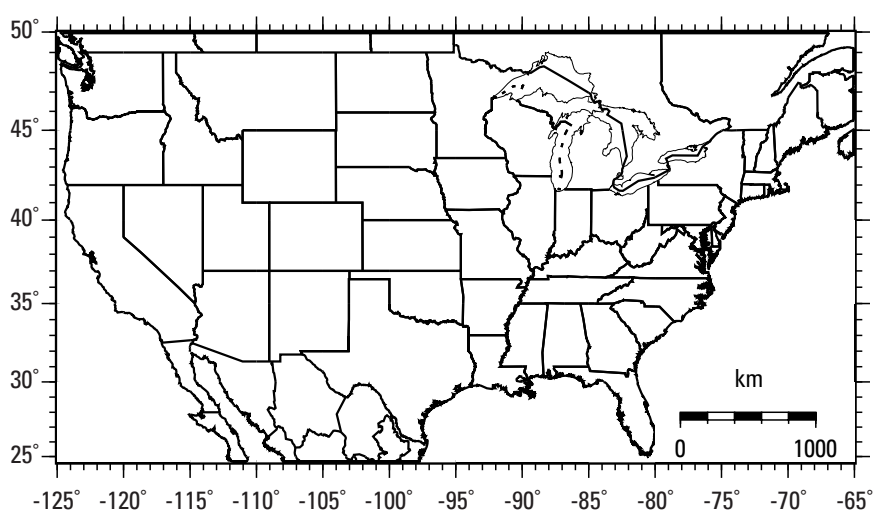

(map 1) - (map 2)

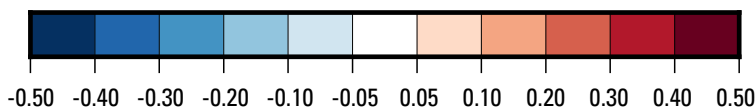

Difference

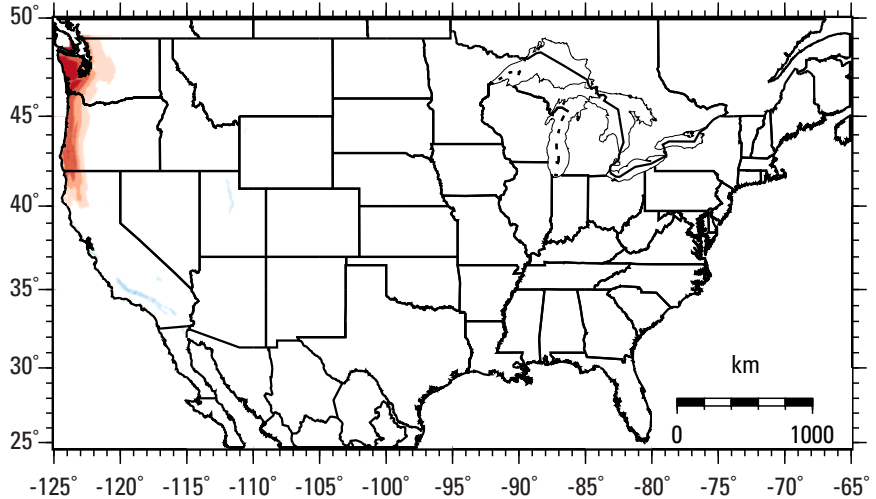

(map 1) / (map 2)

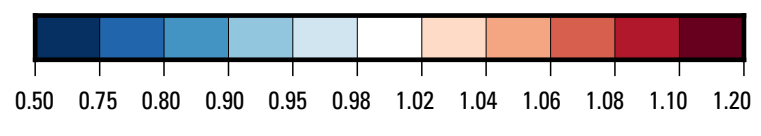

Ratio

Figure 5. Hazard, difference, and ratio maps calculated for the 2014 National Seismic Hazard Model (Petersen and others, 2014, 2015), showing the change in hazard between the updated suite of weighted ground motion models presented in table 3 and the original suite of weighted GMMs, also presented in table 3. For 2 percent in 50-year probability of exceedance $(A)$ peak ground acceleration (PGA), $(B) 0.2$ second, and $(C) 1.0$ second; for 5 percent in 50-year probability of exceedance $(D)$ PGA, $(E) 0.2$ second, and $(F) 1.0$ second; for 10 percent in 50-year probability of exceedance $(G)$ PGA, $(H) 0.2$ second, and $(/) 1.0$ second for the National Earthquake Hazards Reduction Program site class boundary $\mathrm{B} / \mathrm{C}$ (time-averaged shear wave velocity in the upper 30 meters $\left[\mathrm{V}_{\mathrm{S} 30}\right]=760$ meters per second). - Continued 
Comparison of 0.2 Second Total Mean Hazard from the USGS 2014 NSHM

Updated Suite of 2014 NSHM GMMs vs. Original Suite of 2014 NSHM GMMs

$5 \%$ in 50 Years Probability of Exceedance, NEHRP Site Class Boundary B/C (Vs30 = $760 \mathrm{~m} / \mathrm{s})$

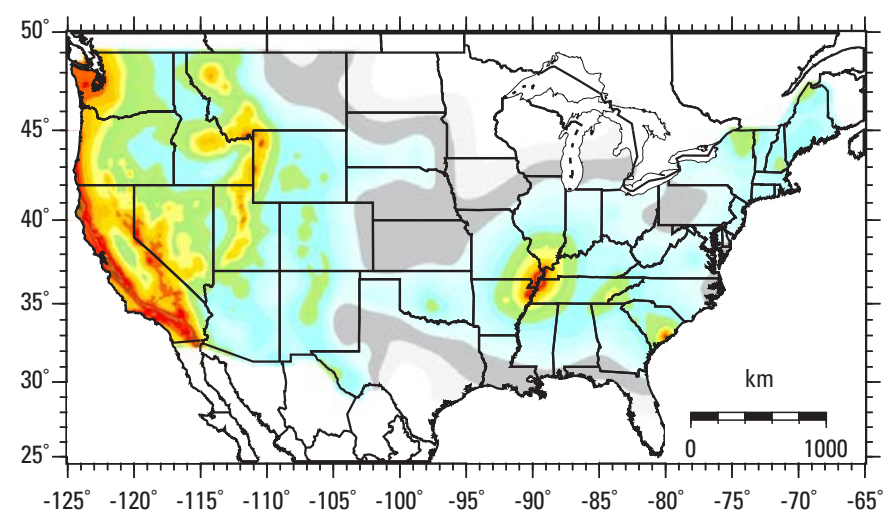

Updated Suite of 2014 GMMs (map 1)

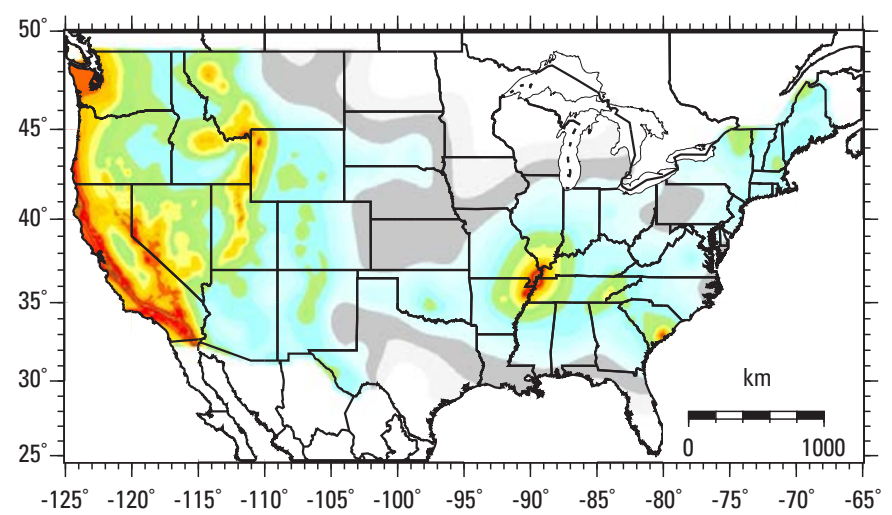

Original Suite of 2014 GMMs (map 2)

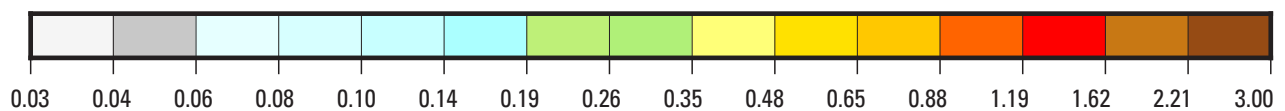

\subsection{Second Spectral Acceleration (g)}
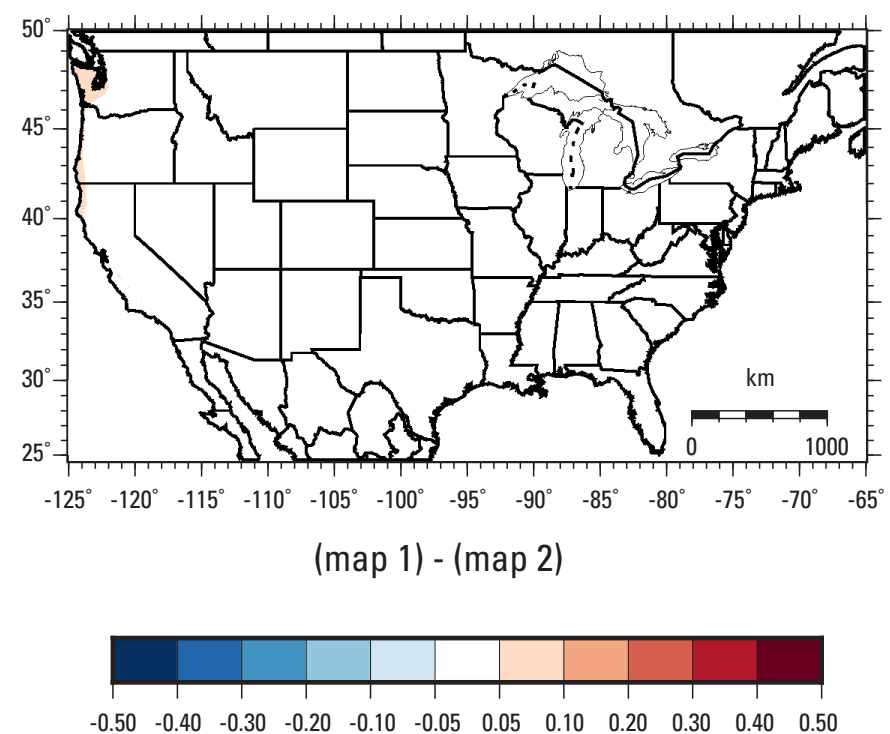

Difference
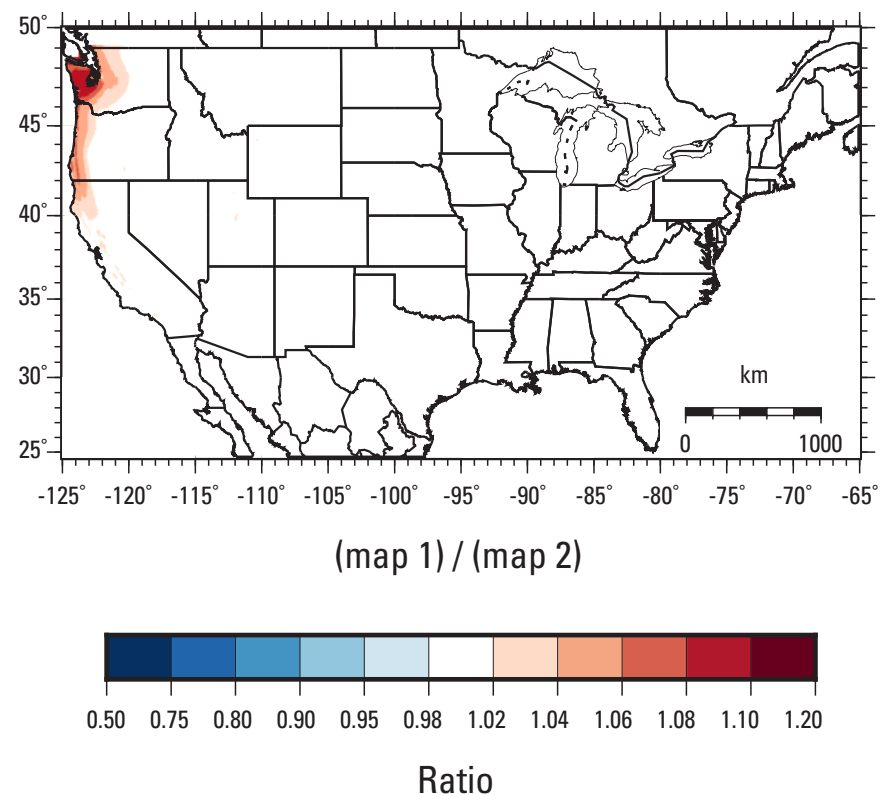

Figure 5. Hazard, difference, and ratio maps calculated for the 2014 National Seismic Hazard Model (Petersen and others, 2014, 2015), showing the change in hazard between the updated suite of weighted ground motion models presented in table 3 and the original suite of weighted GMMs, also presented in table 3. For 2 percent in 50-year probability of exceedance $(A)$ peak ground acceleration (PGA), $(B) 0.2$ second, and $(C) 1.0$ second; for 5 percent in 50-year probability of exceedance $(D)$ PGA, $(E) 0.2$ second, and $(F) 1.0$ second; for 10 percent in 50-year probability of exceedance $(G)$ PGA, $(H) 0.2$ second, and $(/) 1.0$ second for the National Earthquake Hazards Reduction Program site class boundary $\mathrm{B} / \mathrm{C}$ (time-averaged shear wave velocity in the upper 30 meters $\left[\mathrm{V}_{\mathrm{S} 30}\right]=760$ meters per second).-Continued 
Comparison of 1 Second Total Mean Hazard from the USGS 2014 NSHM Updated Suite of 2014 NSHM GMMs vs. Original Suite of 2014 NSHM GMMs $5 \%$ in 50 Years Probability of Exceedance, NEHRP Site Class Boundary B/C (Vs30 = $760 \mathrm{~m} / \mathrm{s})$

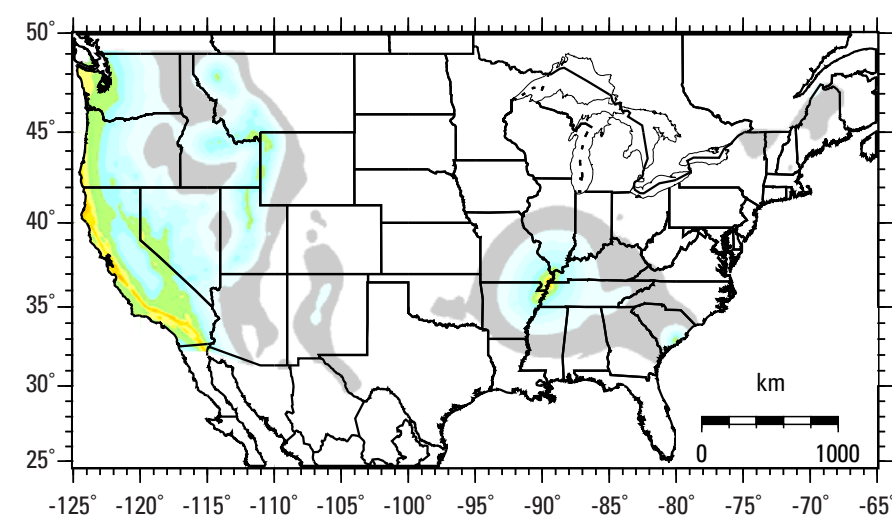

Updated Suite of 2014 GMMs (map 1)

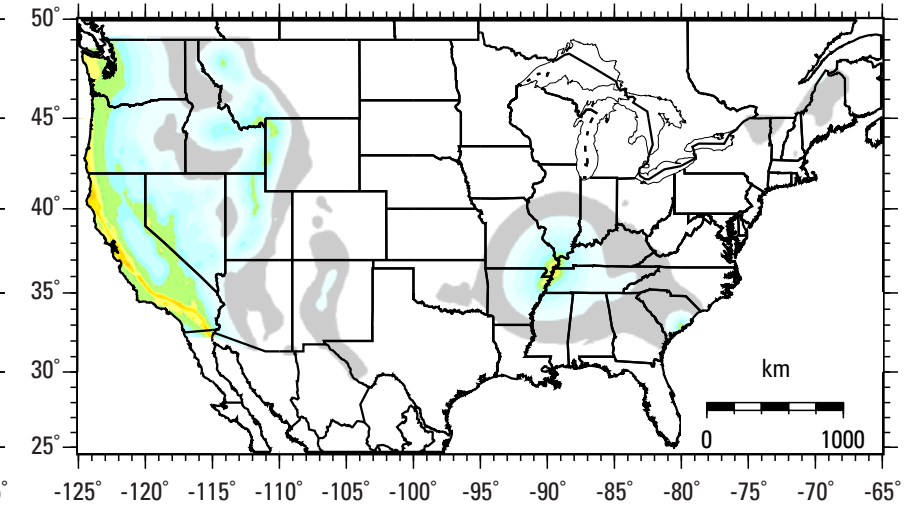

Original Suite of 2014 GMMs (map 2)

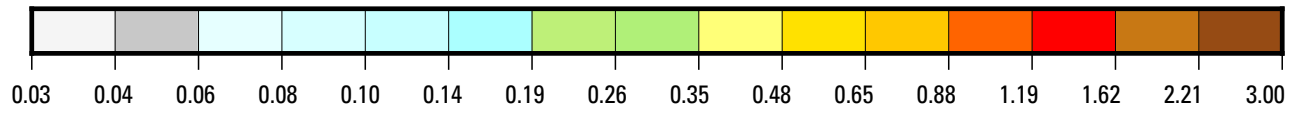

1 Second Spectral Acceleration (g)

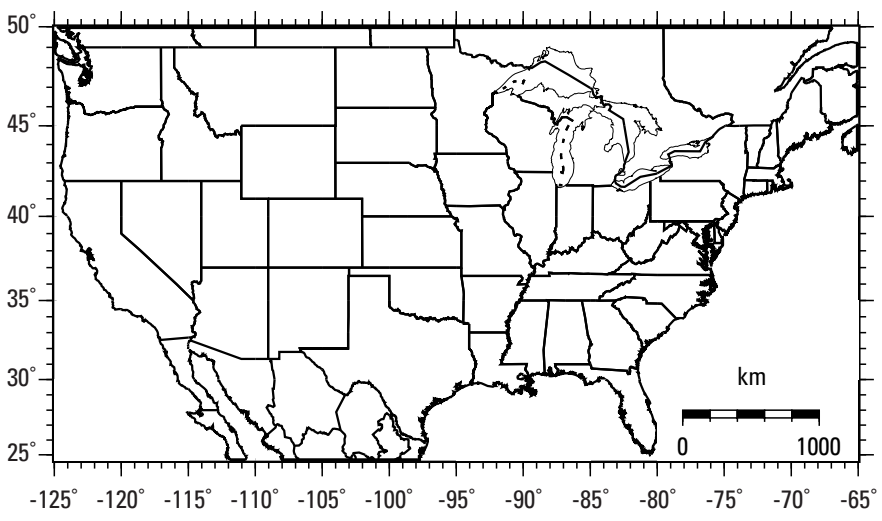

(map 1) - (map 2)

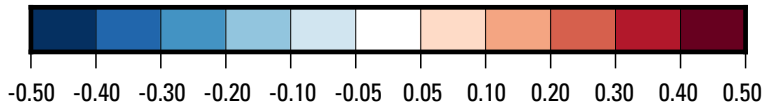

Difference

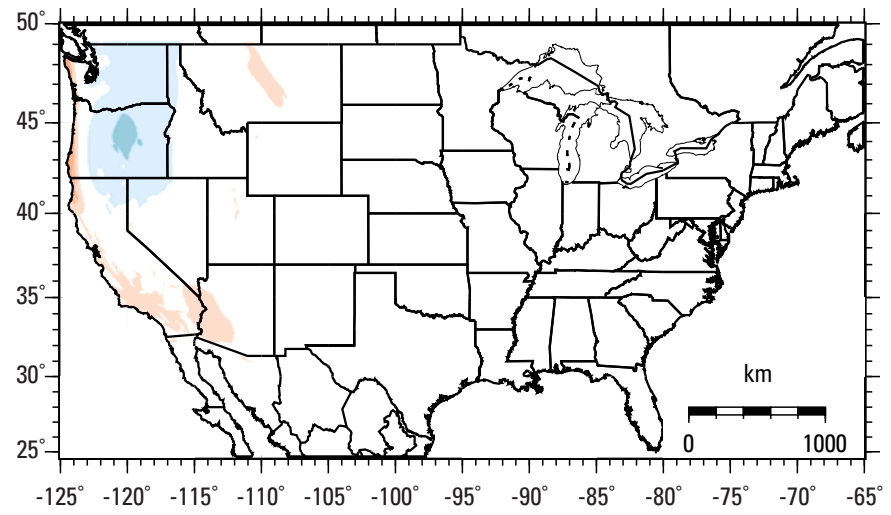

(map 1) / (map 2)

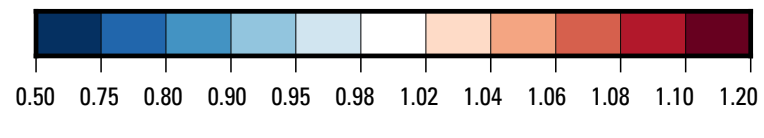

Ratio

Figure 5. Hazard, difference, and ratio maps calculated for the 2014 National Seismic Hazard Model (Petersen and others, 2014, 2015), showing the change in hazard between the updated suite of weighted ground motion models presented in table 3 and the original suite of weighted GMMs, also presented in table 3. For 2 percent in 50-year probability of exceedance $(A)$ peak ground acceleration (PGA), $(B) 0.2$ second, and $(C) 1.0$ second; for 5 percent in 50-year probability of exceedance $(D)$ PGA, $(E) 0.2$ second, and $(F) 1.0$ second; for 10 percent in 50-year probability of exceedance $(G)$ PGA, $(H) 0.2$ second, and $(/) 1.0$ second for the National Earthquake Hazards Reduction Program site class boundary $\mathrm{B} / \mathrm{C}$ (time-averaged shear wave velocity in the upper 30 meters $\left[\mathrm{V}_{\mathrm{S} 30}\right]=760$ meters per second). - Continued 
G

Comparison of PGA Total Mean Hazard from the USGS 2014 NSHM

Updated Suite of 2014 NSHM GMMs vs. Original Suite of 2014 NSHM GMMs

$10 \%$ in 50 Years Probability of Exceedance, NEHRP Site Class Boundary B/C (Vs30 = $760 \mathrm{~m} / \mathrm{s}$ )

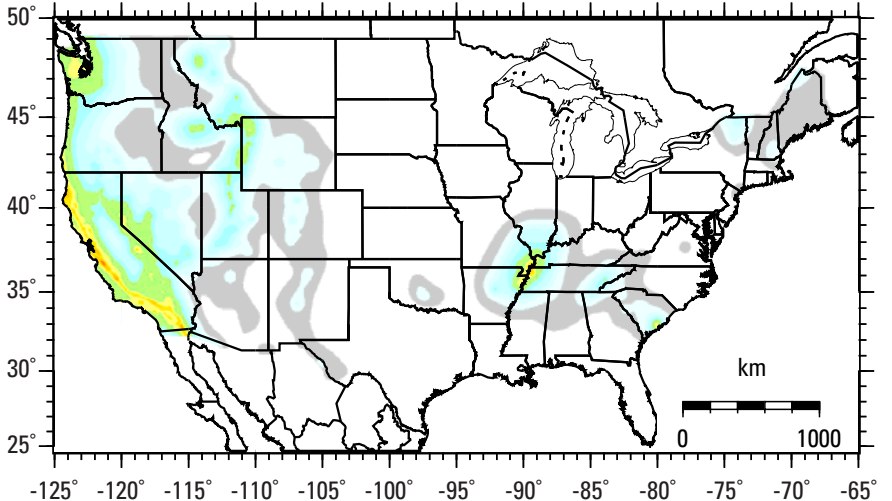

Updated Suite of 2014 GMMs (map 1)

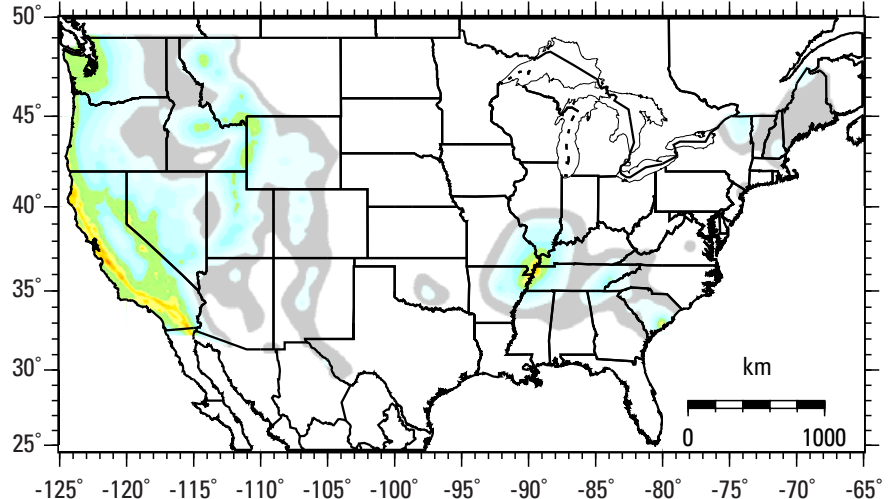

Original Suite of 2014 GMMs (map 2)

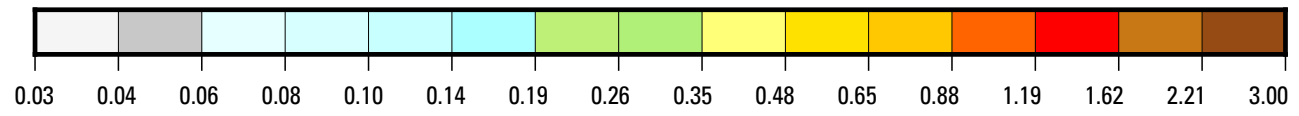

Peak Ground Acceleration (g)

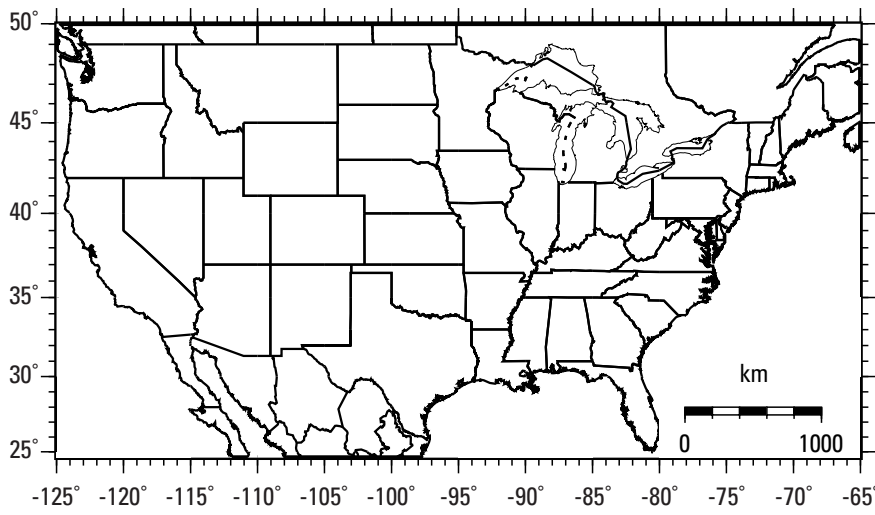

(map 1) - (map 2)

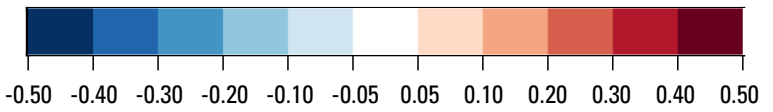

Difference

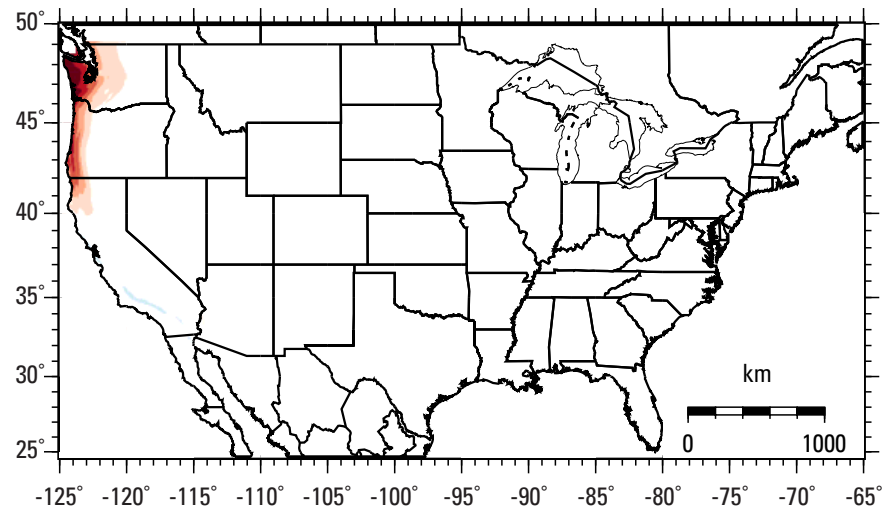

(map 1) / (map 2)

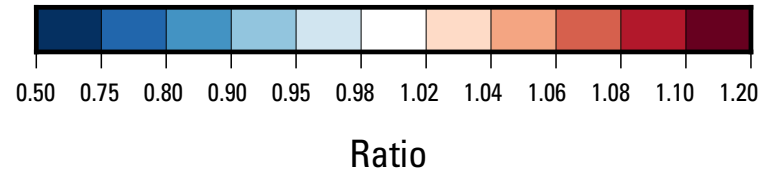

Figure 5. Hazard, difference, and ratio maps calculated for the 2014 National Seismic Hazard Model (Petersen and others, 2014, 2015), showing the change in hazard between the updated suite of weighted ground motion models presented in table 3 and the original suite of weighted GMMs, also presented in table 3. For 2 percent in 50 -year probability of exceedance $(A)$ peak ground acceleration (PGA), $(B) 0.2$ second, and $(C) 1.0$ second; for 5 percent in 50-year probability of exceedance $(D)$ PGA, $(E) 0.2$ second, and $(F) 1.0$ second; for 10 percent in 50-year probability of exceedance $(G)$ PGA, $(H) 0.2$ second, and $(/) 1.0$ second for the National Earthquake Hazards Reduction Program site class boundary $\mathrm{B} / \mathrm{C}$ (time-averaged shear wave velocity in the upper 30 meters $\left[\mathrm{V}_{\mathrm{S} 30}\right]=760$ meters per second).-Continued 
$\boldsymbol{H}$

Comparison of 0.2 Second Total Mean Hazard from the USGS 2014 NSHM

Updated Suite of 2014 NSHM GMMs vs. Original Suite of 2014 NSHM GMMs

$10 \%$ in 50 Years Probability of Exceedance, NEHRP Site Class Boundary B/C (Vs30 = $760 \mathrm{~m} / \mathrm{s}$ )

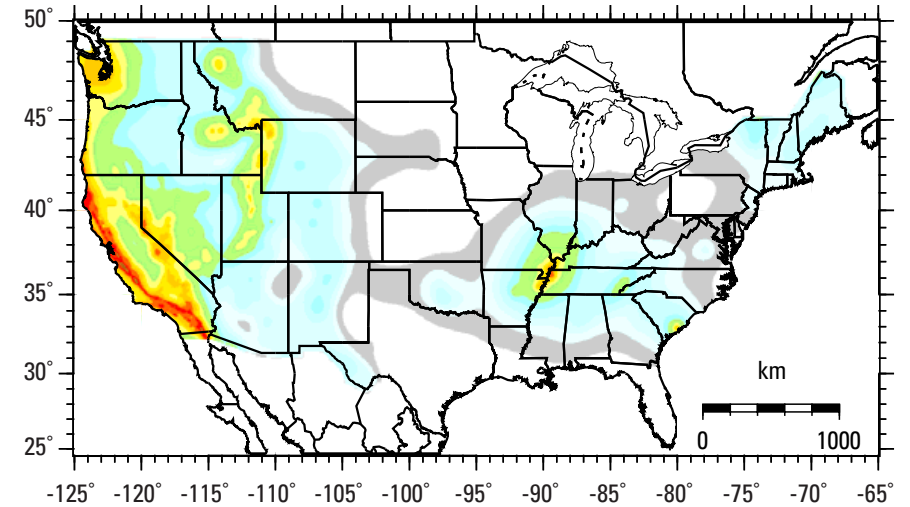

Updated Suite of 2014 GMMs (map 1)

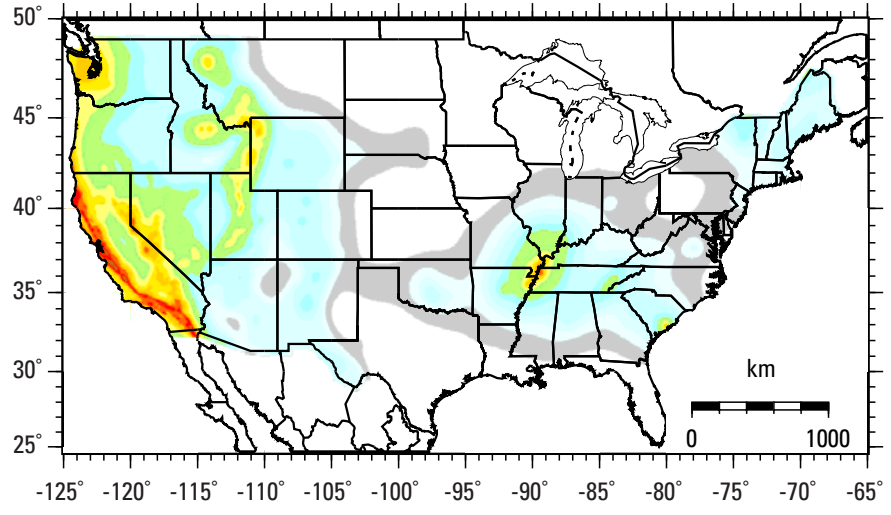

Original Suite of 2014 GMMs (map 2)

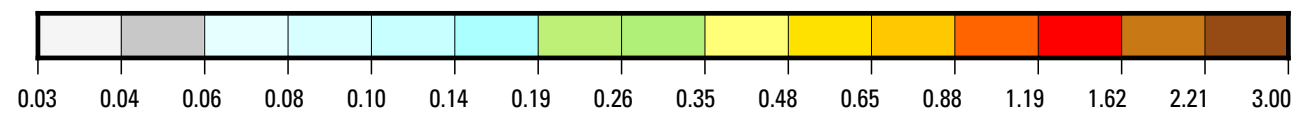

0.2 Second Spectral Acceleration (g)

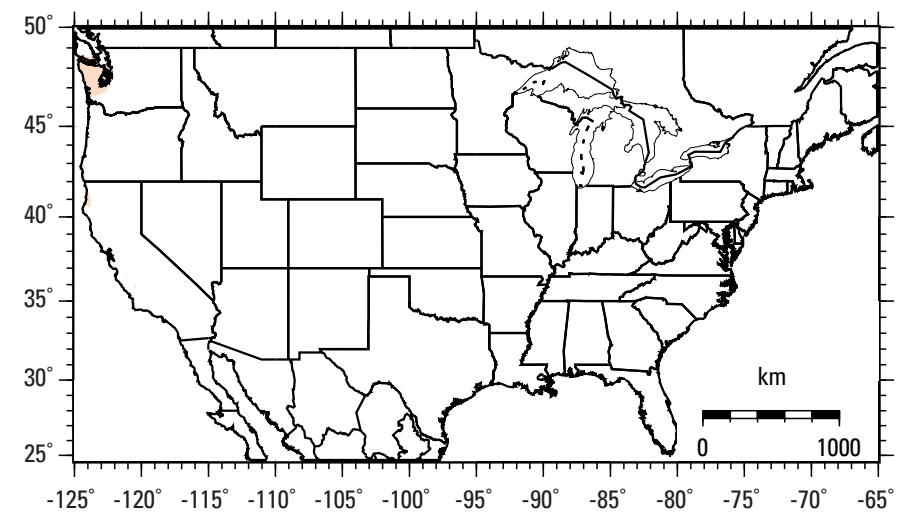

(map 1) - (map 2)

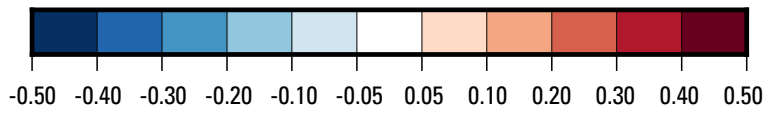

Difference

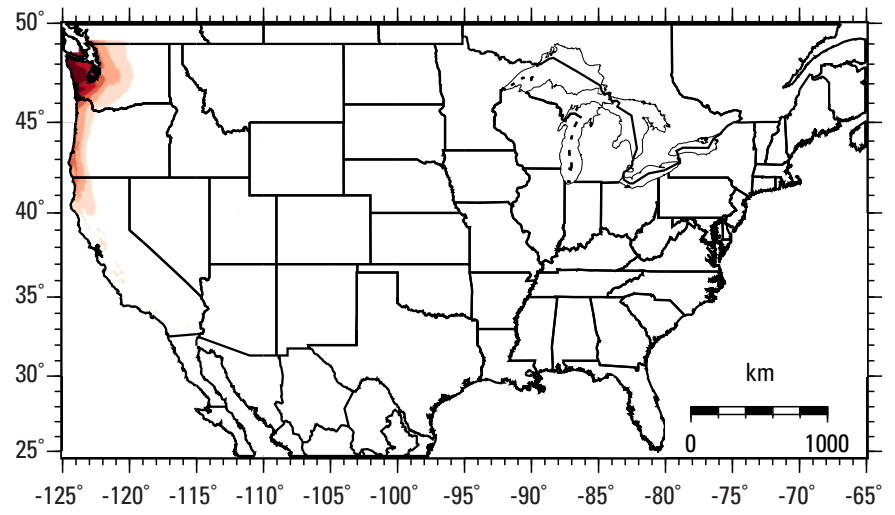

(map 1) / (map 2)

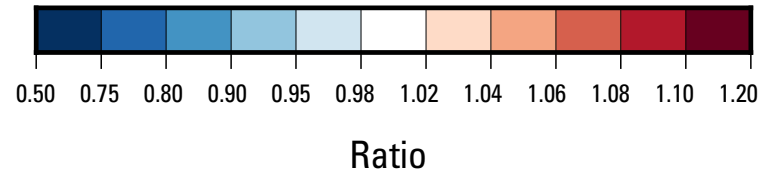

Figure 5. Hazard, difference, and ratio maps calculated for the 2014 National Seismic Hazard Model (Petersen and others, 2014, 2015), showing the change in hazard between the updated suite of weighted ground motion models presented in table 3 and the original suite of weighted GMMs, also presented in table 3. For 2 percent in 50-year probability of exceedance $(A)$ peak ground acceleration (PGA), $(B) 0.2$ second, and $(C) 1.0$ second; for 5 percent in 50-year probability of exceedance $(D)$ PGA, $(E) 0.2$ second, and $(F) 1.0$ second; for 10 percent in 50-year probability of exceedance $(G)$ PGA, $(H) 0.2$ second, and $(/) 1.0$ second for the National Earthquake Hazards Reduction Program site class boundary $B / C$ (time-averaged shear wave velocity in the upper 30 meters $\left[V_{S 30}\right]=760$ meters per second). - Continued 


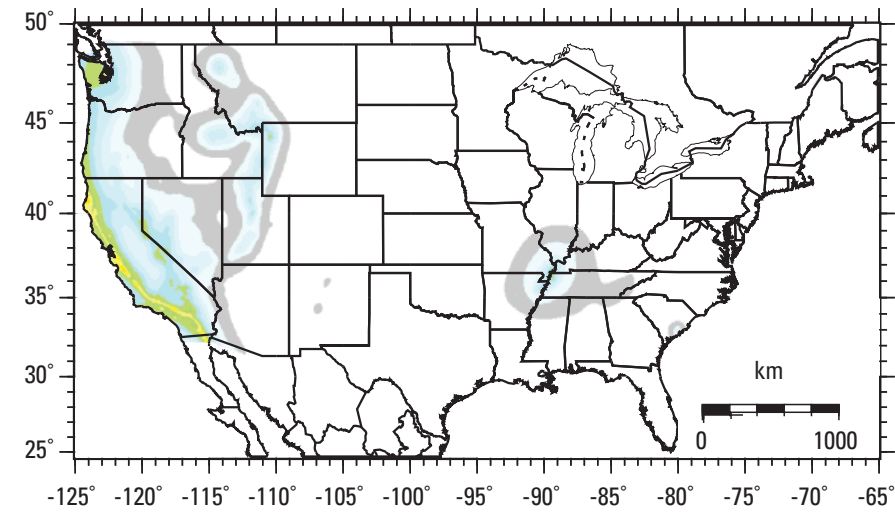

Updated Suite of 2014 GMMs (map 1)

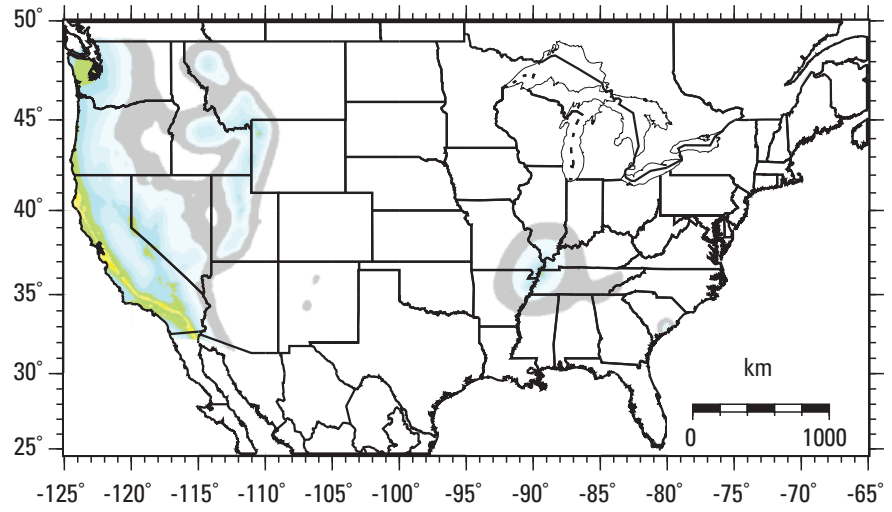

Original Suite of 2014 GMMs (map 2)

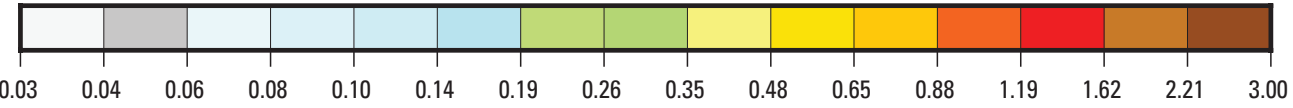

1 Second Spectral Acceleration $(\mathrm{g})$

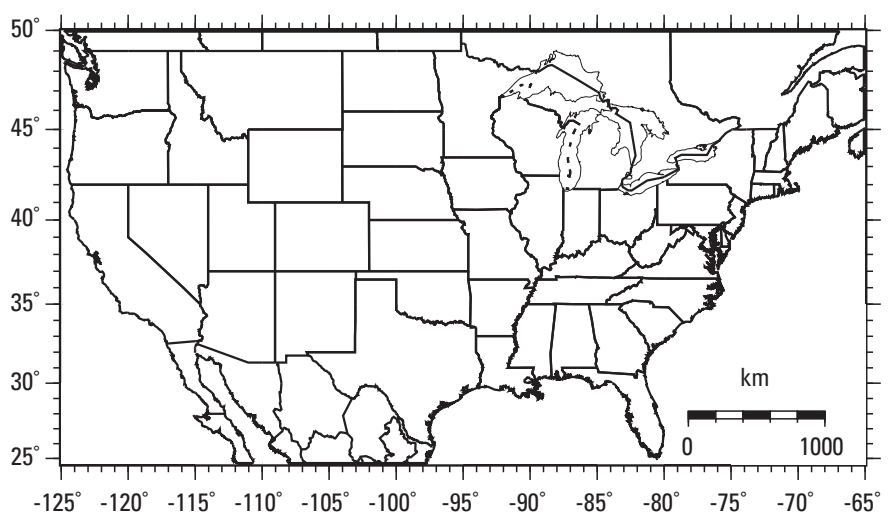

(map 1) - (map 2)

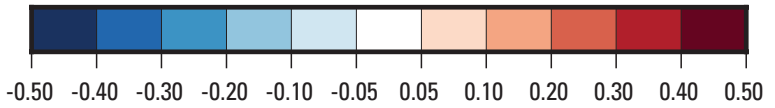

Difference
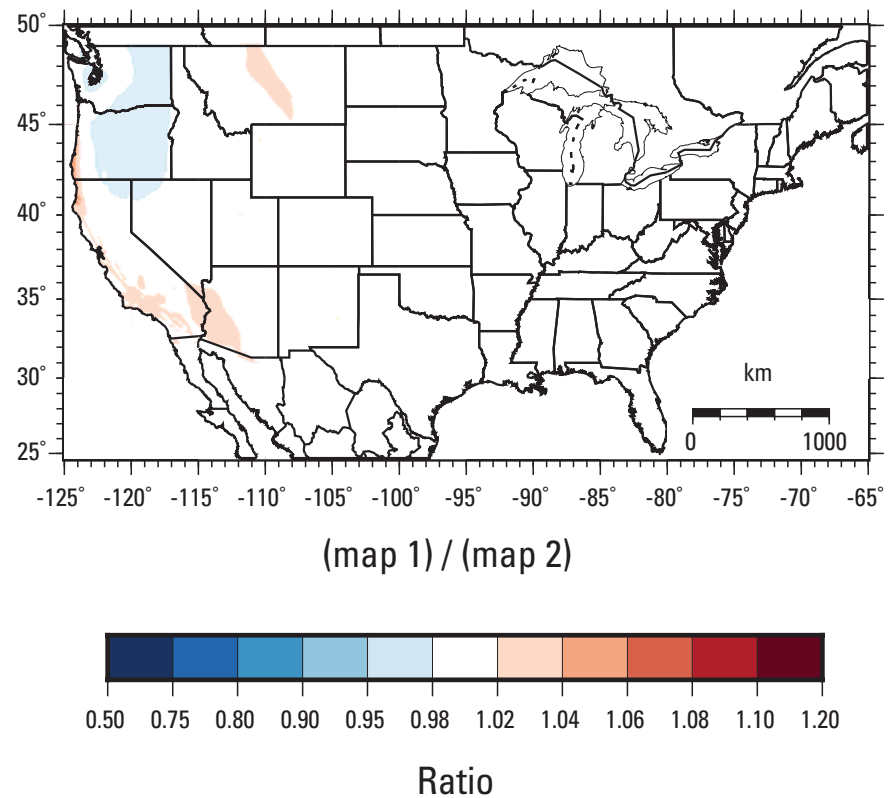

Figure 5. Hazard, difference, and ratio maps calculated for the 2014 National Seismic Hazard Model (Petersen and others, 2014, 2015), showing the change in hazard between the updated suite of weighted ground motion models presented in table 3 and the original suite of weighted GMMs, also presented in table 3. For 2 percent in 50-year probability of exceedance $(A)$ peak ground acceleration (PGA), $(B) 0.2$ second, and $(C) 1.0$ second; for 5 percent in 50-year probability of exceedance $(D)$ PGA, $(E) 0.2$ second, and $(A) 1.0$ second; for 10 percent in 50-year probability of exceedance $(G)$ PGA, $(H) 0.2$ second, and $(/) 1.0$ second for the National Earthquake Hazards Reduction Program site class boundary $\mathrm{B} / \mathrm{C}$ (time-averaged shear wave velocity in the upper 30 meters $\left[\mathrm{V}_{\mathrm{s30}}\right]=760$ meters per second).—Continued 
Figure 6. (A) Site in the Pacific Northwest $(46.574,-122.531)$ in which a $(B)$ deaggregation was performed for peak ground acceleration hazard at 2 percent in 50-year probability of exceedance for the National Earthquake Hazards Reduction Program site class boundary $\mathrm{B} / \mathrm{C}$ (shear wave velocity in the upper 30 meters $\left[\mathrm{V}_{\mathrm{S} 30}\right]=760$ meters per second). The highest contributors to hazard are interface, intraslab, and grid sources (labeled 1-3 on the plot, respectively). The deaggregation plot was generated using the Unified Hazard Tool on the U.S. Geological Survey website (https://earthquake. usgs.gov/hazards/interactive/) using the "Dynamic: Conterminous U.S. 2014 (v4.1.1)" Edition, last accessed April 2018. PGA, peak ground acceleration; NEHRP, National Earthquake Hazards Reduction Program; km, kilometers; $g$, gravitational acceleration constant equal to 9.81 meters per second squared; $\mathrm{R}$, distance (kilometers); $M$, magnitude; $\mathrm{M}_{\mathrm{w}^{\prime}}$ moment magnitude; $\varepsilon$ epsilon; $\sigma$, sigma; $\infty$, infinity; $\%$, percent; rRup, closest distance to rupture plane (kilometers).
A

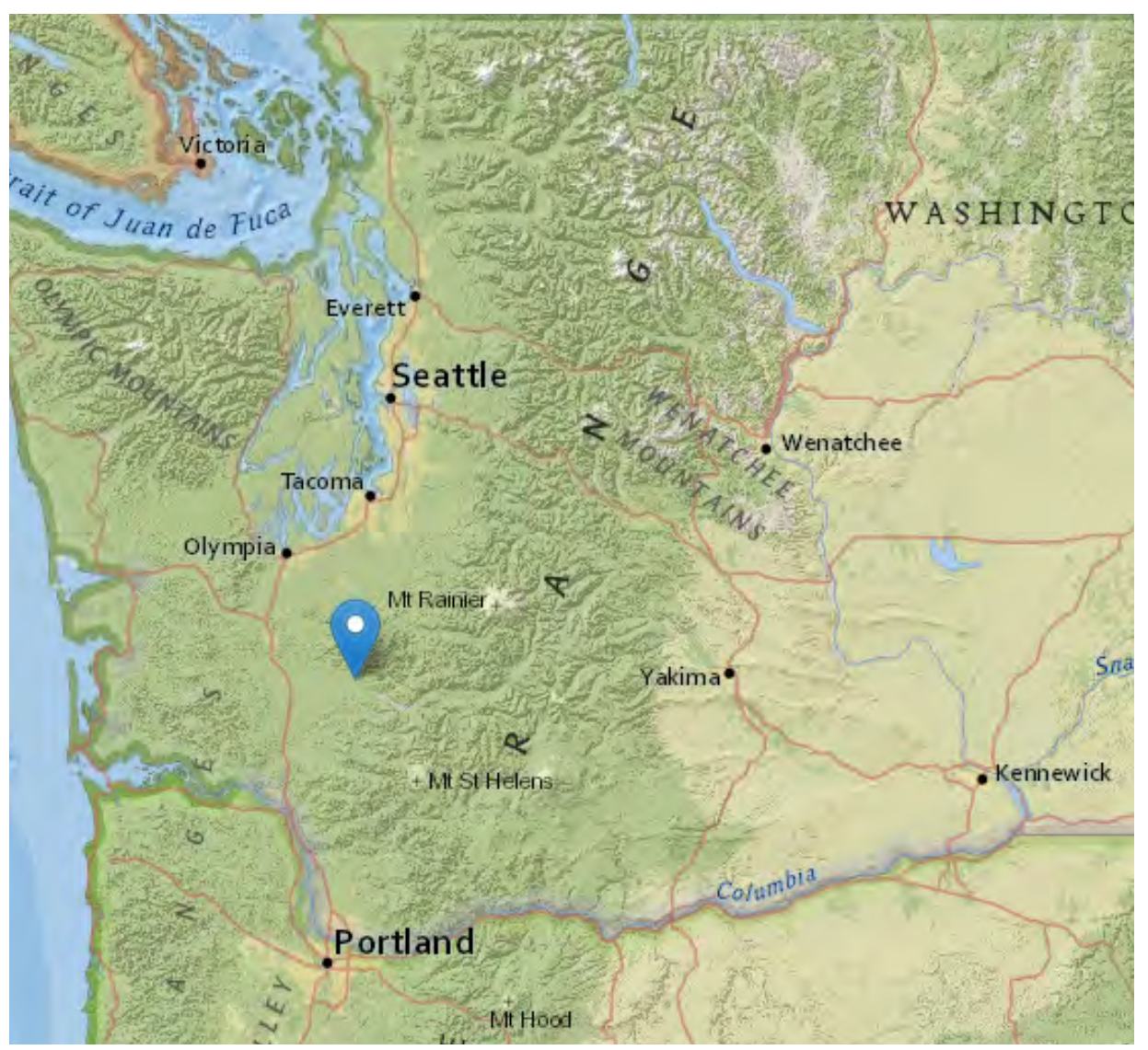

B

PGA Deaggregation of NEHRP Site Class Boundary B/C $(760 \mathrm{~m} / \mathrm{s})$

PGA amplitude: $0.4853 \mathrm{~g}$

Exceedance Rate: $3.95 \times 10_{4}$ years

Mean Return Period: 2530 years

Mean $\left(\mathrm{R}, \mathrm{M}, \varepsilon_{0}\right): 48.82 \mathrm{~km}, \mathrm{M} 7.3,1.2 \sigma$

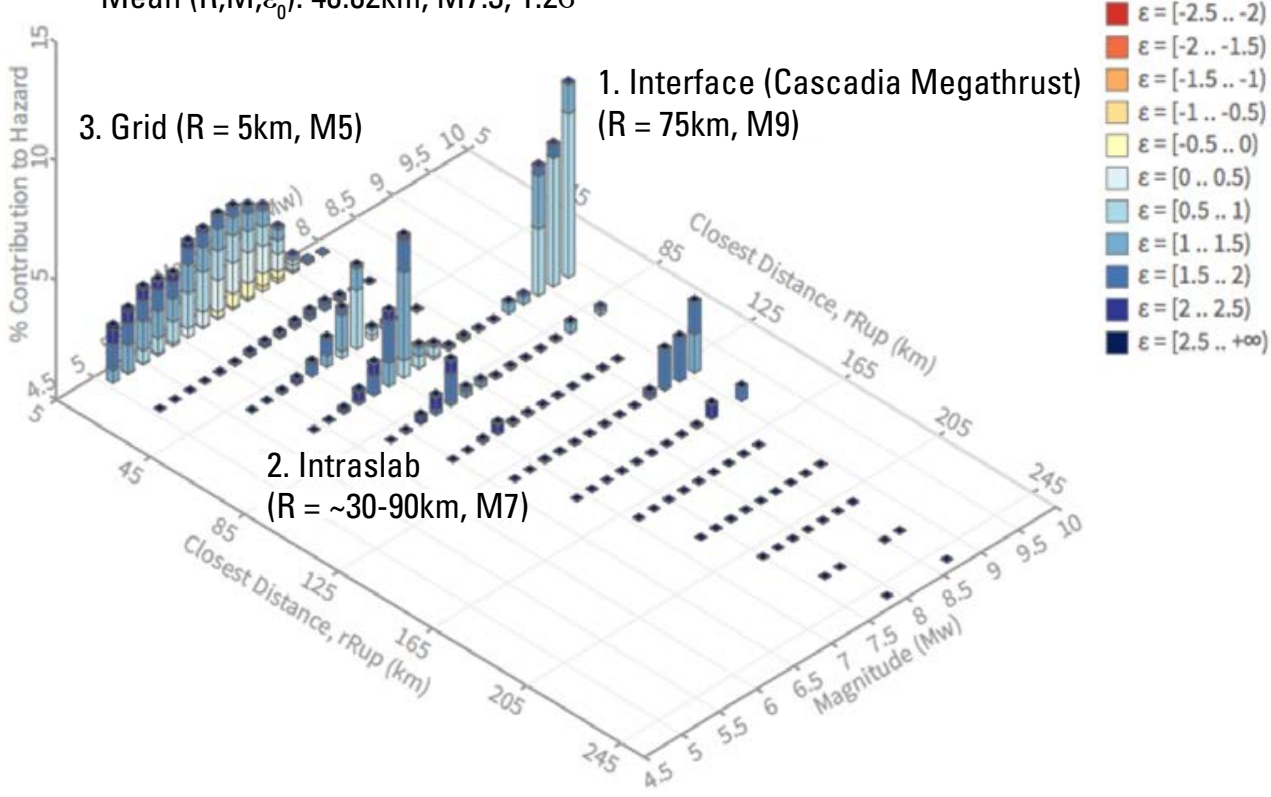


Figure 6. Ground motion magnitude-distance scaling relations plots for $(C)$ interface and $(D)$ intraslab ground motion models are shown to aid in the explanation of the deaggregation. zTop, depth to top of rupture (kilometers); zHyp, hypocentral depth (kilometers); $\mathrm{km}$, kilometers. See table 3 for GMM abbreviations.-Continued
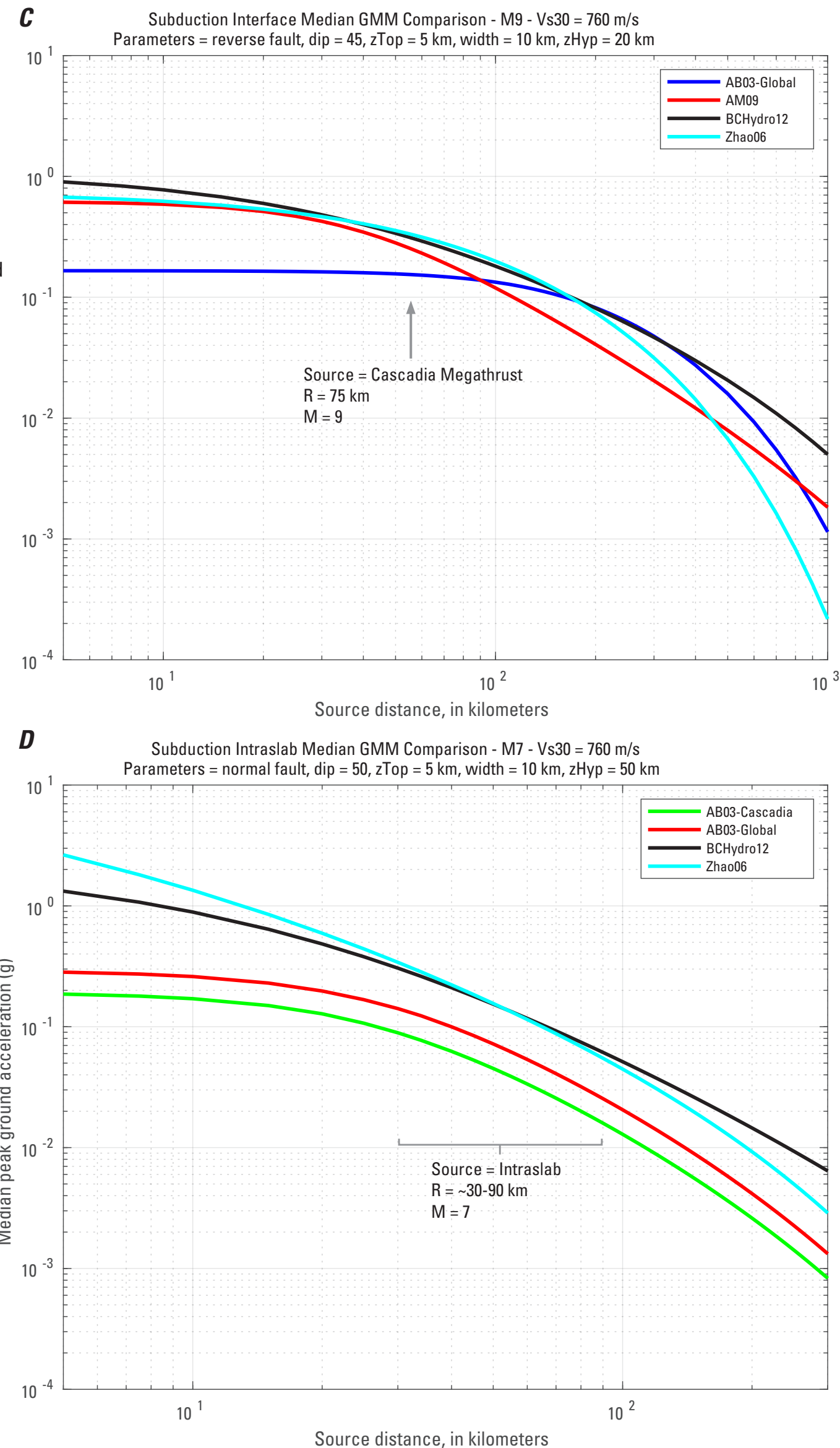


\section{Hazard Curves and Uniform Hazard Response Spectra}

We produced hazard curves and uniform hazard response spectra (UHRS) at 190 test sites across the conterminous United States to verify that hazard results were reasonable. A sample set of hazard curves and UHRS plots are shown in figure $7 A-D$ for sites in the CEUS (Memphis, Tenn.), WUS (Salt Lake City, Utah), PNW (Seattle, Wash.), and California (Los Angeles, Calif.). These figures allowed us to look at a wide range of sites across the conterminous United States and verify that hazard curves were realistic, based on what we know about the source and ground motion models and their expected hazard relation to the sites. We were also able to look at the UHRS plots to verify that the site amplification model in the WUS was implement correctly, as well as the amplification factors in the CEUS.

\section{$\boldsymbol{A}$}

Memphis, TN $(35.2,-90.1)$
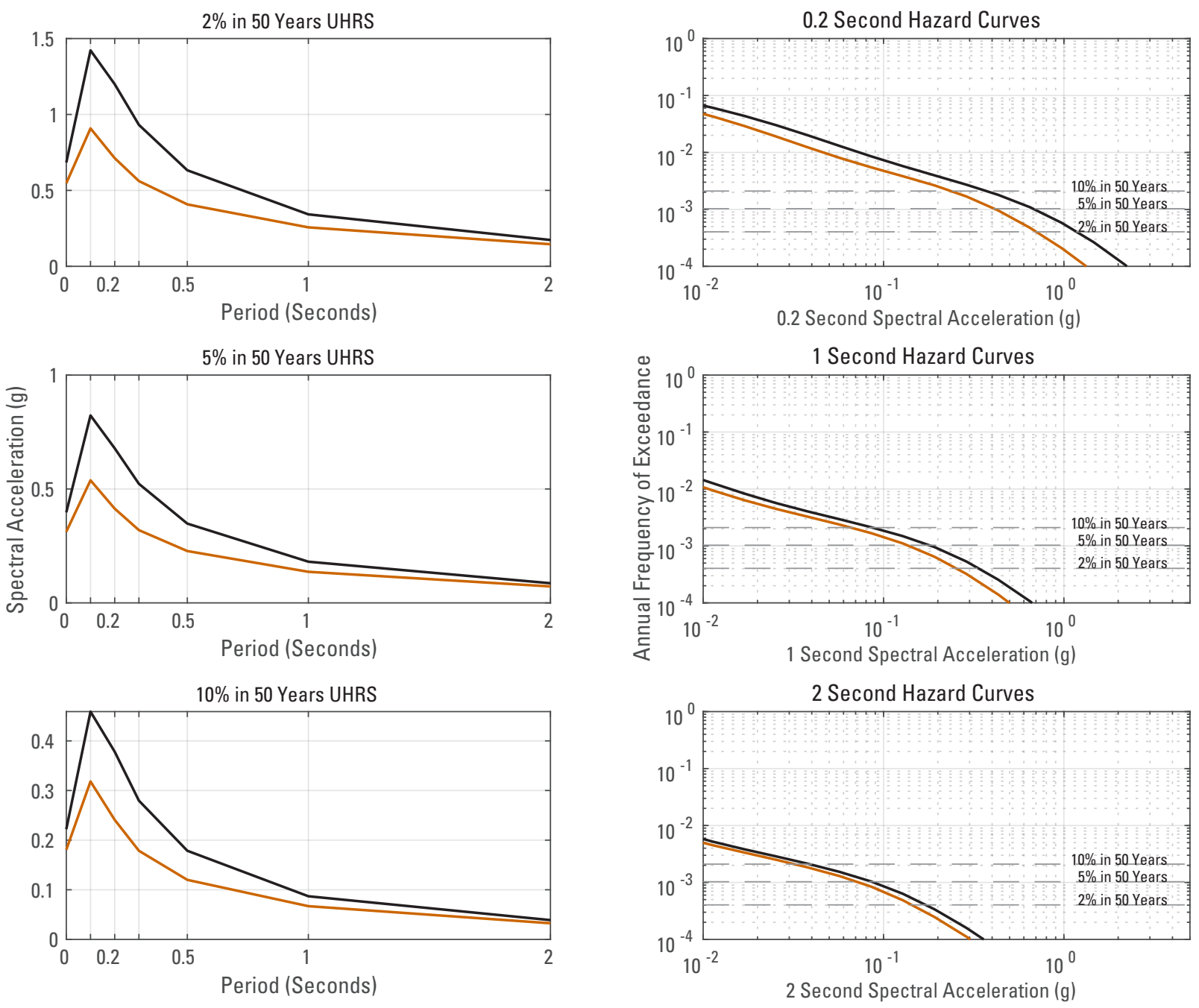

NEHRP Site Classes:

A $B / C$

Figure 7. Summary figure showing 2, 5, and 10 percent (\%) probabilities of exceedance in 50 years uniform hazard response spectra (UHRS) plots and select hazard curves for (A) Memphis, Tenn., (B) Salt Lake City, Utah, $(C)$ Seattle, Wash., and $(D)$ Los Angeles, Calif. 
Salt Lake City, UT $(40.8,-111.9)$
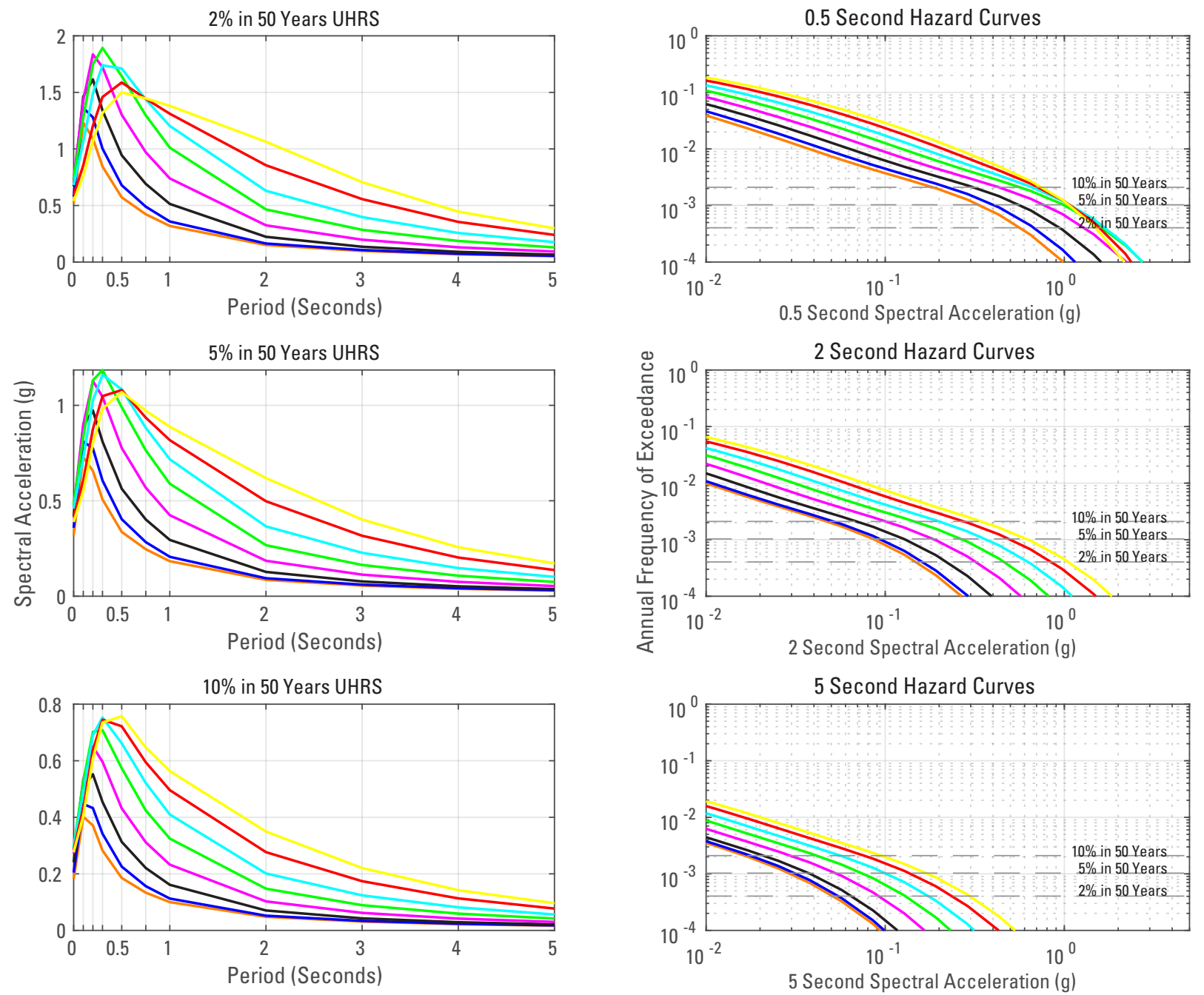

NEHRP Site Classes:

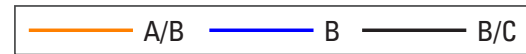

$\mathrm{C}$

$\mathrm{C} / \mathrm{D} \longrightarrow \mathrm{D}$

D/E

Figure 7. Summary figure showing 2, 5, and 10 percent (\%) probabilities of exceedance in 50 years uniform hazard response spectra (UHRS) plots and select hazard curves for (A) Memphis, Tenn., (B) Salt Lake City, Utah, (C) Seattle, Wash., and (D) Los Angeles, Calif.-Continued 

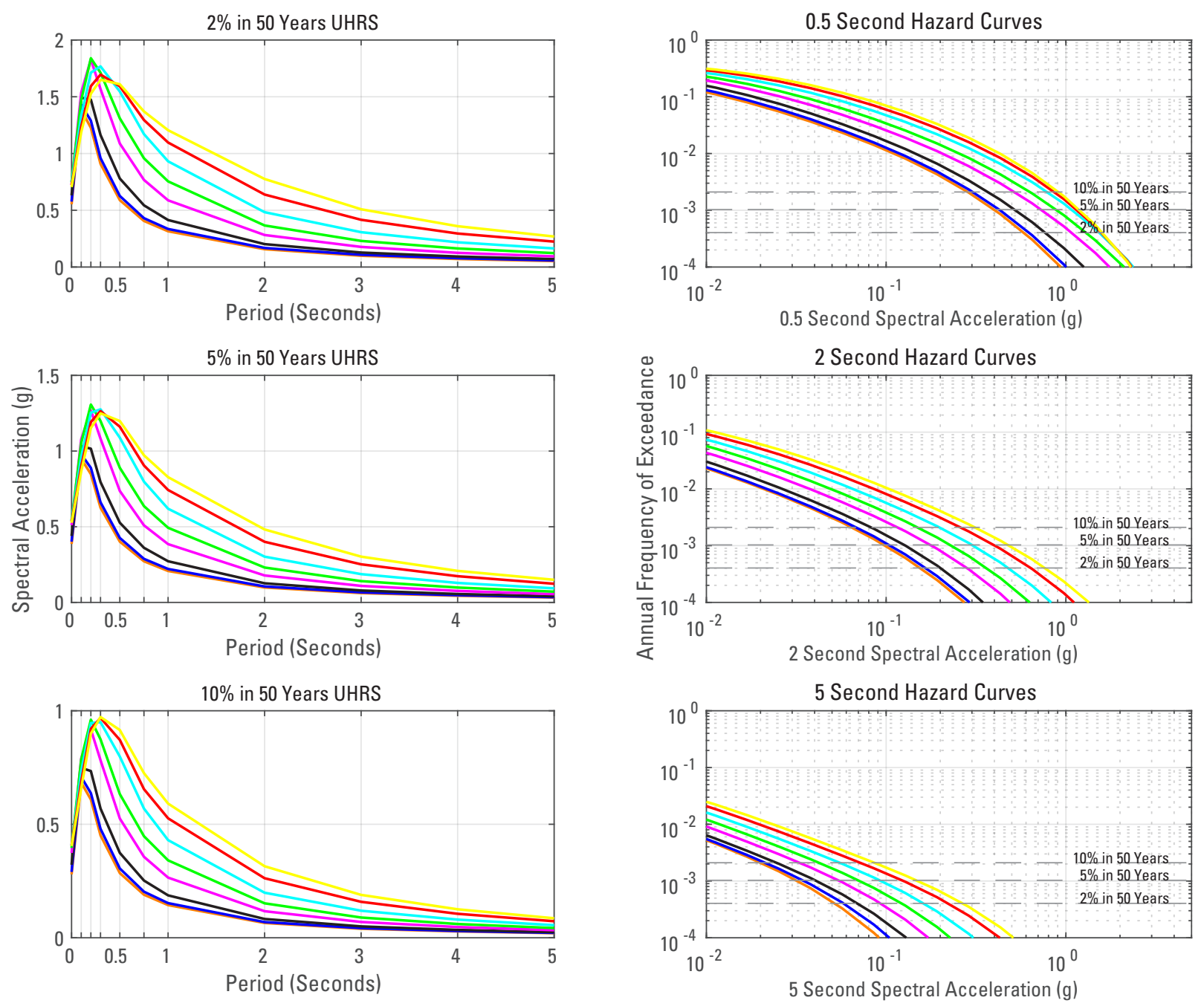

NEHRP Site Classes:

A/B

$\mathrm{B} \longrightarrow \mathrm{B} / \mathrm{C}$

$\mathrm{C} \longrightarrow \mathrm{C} / \mathrm{D} \longrightarrow \mathrm{D} / \mathrm{E} \longrightarrow \mathrm{E}$

Figure 7. Summary figure showing 2, 5, and 10 percent $(\%)$ probabilities of exceedance in 50 years uniform hazard response spectra (UHRS) plots and select hazard curves for (A) Memphis, Tenn., (B) Salt Lake City, Utah, (C) Seattle, Wash., and (D) Los Angeles, Calif.-Continued 

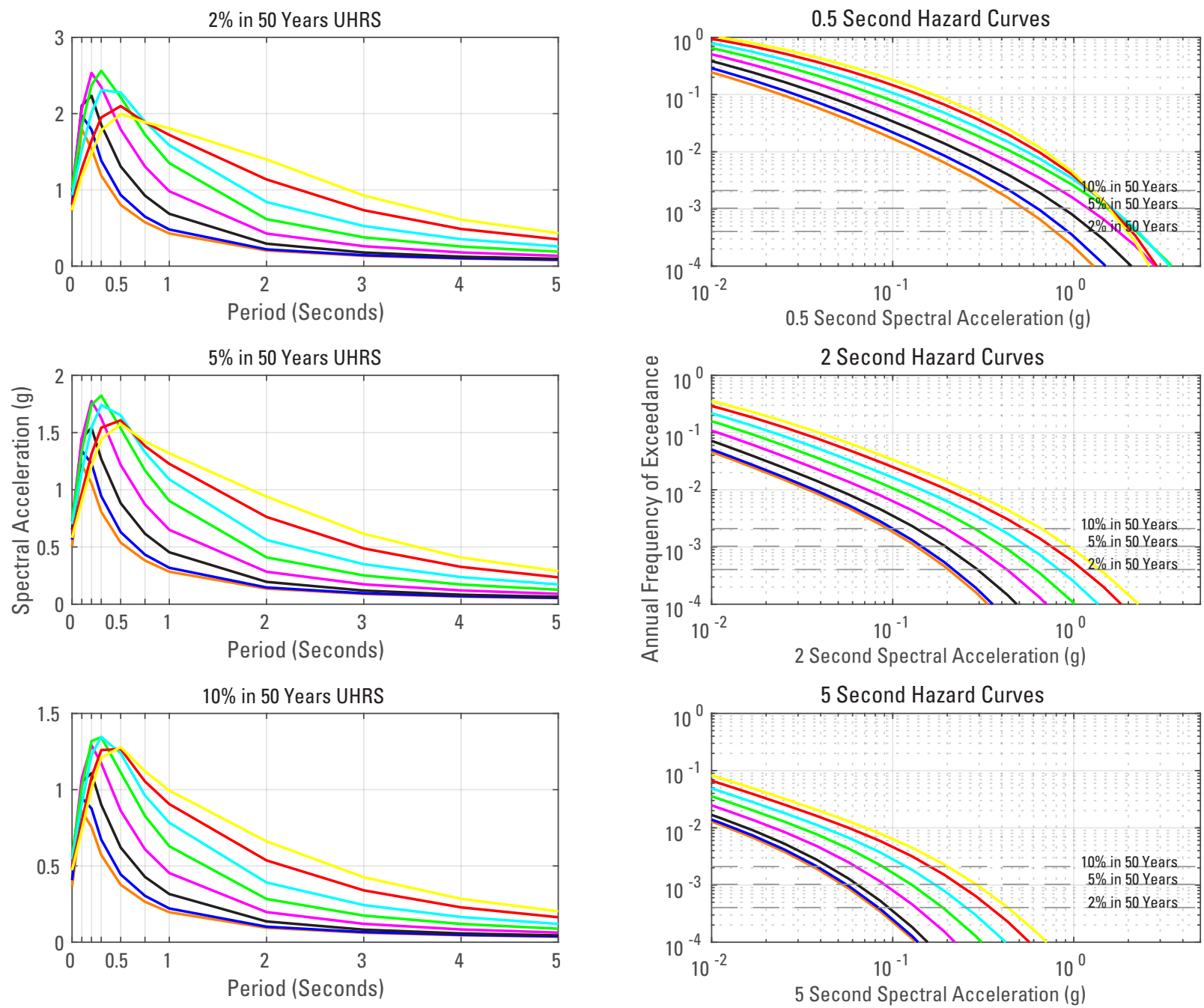

NEHRP Site Classes:

$\longrightarrow \mathrm{A} / \mathrm{B} \longrightarrow \mathrm{B} / \mathrm{C}$

$\mathrm{C} \longrightarrow \mathrm{C} / \mathrm{D} \longrightarrow \mathrm{D} / \mathrm{E} \longrightarrow \mathrm{E}$

Figure 7. Summary figure showing 2, 5, and 10 percent (\%) probabilities of exceedance in 50 years uniform hazard response spectra (UHRS) plots and select hazard curves for (A) Memphis, Tenn., (B) Salt Lake City, Utah, (C) Seattle, Wash., and (D) Los Angeles, Calif.-Continued 


\section{Results}

Figure $8 A-K$ shows a set of hazard maps for 2 percent probability of exceedance in 50 years, derived from hazard curves for PGA, 0.1, 0.2, 0.3, 0.5, 0.75, 1.0, 2.0, 3.0, 4.0, and 5.0 second SAs (maps for 0.75, 3.0, 4.0, and 5.0 second SA are calculated for the WUS only) with 5 percent damping for NEHRP site class boundary B/C $\left(V_{\mathrm{S} 30}=760 \mathrm{~m} / \mathrm{s}\right)$. The difference in hazard between the 2014 NSHM (using updated suites of weighted GMMs) and the 2008 NSHM is presented in the form of hazard, difference, and ratio maps. Details about the differences in these two source models, and why the hazard has increased or decreased in certain areas, are not discussed in this report; please see the documentation for the 2008 NSHM (Petersen and others, 2008) and the 2014 NSHM (Petersen and others, 2014, 2015) for more details. Additional hazard curves and maps for the spectral periods and site classes listed in table 1 are available at the USGS ScienceBase Catalog (Shumway, 2018). See the appendix for a complete list of available files for download.

\section{Uncertainty in Long-Period Maps}

As part of this report, we have provided new WUS long-period maps (>1.0 second) for the 2014 NSHM. When calculating these ground motion maps, we use default basin terms that account for the average basin depth amplification that is a function of the shallow crustal velocity terms defined using $\mathrm{V}_{\mathrm{S} 30}$. Some engineers have observed that the seismic hazard for long periods and soft soils at some WUS urban sites that overlie deep sedimentary basins is lower compared to more detailed analyses that consider basin-depth data. They are concerned about the consequences of not properly accounting for the enhanced ground motions for long-period structures in the building codes. The NSHMP is currently evaluating how to implement such models in future NSHM updates. Users of these 2014 NSHM WUS long-period maps should consider this uncertainty when evaluating these maps.

\section{Future Updates of the National Seismic Hazard Model for the Conterminous United States}

The NSHMP plans to update the NSHM in 2018 and 2020. The two closely timed updates are planned to allow more time for the building code community to analyze the consequences of the hazard model changes in the design criteria. In addition to evaluating the use of nondefault basin terms in certain areas of the WUS, we also plan to update the suite of CEUS GMMs and implement a site amplification model for the CEUS. This will allow for the calculation of uniform period and site class maps across the conterminous United States.

\section{Conclusions}

In this report, we present probabilistic ground motion maps for 2, 5, and 10 percent probabilities of exceedance in 50 years, derived from seismic hazard curves for PGA, 0.1, 0.2, 0.3, 0.5, 1.0, and 2.0 second SAs in the CEUS (this includes uniform NEHRP site class A and site class boundary B/C maps) and for PGA, 0.1, 0.2, 0.3, 0.5, 0.75, 1.0, 2.0, 3.0, 4.0, and 5.0 second SAs in the WUS (this includes uniform NEHRP site classes B, C, D, and E, and site class boundaries A/B, B/C, C/D, and D/E maps) using the 2014 NSHM with updated suites of weighted GMMs. We present hazard, difference, and ratio maps, comparing the change in hazard from the original suites of weighted GMMs and the updated suites of weighted GMMs for PGA, 0.2 and 1.0 second SAs. We also present hazard, difference, and ratio maps comparing the 2014 NSHM additional period and site class maps with the 2008 NSHM maps.

The additional period and uniform site class hazard curves and maps for the 2014 NSHM are available for download at the USGS ScienceBase Catalog (Shumway, 2018).

\section{Acknowledgments}

We wish to thank the Earthquake Hazards Program for funding the development of the additional period and site class maps for the 2014 NSHM. In addition, we appreciate the efforts of Katherine D. Jacques who served as editor of this report and Janet L. Slate who reviewed the document for content and policy issues. Thank you also to Jill McCarthy, Morgan Moschetti, Chuck Mueller, and Susan Hoover for reviewing this report and providing helpful feedback. 


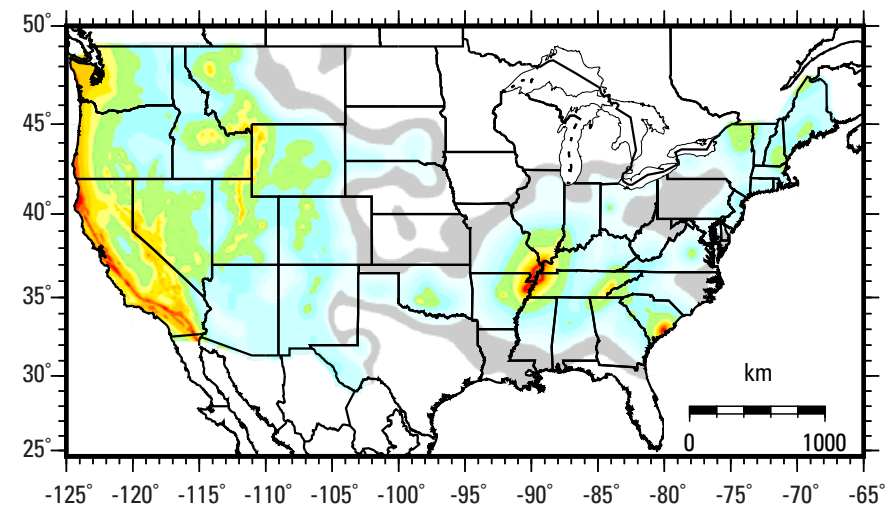

2014 NSHM(map 1)
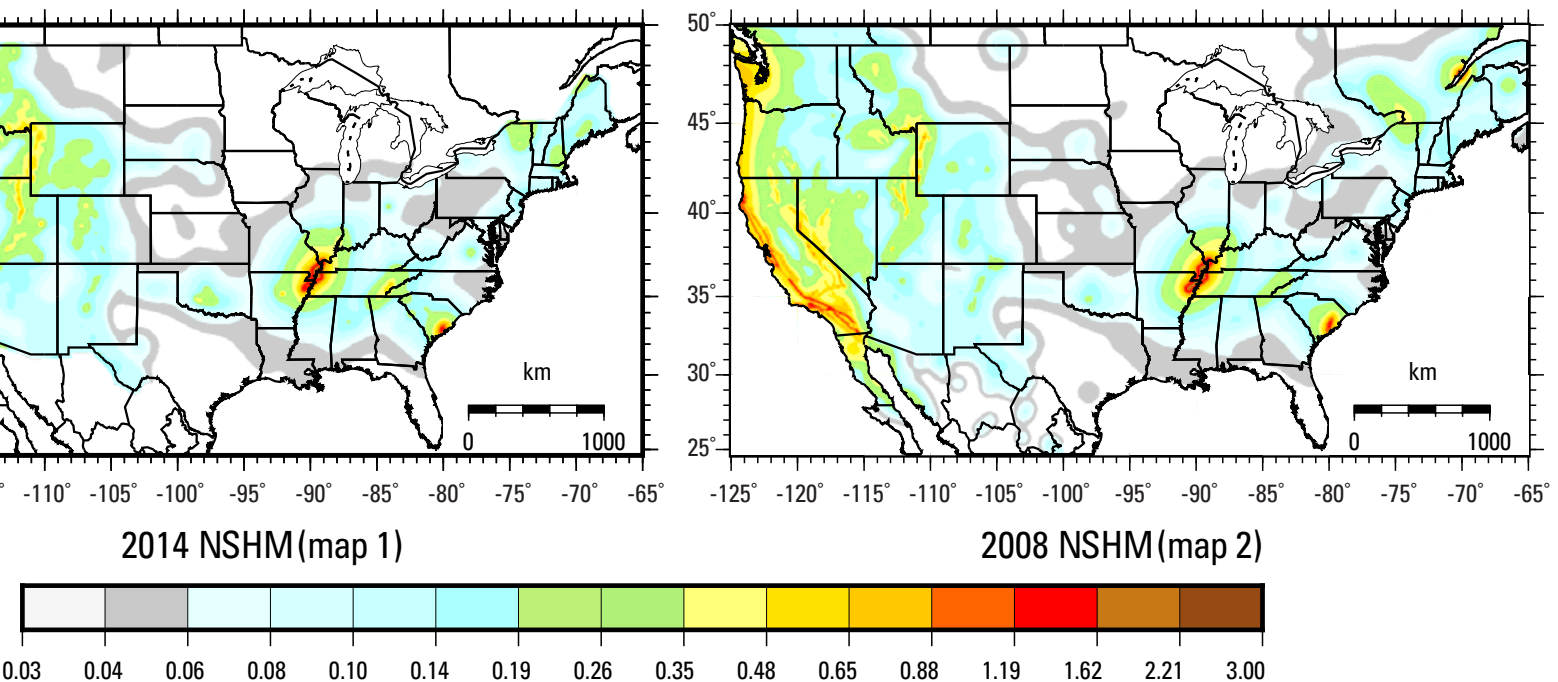

Peak Ground Acceleration (g)
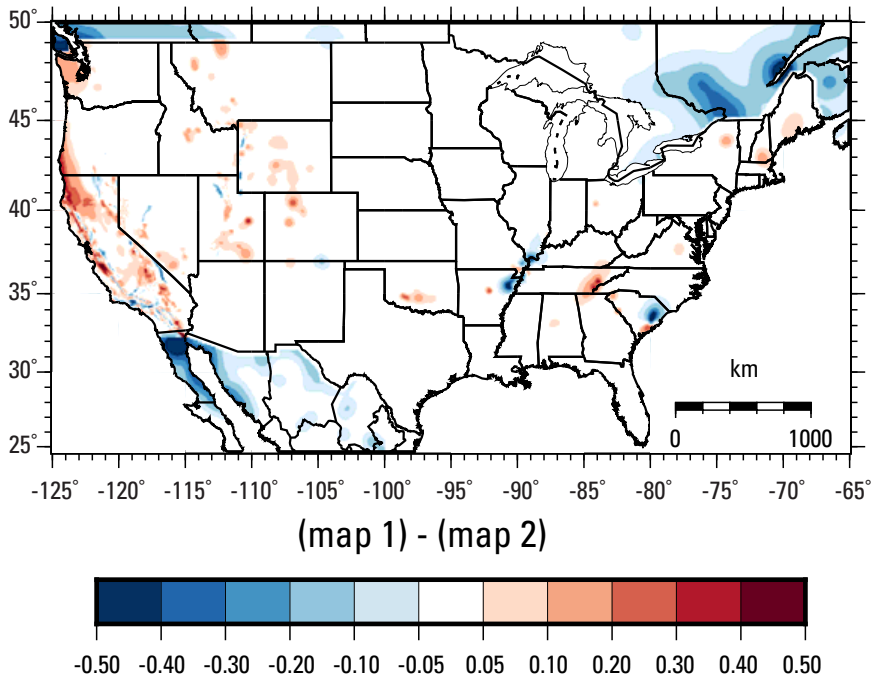

Difference
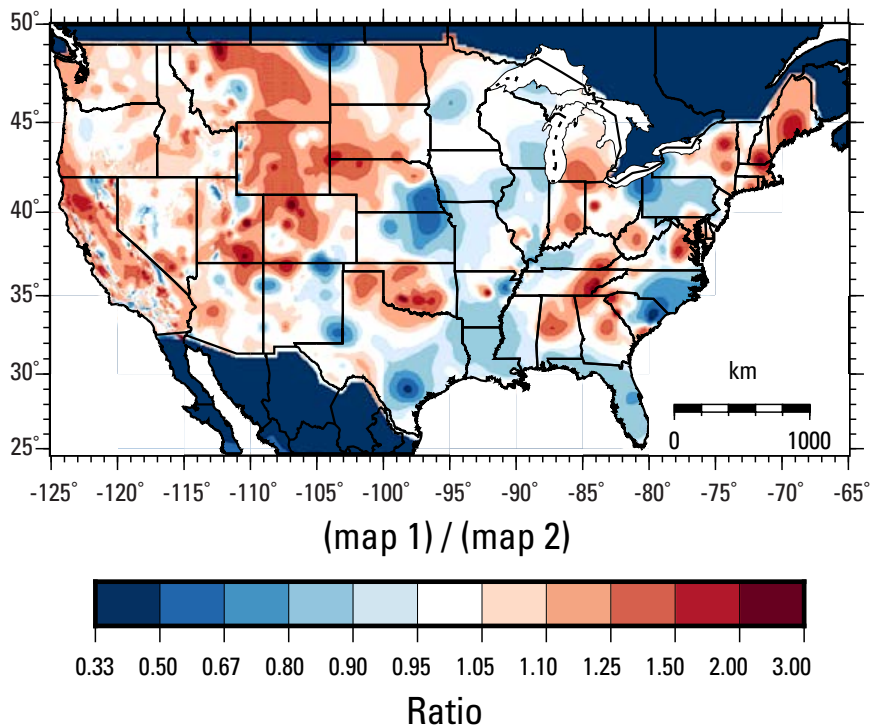

Figure 8. Hazard, difference, and ratio maps for $(A)$ peak ground acceleration, $(B) 0.1$ second, $(C) 0.2$ second, $(D) 0.3$ second, (E) 0.5 second, $(F) .75$ second, $(G) 1.0$ second, $(H) 2.0$ second, $(/) 3.0$ second, $(J) 4.0$ second, and $(K) 5.0$ second spectral acceleration $(\mathrm{SA})$ for 2 percent in 50-year probability of exceedance for the National Earthquake Hazards Reduction Program site class boundary $\mathrm{B} / \mathrm{C}$ (shear wave velocity in the upper 30 meters $\left[\mathrm{V}_{\mathrm{S} 30}\right]=760$ meters per second). Maps for $0.75,3.0,4.0$, and 5.0 second $\mathrm{SA}$ are calculated for the western United States (WUS) only. Difference and ratio maps show the changes in hazard between the 2014 National Seismic Hazard Model (NSHM) (Petersen and others, 2014, 2015) (with updated suites of weighted ground motion models described in this report) and the 2008 NSHM (Petersen and others, 2008). 
B

Comparison of 0.1 Second Total Mean Hazard for the US 2014 NSHM vs. 2008 NSHM

$2 \%$ in 50 Years Probability of Exceedance, NEHRP Site Class Boundary B/C $\left(\mathrm{V}_{S 30}=760 \mathrm{~m} / \mathrm{s}\right)$
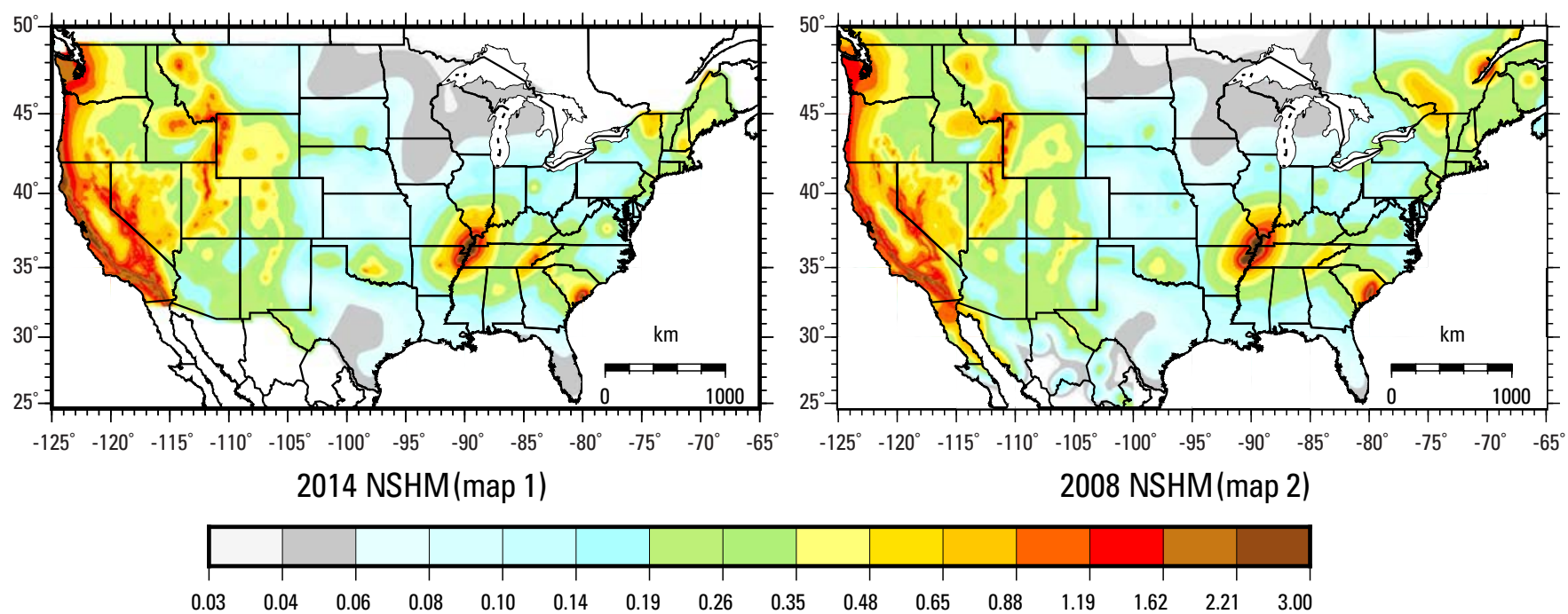

0.1 Second Spectral Acceleration (g)
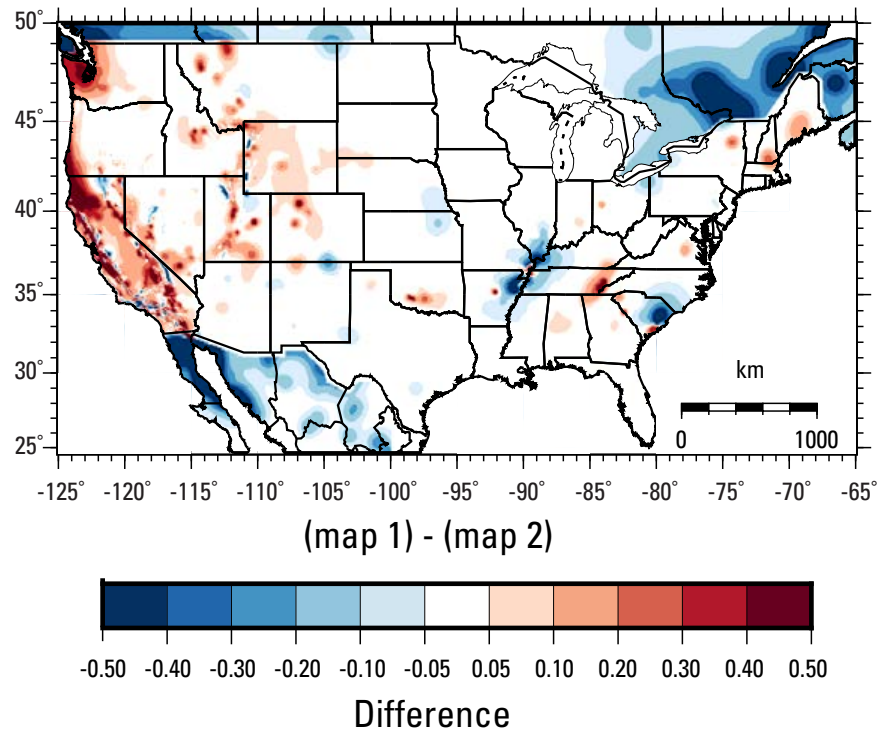
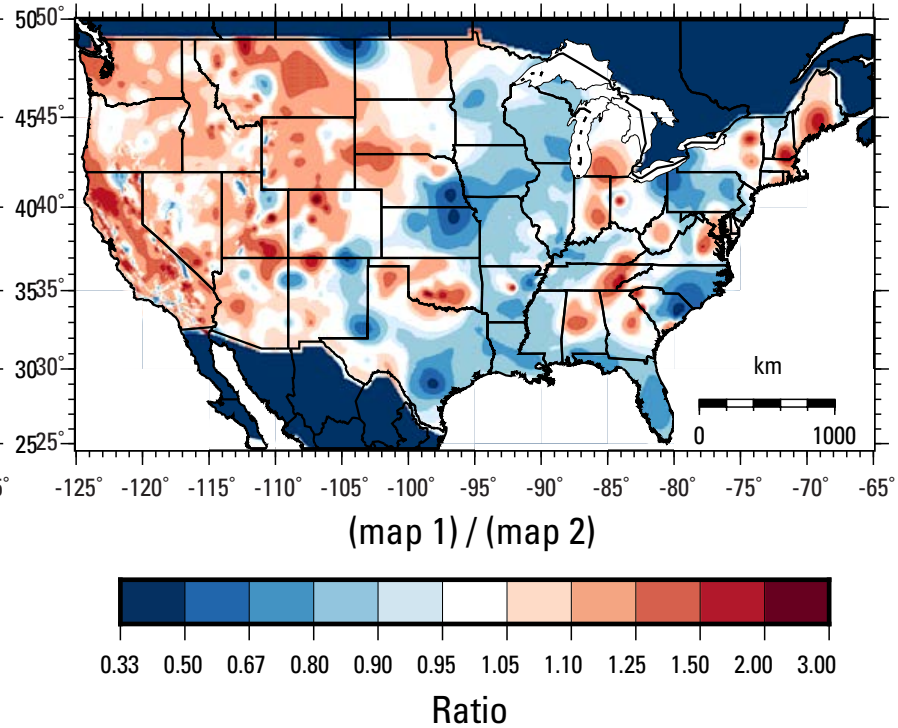

Figure 8. Hazard, difference, and ratio maps for $(A)$ peak ground acceleration, $(B) 0.1$ second, $(C) 0.2$ second, $(D) 0.3$ second, (E) 0.5 second, $(F) 0.75$ second, $(G) 1.0$ second, $(H) 2.0$ second, $(/) 3.0$ second, $(J) 4.0$ second, and $(K) 5.0$ second spectral acceleration (SA) for 2 percent in 50-year probability of exceedance for the National Earthquake Hazards Reduction Program site class boundary $\mathrm{B} / \mathrm{C}$ (shear wave velocity in the upper 30 meters $\left[\mathrm{V}_{\mathrm{S} 30}\right]=760$ meters per second). Maps for $0.75,3.0,4.0$, and 5.0 second SA are calculated for the western United States (WUS) only. Difference and ratio maps show the changes in hazard between the 2014 National Seismic Hazard Model (NSHM) (Petersen and others, 2014, 2015) (with updated suites of weighted ground motion models described in this report) and the 2008 NSHM (Petersen and others, 2008).-Continued 

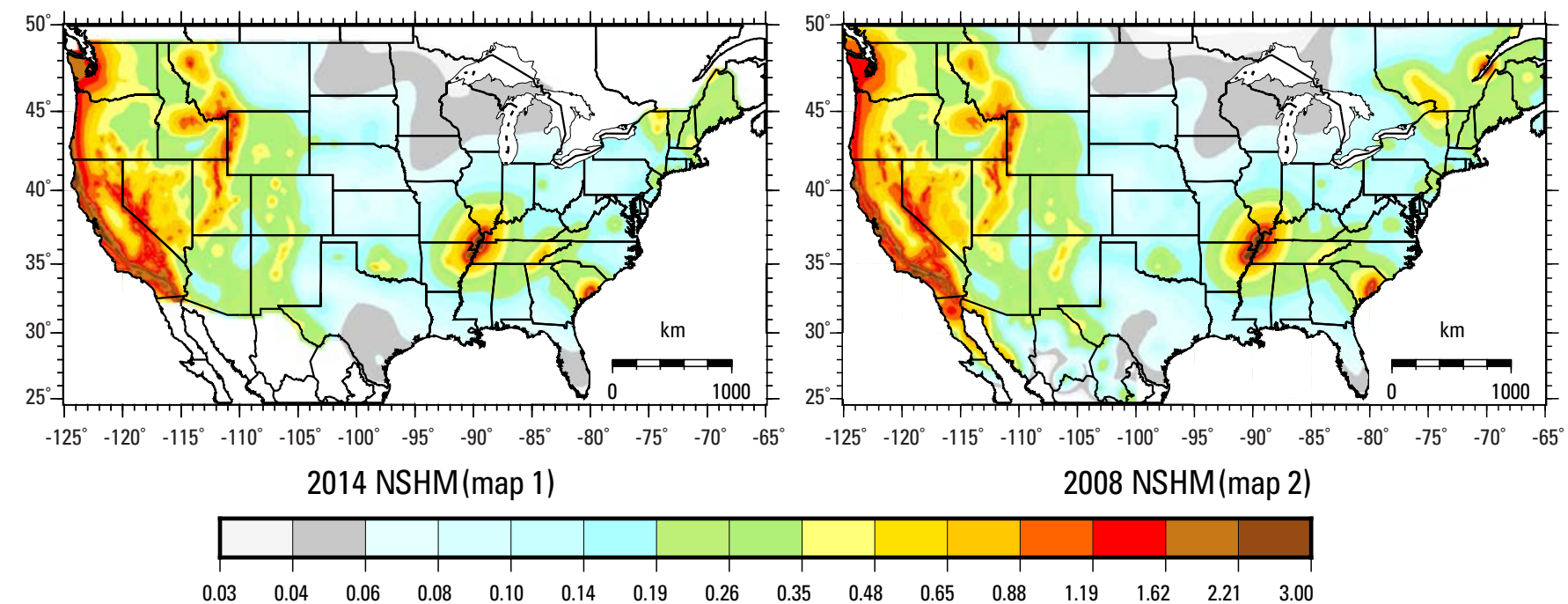

0.2 Second Spectral Acceleration (g)
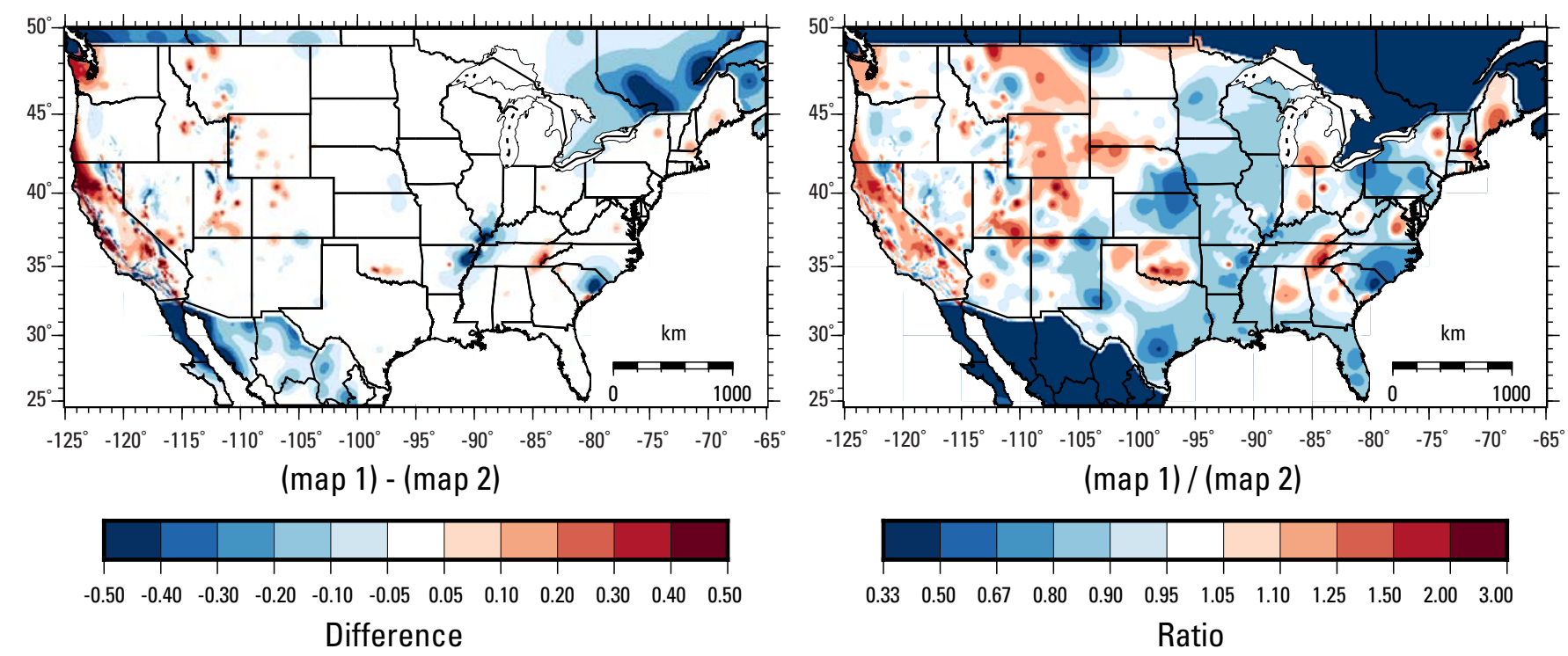

Figure 8. Hazard, difference, and ratio maps for $(A)$ peak ground acceleration, $(B) 0.1$ second, $(C) 0.2$ second, $(D) 0.3$ second, (E) 0.5 second, $(F) 0.75$ second, $(G) 1.0$ second, $(H) 2.0$ second, $(/) 3.0$ second, $(J) 4.0$ second, and $(K) 5.0$ second spectral acceleration (SA) for 2 percent in 50-year probability of exceedance for the National Earthquake Hazards Reduction Program site class boundary $\mathrm{B} / \mathrm{C}$ (shear wave velocity in the upper 30 meters $\left[\mathrm{V}_{\mathrm{S} 30}\right]=760$ meters per second). Maps for $0.75,3.0,4.0$, and 5.0 second $\mathrm{SA}$ are calculated for the western United States (WUS) only. Difference and ratio maps show the changes in hazard between the 2014 National Seismic Hazard Model (NSHM) (Petersen and others, 2014, 2015) (with updated suites of weighted ground motion models described in this report) and the 2008 NSHM (Petersen and others, 2008).-Continued 

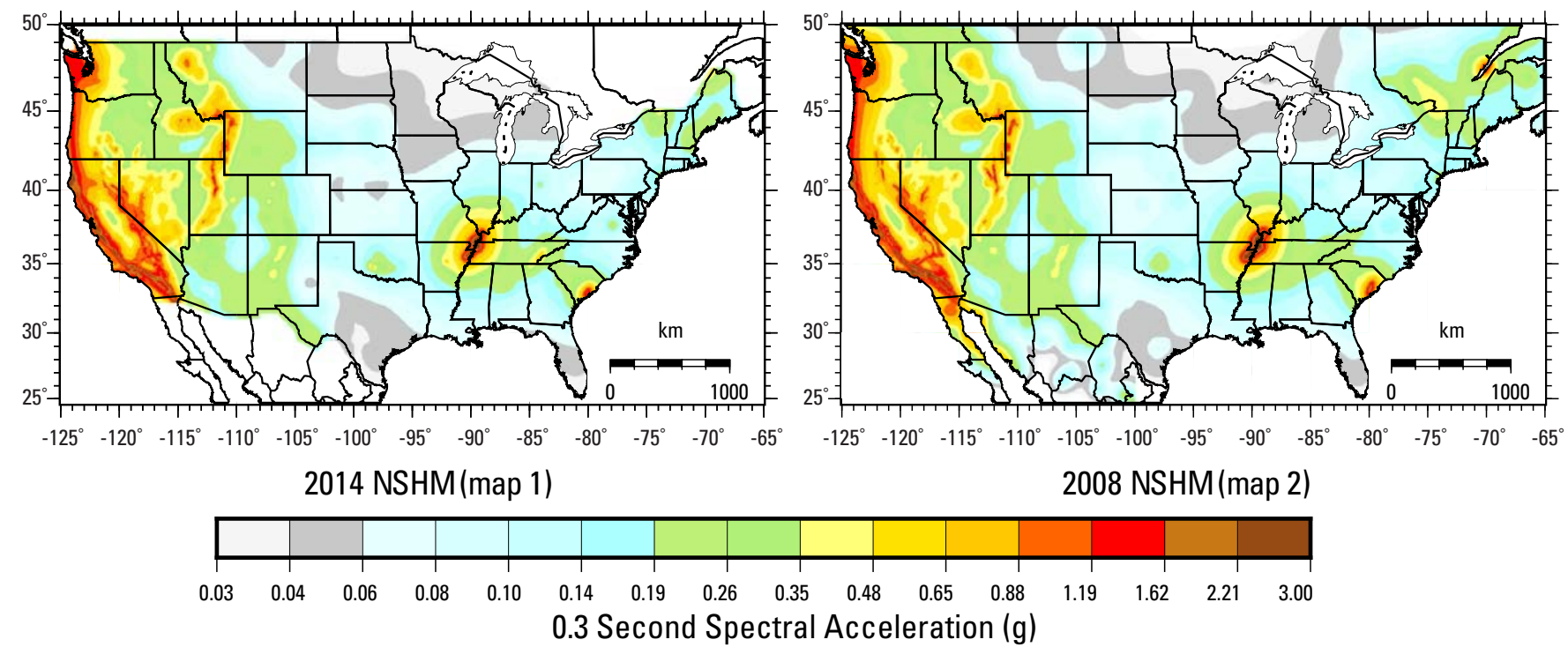
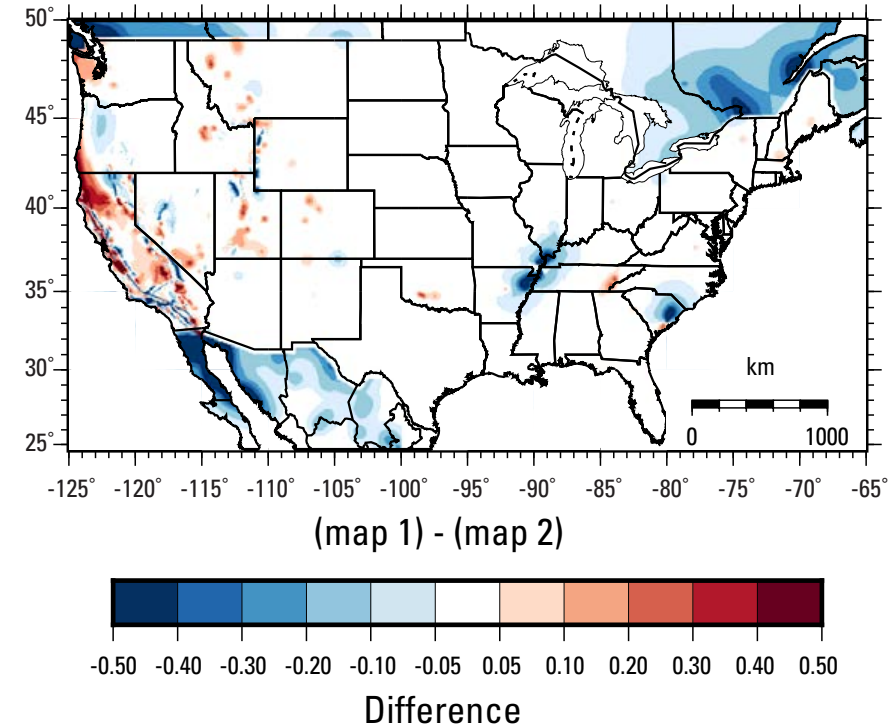
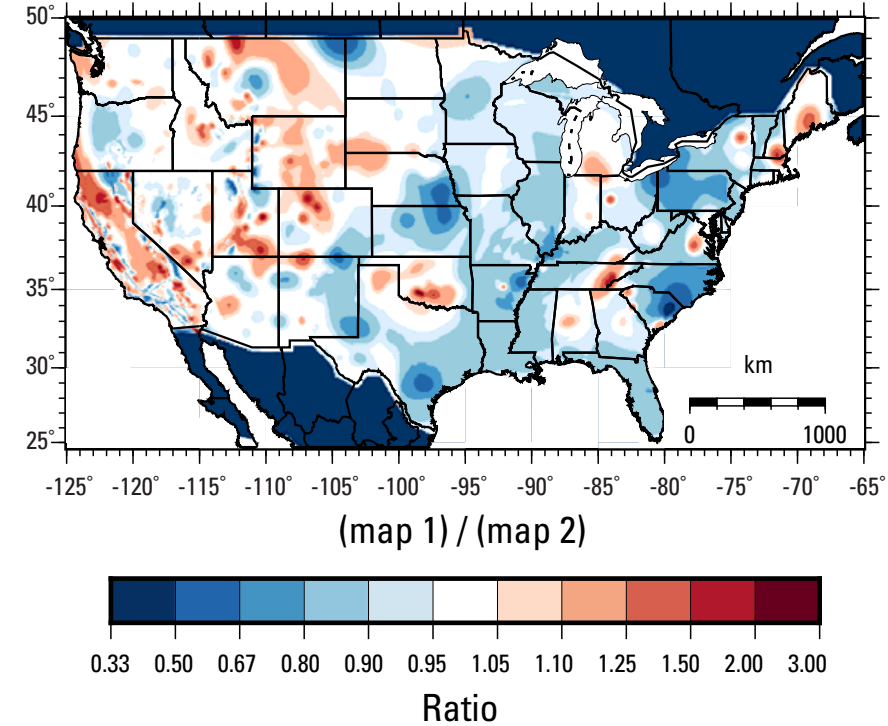

Figure 8. Hazard, difference, and ratio maps for $(A)$ peak ground acceleration, $(B) 0.1$ second, $(C) 0.2$ second, $(D) 0.3$ second, $(E) 0.5$ second, $(F) 0.75$ second, $(G) 1.0$ second, $(H) 2.0$ second, $(/) 3.0$ second, $(J) 4.0$ second, and $(K) 5.0$ second spectral acceleration (SA) for 2 percent in 50-year probability of exceedance for the National Earthquake Hazards Reduction Program site class boundary $\mathrm{B} / \mathrm{C}$ (shear wave velocity in the upper 30 meters $\left[\mathrm{V}_{S 30}\right]=760$ meters per second). Maps for 0.75, 3.0, 4.0, and 5.0 second $\mathrm{SA}$ are calculated for the western United States (WUS) only. Difference and ratio maps show the changes in hazard between the 2014 National Seismic Hazard Model (NSHM) (Petersen and others, 2014, 2015) (with updated suites of weighted ground motion models described in this report) and the 2008 NSHM (Petersen and others, 2008).-Continued 

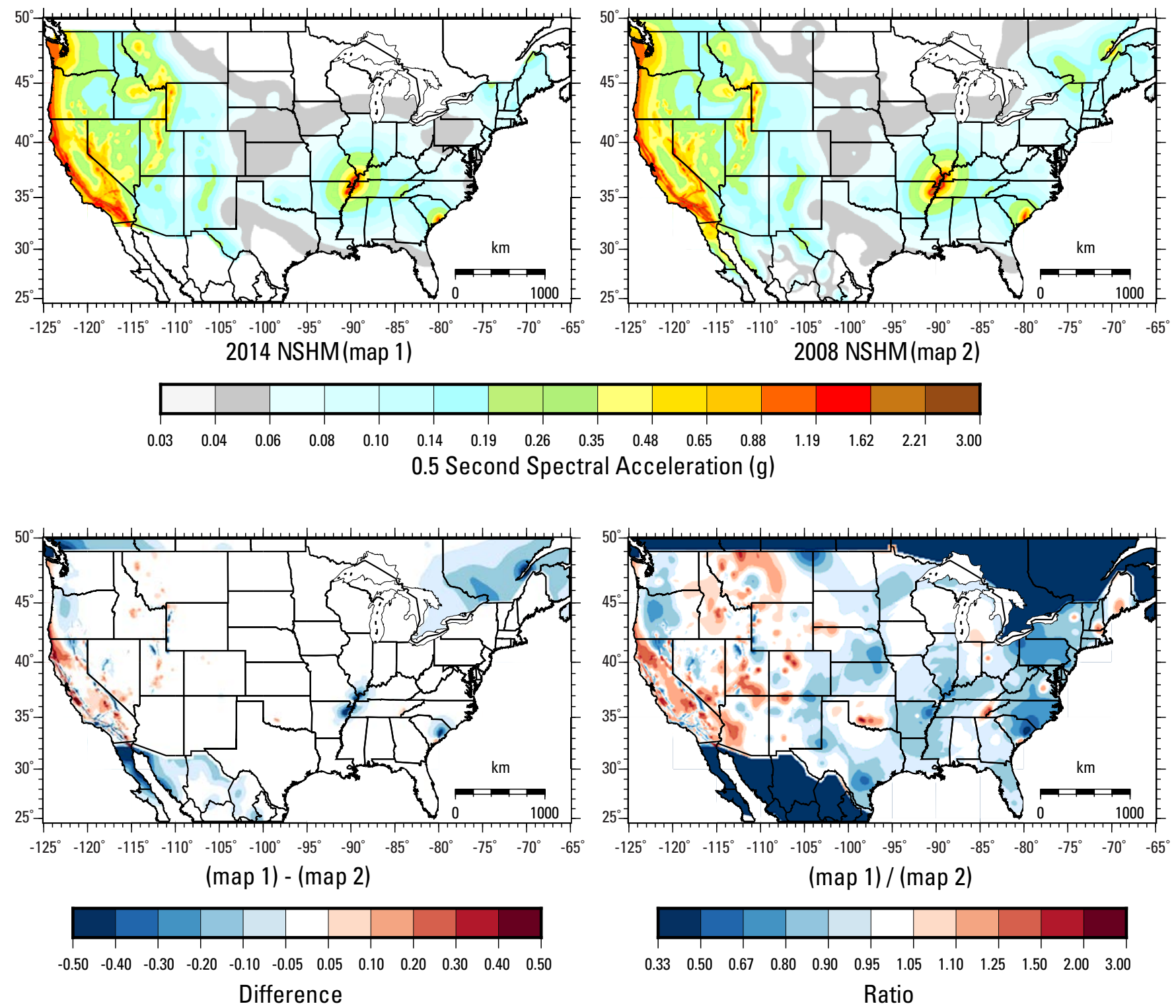

Figure 8. Hazard, difference, and ratio maps for $(A)$ peak ground acceleration, $(B) 0.1$ second, $(C) 0.2$ second, $(D) 0.3$ second, (E) 0.5 second, ( $F) 0.75$ second, $(G) 1.0$ second, $(H) 2.0$ second, $(I) 3.0$ second, $(J) 4.0$ second, and $(K) 5.0$ second spectral acceleration (SA) for 2 percent in 50-year probability of exceedance for the National Earthquake Hazards Reduction Program site class boundary $\mathrm{B} / \mathrm{C}$ (shear wave velocity in the upper 30 meters $\left[\mathrm{V}_{S 30}\right]=760$ meters per second). Maps for $0.75,3.0,4.0$, and 5.0 second SA are calculated for the western United States (WUS) only. Difference and ratio maps show the changes in hazard between the 2014 National Seismic Hazard Model (NSHM) (Petersen and others, 2014, 2015) (with updated suites of weighted ground motion models described in this report) and the 2008 NSHM (Petersen and others, 2008).-Continued 
$2 \%$ in 50 Years Probability of Exceedance, NEHRP Site Class Boundary B/C ( $\left.\mathrm{V}_{\mathrm{S} 30}=760 \mathrm{~m} / \mathrm{s}\right)$


Figure 8. Hazard, difference, and ratio maps for $(A)$ peak ground acceleration, $(B) 0.1$ second, $(C) 0.2$ second, $(D) 0.3$ second, (E) 0.5 second, $(F) 0.75$ second, $(G) 1.0$ second, $(H) 2.0$ second, $(/) 3.0$ second, $(J) 4.0$ second, and $(K) 5.0$ second spectral acceleration (SA) for 2 percent in 50-year probability of exceedance for the National Earthquake Hazards Reduction Program site class boundary $\mathrm{B} / \mathrm{C}$ (shear wave velocity in the upper 30 meters $\left[\mathrm{V}_{\mathrm{S} 30}\right]=760$ meters per second). Maps for $0.75,3.0,4.0$, and 5.0 second SA are calculated for the western United States (WUS) only. Difference and ratio maps show the changes in hazard between the 2014 National Seismic Hazard Model (NSHM) (Petersen and others, 2014, 2015) (with updated suites of weighted ground motion models described in this report) and the 2008 NSHM (Petersen and others, 2008).-Continued 

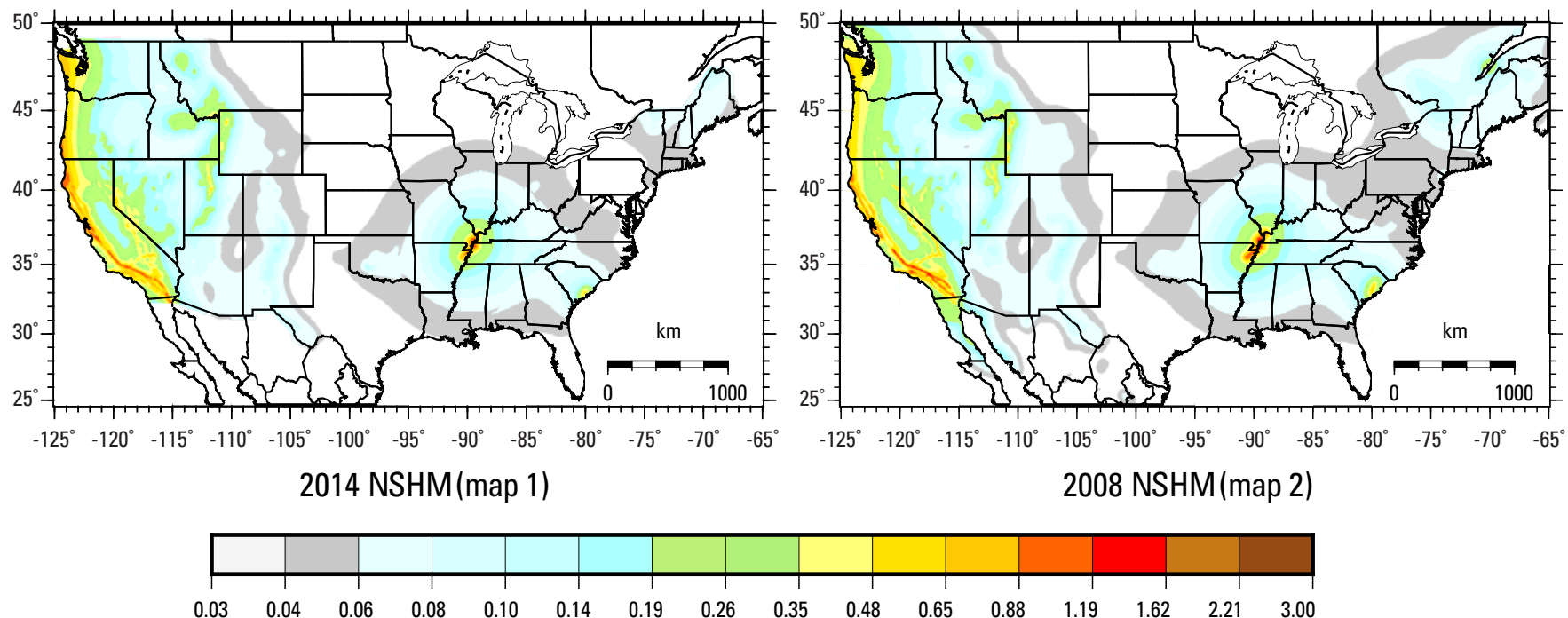

1 Second Spectral Acceleration (g)

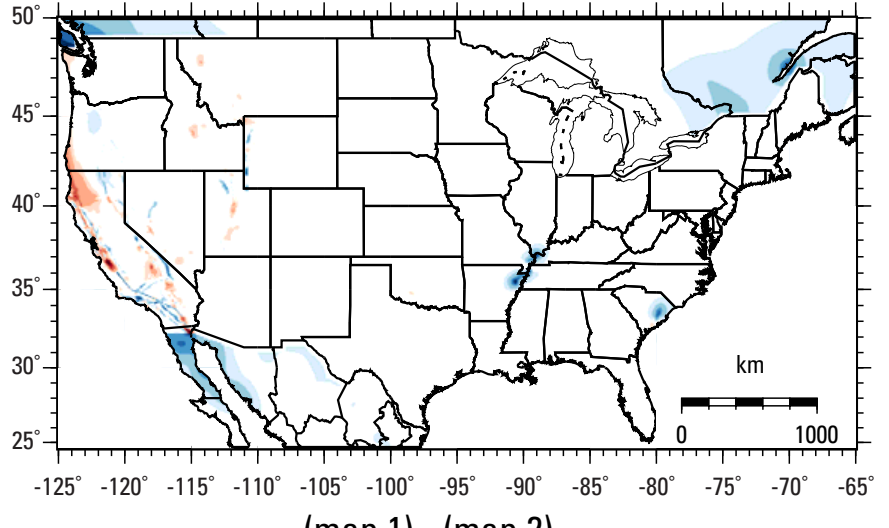

(map 1) - (map 2)

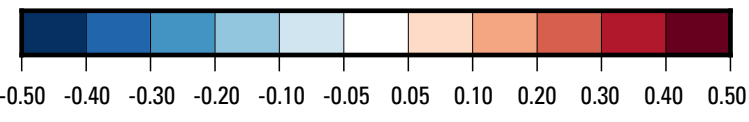

Difference
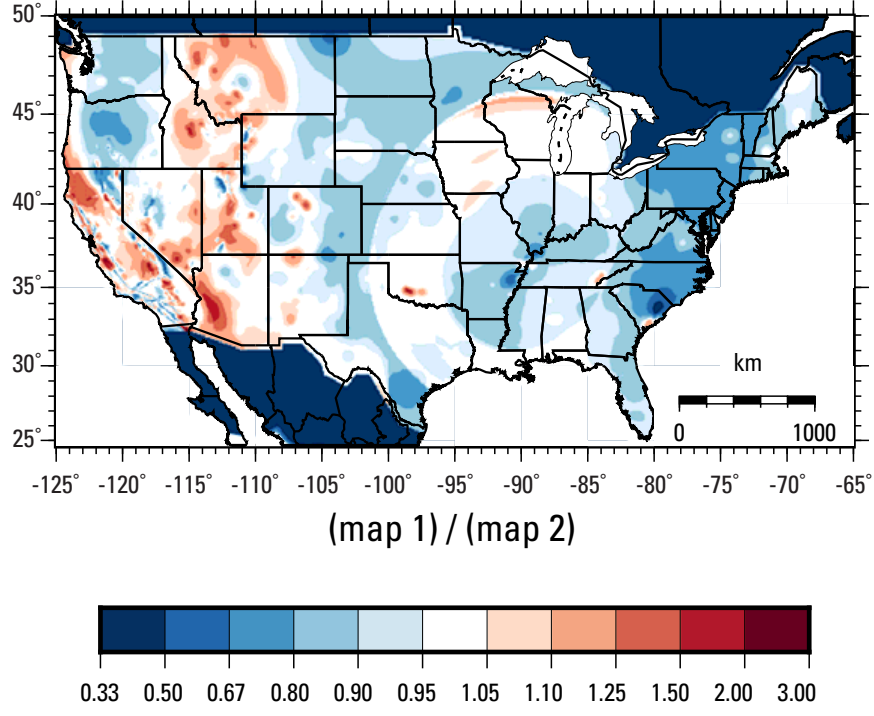

Ratio

Figure 8. Hazard, difference, and ratio maps for $(A)$ peak ground acceleration, $(B) 0.1$ second, $(C) 0.2$ second, $(D) 0.3$ second, (E) 0.5 second, $(F) 0.75$ second, $(G) 1.0$ second, $(H) 2.0$ second, $(/) 3.0$ second, $(J) 4.0$ second, and $(K) 5.0$ second spectral acceleration $(\mathrm{SA})$ for 2 percent in 50-year probability of exceedance for the National Earthquake Hazards Reduction Program site class boundary $\mathrm{B} / \mathrm{C}$ (shear wave velocity in the upper 30 meters $\left[\mathrm{V}_{\mathrm{S} 30}\right]=760$ meters per second). Maps for $0.75,3.0,4.0$, and 5.0 second $\mathrm{SA}$ are calculated for the western United States (WUS) only. Difference and ratio maps show the changes in hazard between the 2014 National Seismic Hazard Model (NSHM) (Petersen and others, 2014, 2015) (with updated suites of weighted ground motion models described in this report) and the 2008 NSHM (Petersen and others, 2008).-Continued 

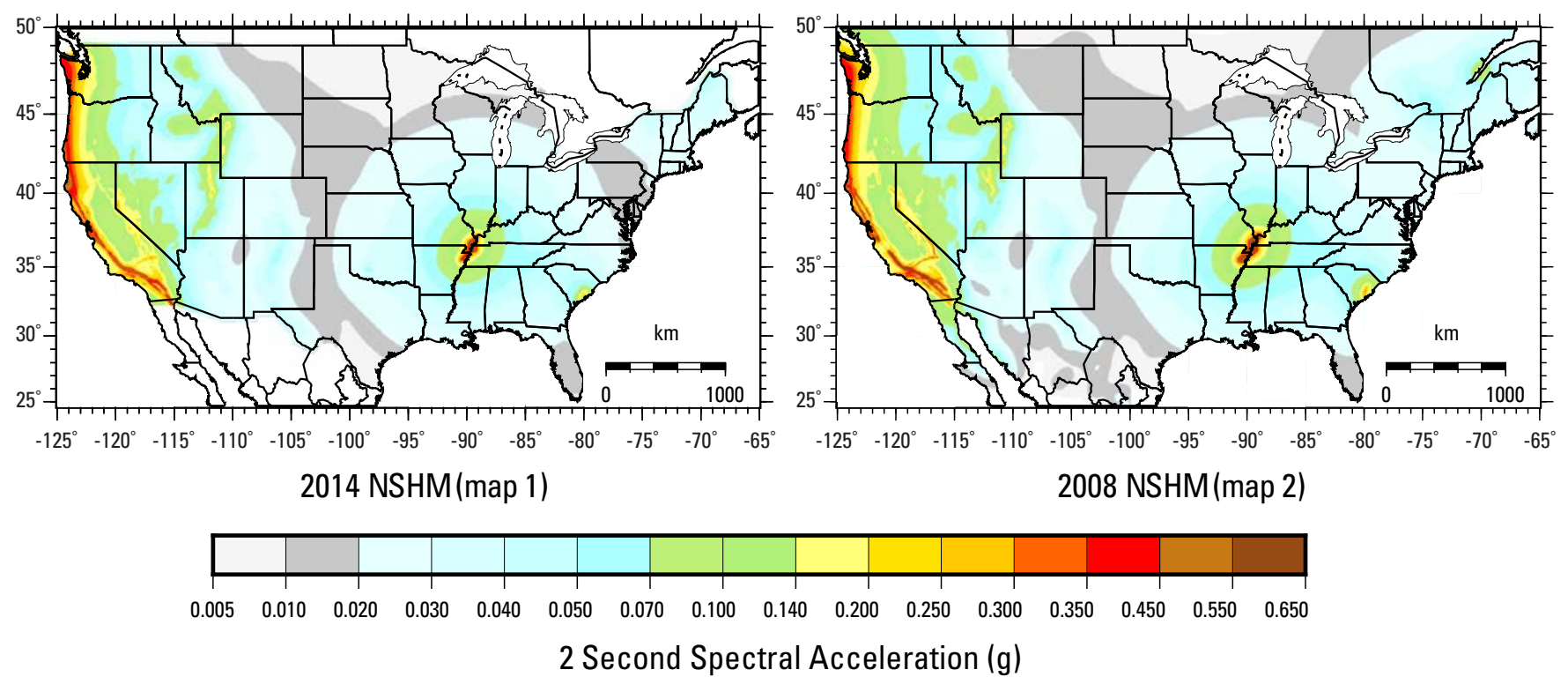

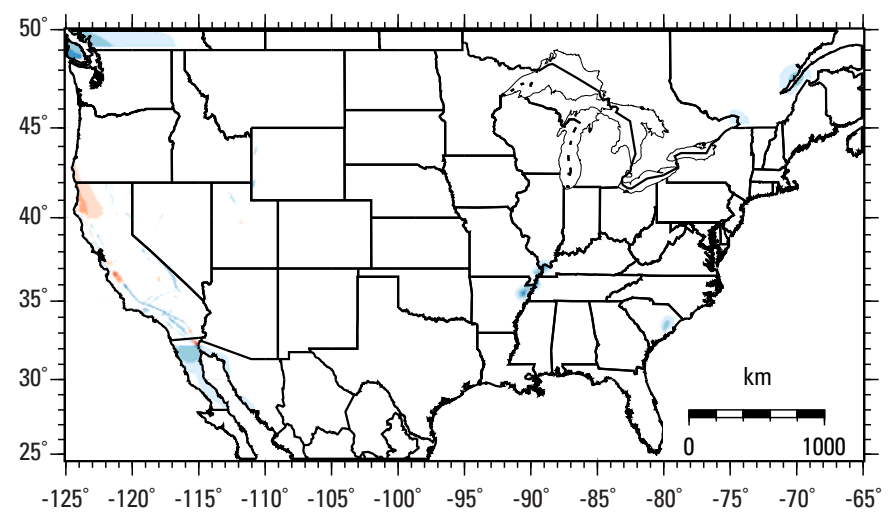

(map 1) - (map 2)

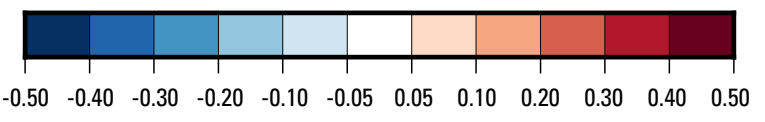

Difference
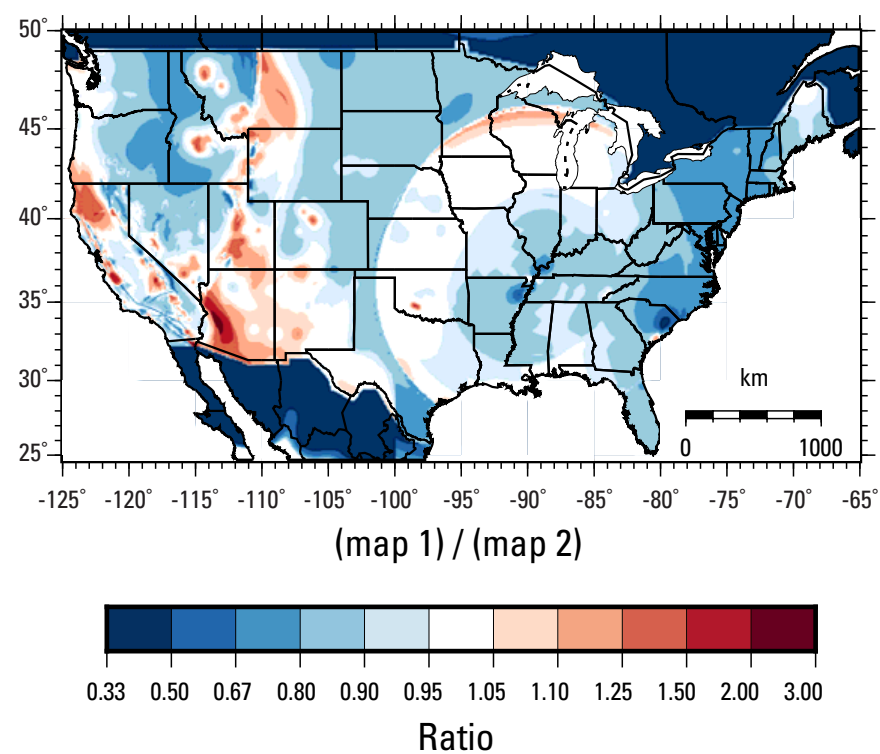

Figure 8. Hazard, difference, and ratio maps for $(A)$ peak ground acceleration, $(B) 0.1$ second, $(C) 0.2$ second, $(D) 0.3$ second, (E) 0.5 second, $(F) 0.75$ second, $(G) 1.0$ second, $(H) 2.0$ second, $(/) 3.0$ second, $(J) 4.0$ second, and $(K) 5.0$ second spectral acceleration (SA) for 2 percent in 50-year probability of exceedance for the National Earthquake Hazards Reduction Program site class boundary $\mathrm{B} / \mathrm{C}$ (shear wave velocity in the upper 30 meters $\left[\mathrm{V}_{\mathrm{S} 30}\right]=760$ meters per second). Maps for $0.75,3.0,4.0$, and 5.0 second SA are calculated for the western United States (WUS) only. Difference and ratio maps show the changes in hazard between the 2014 National Seismic Hazard Model (NSHM) (Petersen and others, 2014, 2015) (with updated suites of weighted ground motion models described in this report) and the 2008 NSHM (Petersen and others, 2008).-Continued 
Comparison of 3 Second Total Mean Hazard for the WUS

2014 NSHM vs. 2008 NSHM

$2 \%$ in 50 Years Probability of Exceedance, NEHRP Site Class Boundary B/C $\left(V_{S 30}=760 \mathrm{~m} / \mathrm{s}\right)$
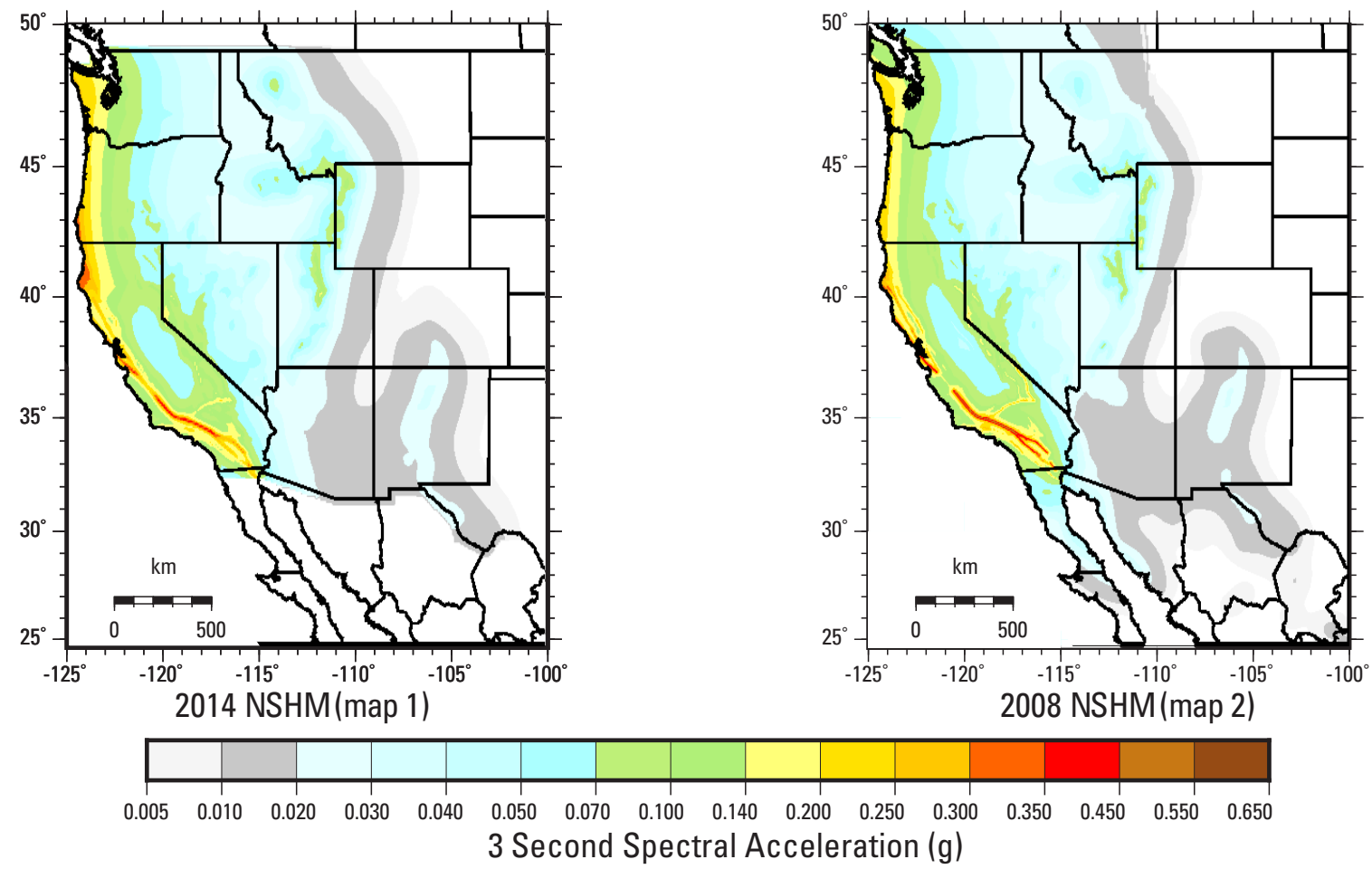
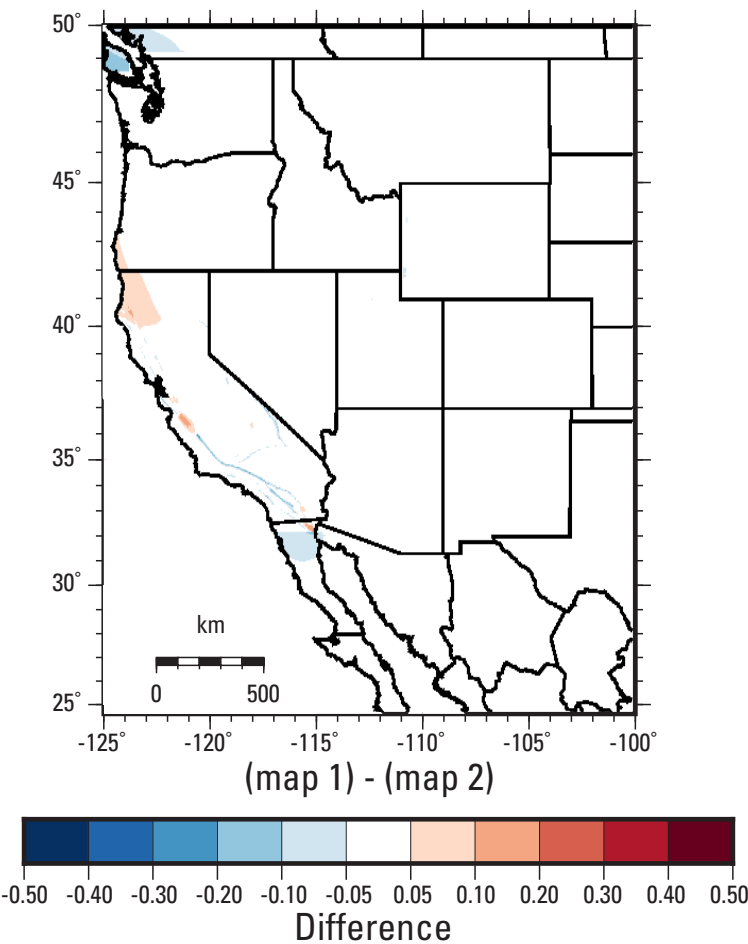
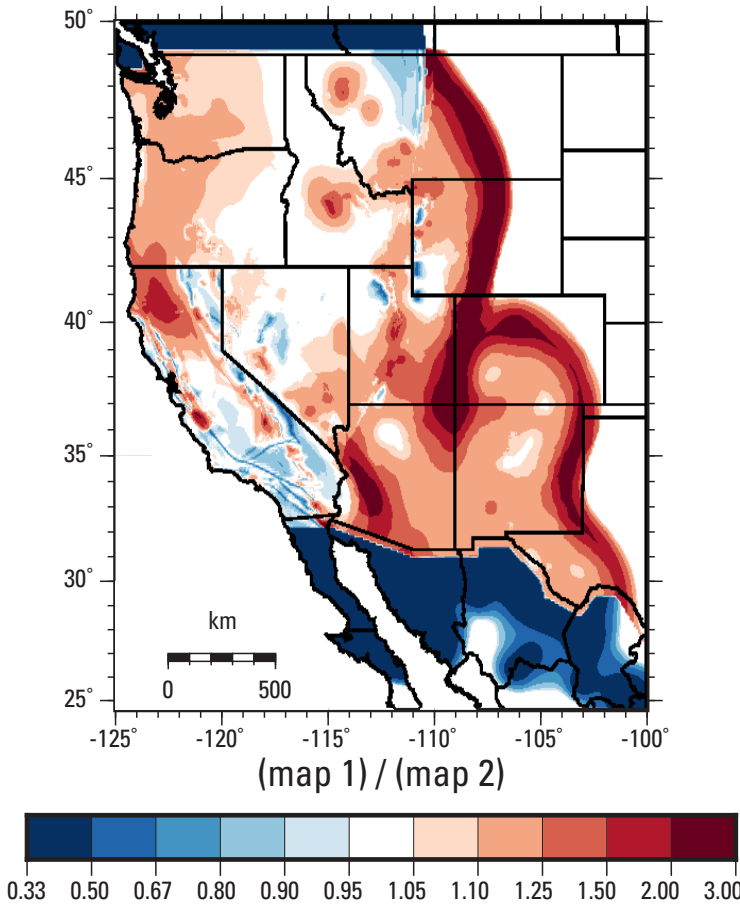

Ratio

Figure 8. Hazard, difference, and ratio maps for $(A)$ peak ground acceleration, $(B) 0.1$ second, $(C) 0.2$ second, $(D) 0.3$ second, (E) 0.5 second, $(F) 0.75$ second, $(G) 1.0$ second, $(H) 2.0$ second, $(/) 3.0$ second, $(J) 4.0$ second, and $(K) 5.0$ second spectral acceleration (SA) for 2 percent in 50-year probability of exceedance for the National Earthquake Hazards Reduction Program site class boundary $\mathrm{B} / \mathrm{C}$ (shear wave velocity in the upper 30 meters $\left[\mathrm{V}_{\mathrm{S} 30}\right]=760$ meters per second). Maps for $0.75,3.0,4.0$, and 5.0 second $\mathrm{SA}$ are calculated for the western United States (WUS) only. Difference and ratio maps show the changes in hazard between the 2014 National Seismic Hazard Model (NSHM) (Petersen and others, 2014, 2015) (with updated suites of weighted ground motion models described in this report) and the 2008 NSHM (Petersen and others, 2008).-Continued 
Comparison of 4 Second Total Mean Hazard for the WUS 2014 NSHM vs. 2008 NSHM
$2 \%$ in 50 Years Probability of Exceedance, NEHRP Site Class Boundary B/C (VS30 $=760 \mathrm{~m} / \mathrm{s})$
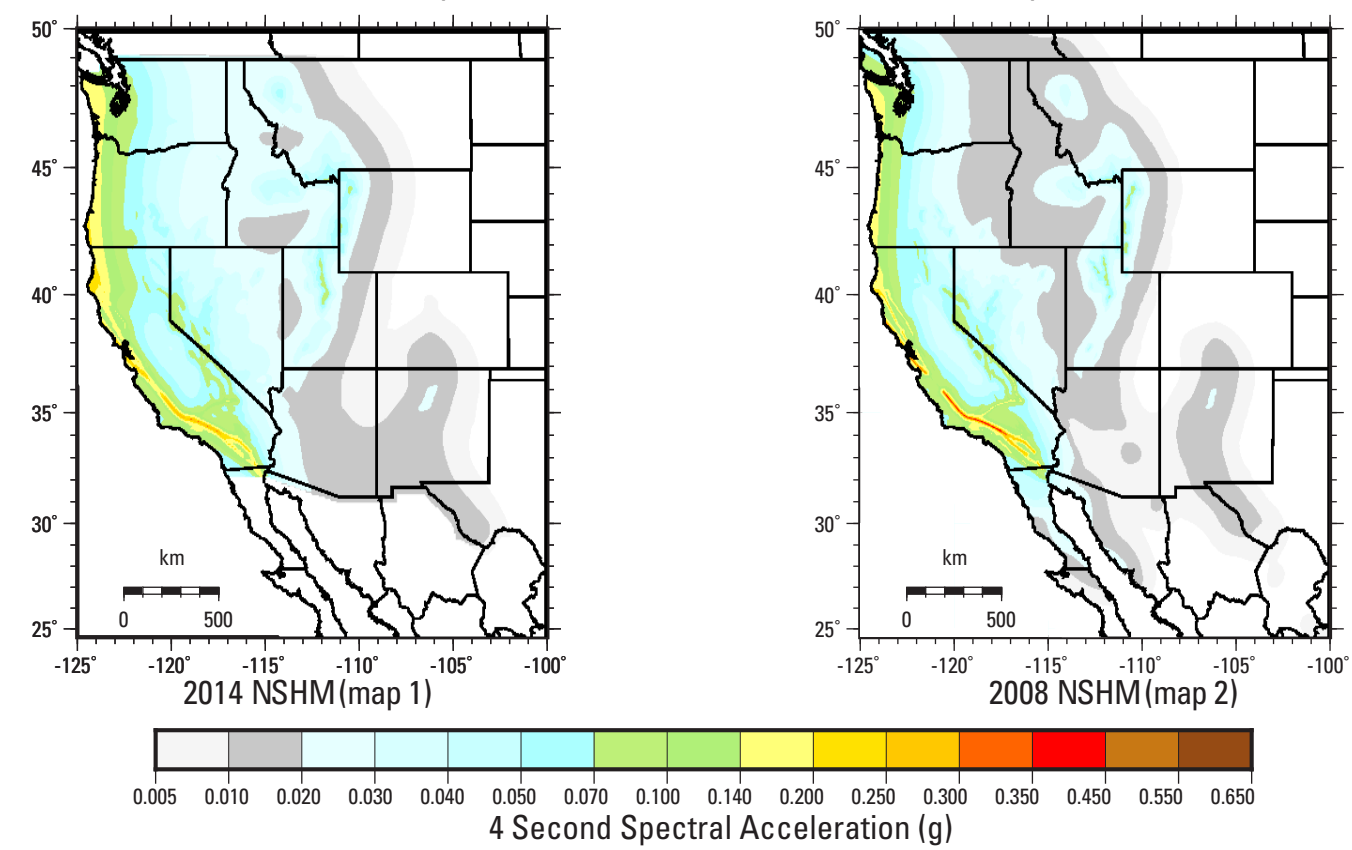
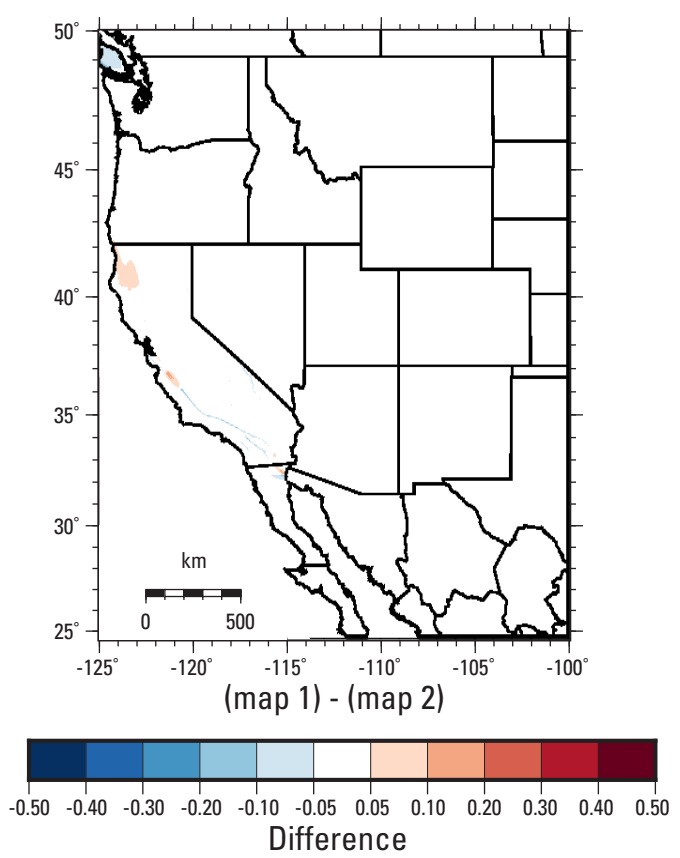
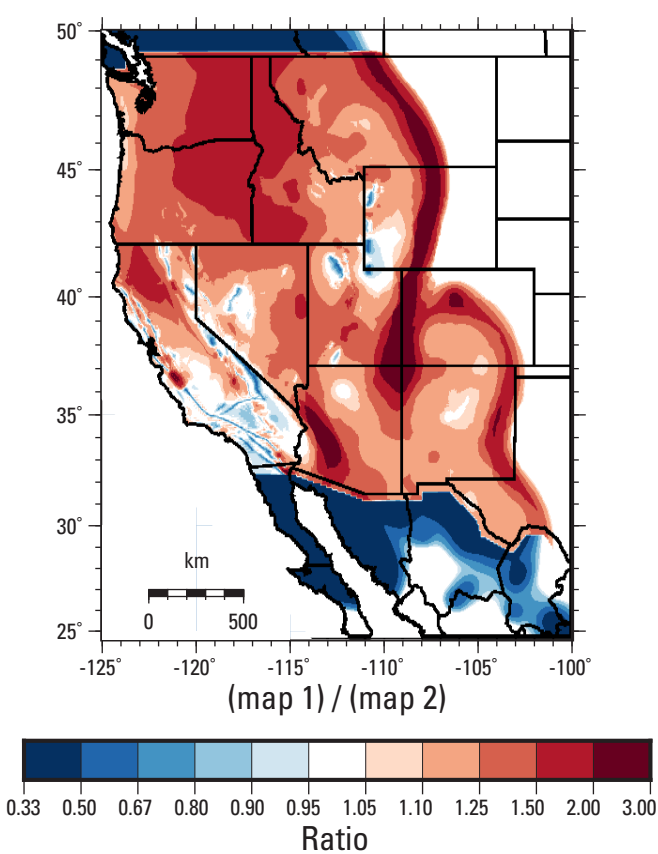

Figure 8. Hazard, difference, and ratio maps for $(A)$ peak ground acceleration, $(B) 0.1$ second, $(C) 0.2$ second, $(D) 0.3$ second, (E) 0.5 second, $(F) 0.75$ second, $(G) 1.0$ second, $(H) 2.0$ second, $(/) 3.0$ second, $(J) 4.0$ second, and $(K) 5.0$ second spectral acceleration (SA) for 2 percent in 50-year probability of exceedance for the National Earthquake Hazards Reduction Program site class boundary $\mathrm{B} / \mathrm{C}$ (shear wave velocity in the upper 30 meters $\left[\mathrm{V}_{\mathrm{S} 30}\right]=760$ meters per second). Maps for $0.75,3.0,4.0$, and 5.0 second SA are calculated for the western United States (WUS) only. Difference and ratio maps show the changes in hazard between the 2014 National Seismic Hazard Model (NSHM) (Petersen and others, 2014, 2015) (with updated suites of weighted ground motion models described in this report) and the 2008 NSHM (Petersen and others, 2008).-Continued 


\section{$2 \%$ in 50 Years Probability of Exceedance, NEHRP Site Class Boundary B/C ( $\left.V_{S 30}=760 \mathrm{~m} / \mathrm{s}\right)$}
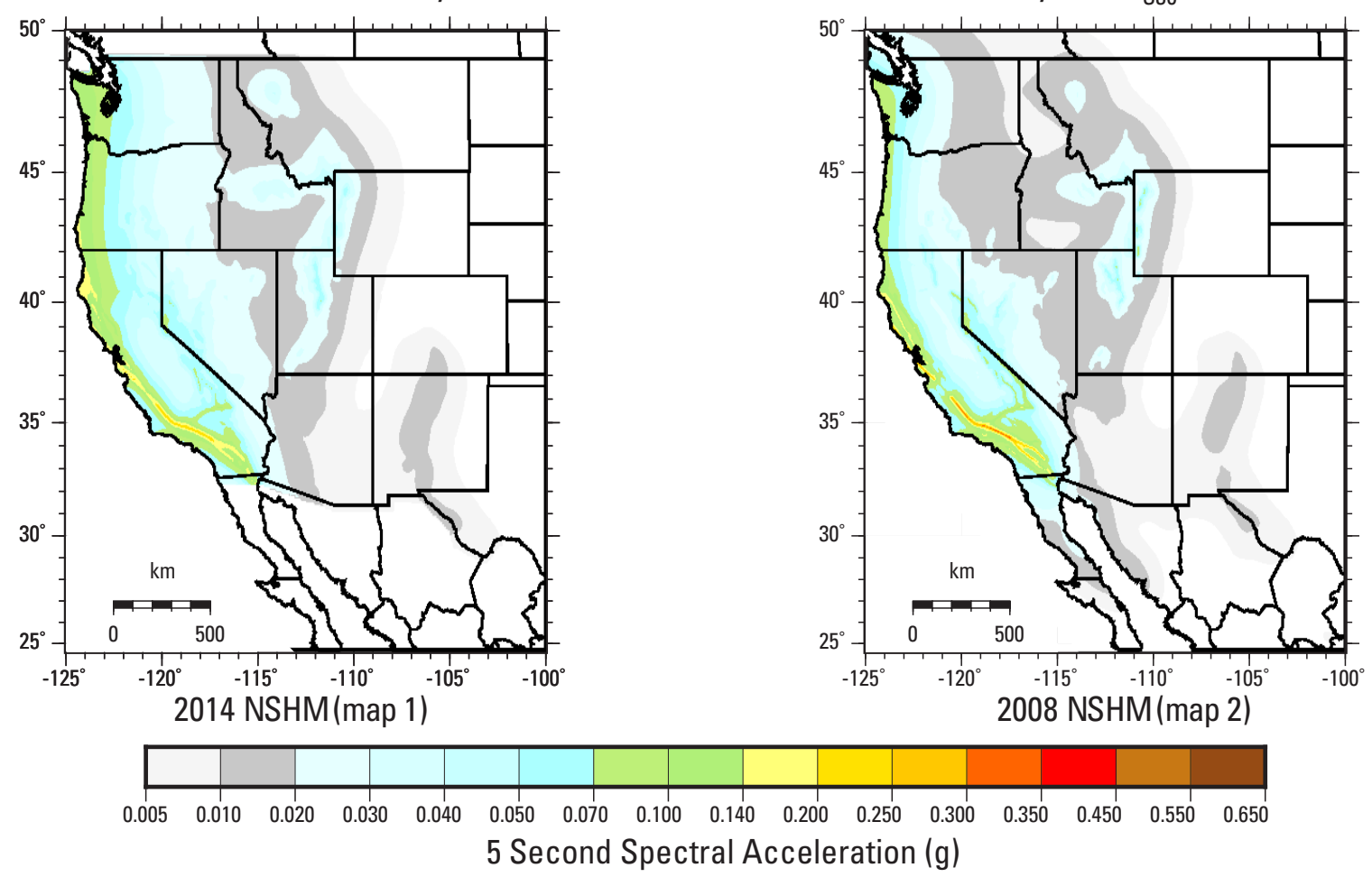
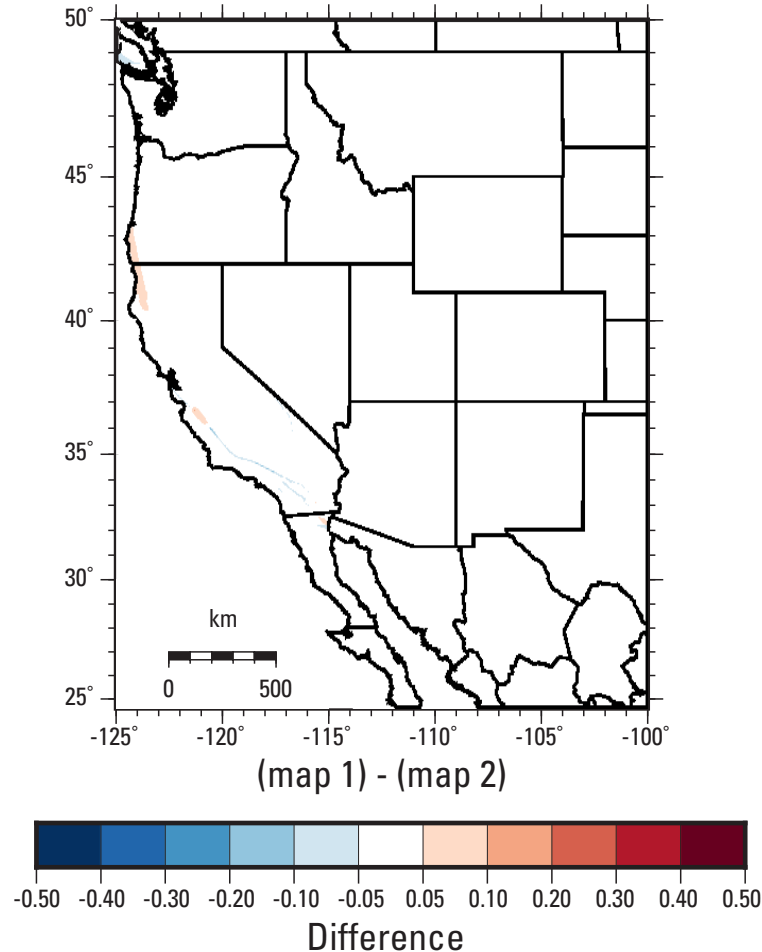
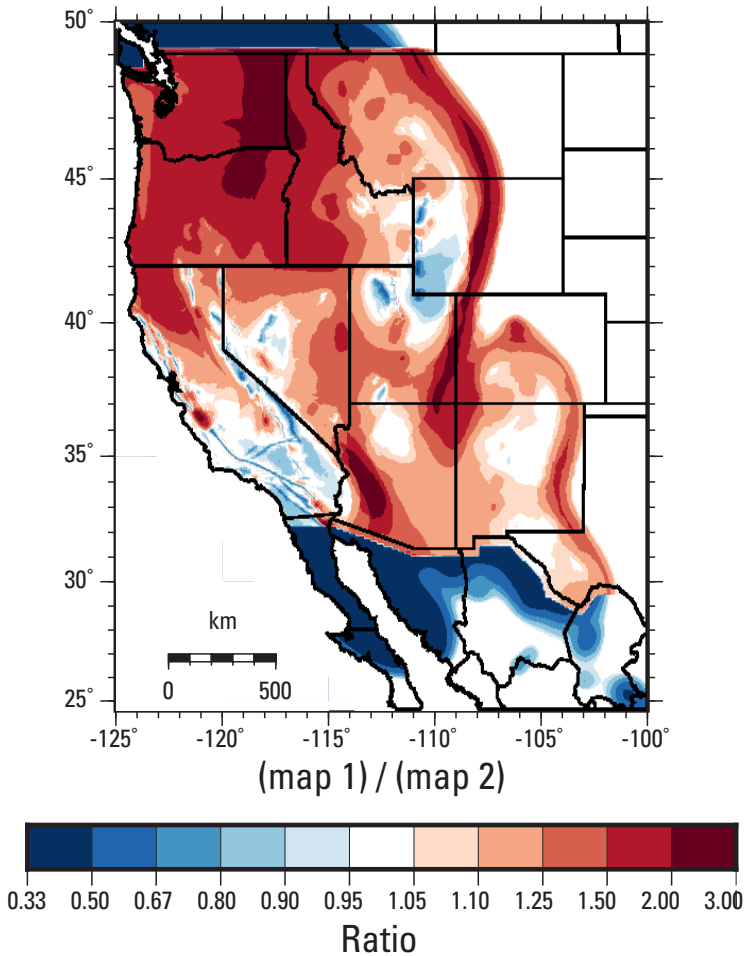

Figure 8. Hazard, difference, and ratio maps for $(A)$ peak ground acceleration, $(B) 0.1$ second, $(C) 0.2$ second, $(D) 0.3$ second, (E) 0.5 second, ( $F) 0.75$ second, $(G) 1.0$ second, $(H) 2.0$ second, $(I) 3.0$ second, $(J) 4.0$ second, and $(K) 5.0$ second spectral acceleration (SA) for 2 percent in 50-year probability of exceedance for the National Earthquake Hazards Reduction Program site class boundary $\mathrm{B} / \mathrm{C}$ (shear wave velocity in the upper 30 meters $\left[\mathrm{V}_{\mathrm{s} 30}\right]=760$ meters per second). Maps for $0.75,3.0,4.0$, and 5.0 second SA are calculated for the western United States (WUS) only. Difference and ratio maps show the changes in hazard between the 2014 National Seismic Hazard Model (NSHM) (Petersen and others, 2014, 2015) (with updated suites of weighted ground motion models described in this report) and the 2008 NSHM (Petersen and others, 2008).-Continued 


\section{References Cited}

Abrahamson, N.A., Gregor, N., and Addo, K., 2016, BC Hydro ground motion prediction equations for subduction earthquakes: Earthquake Spectra, v. 32, no. 1, p. 23-44, accessed July 2018 at https://doi.org/10.1193/051712EQS188MR.

Abrahamson, N.A., Silva, W.J., and Kamai, R., 2014, Summary of the ASK14 ground motion relation for active crustal regions: Earthquake Spectra, v. 30, no. 3, p. 1025-1055, accessed July 2018 at https://doi.org/10.1193/070913EQS198M.

American Society of Civil Engineers, 2017, Minimum design loads and associated criteria for buildings and other structures: ASCE/SEI 7-16, Reston, Va., 888 p.

Atkinson, G.M., 2008, Ground-motion prediction equations for eastern North America from a referenced empirical approachImplications for epistemic uncertainty: Bulletin of the Seismological Society of America, v. 98, p. 1304-1318, accessed July 2018 at https://doi.org/10.1785/0120070199.

Atkinson, G.M., and Boore, D.M., 2003, Empirical ground-motion relations for subduction-zone earthquakes and their application to Cascadia and other regions: Bulletin of the Seismological Society of America, v. 93, p. 1,703-1,729, accessed July 2018 at https://doi.org/10.1785/0120020156.

Atkinson, G.M., and Boore, D.M., 2006, Earthquake ground-motion prediction equations for eastern North America: Bulletin of the Seismological Society of America, v. 96, p. 2,181-2, 205, accessed July 2018 at https://doi.org/10.1785/0120050245.

Atkinson, G.M., and Boore, D.M., 2011, Modifications to existing ground-motion prediction equations in light of new data: Bulletin of the Seismological Society of America, v. 101, p. 1,121-1,135, accessed July 2018 at https://doi. org/10.1785/0120100270.

Atkinson, G.M., and Macias, M., 2009, Predicted ground motions for great interface earthquakes in the Cascadia subduction zone: Bulletin of the Seismological Society of America, v. 99, p. 1552-1578, accessed July 2018 at https://doi. org/10.1785/0120080147.

Boore, D.M., Stewart, J.P., Seyhan, E., and Atkinson, G.M., 2014, NGA-West2 equations for predicting PGA, PGV, and 5\% damped PSA for shallow crustal earthquakes: Earthquake Spectra, v. 30, no. 3, p. 1057-1085, accessed July 2018 at https:// doi.org/10.1193/070113EQS184M.

Building Seismic Safety Council, 2010, NEHRP recommended seismic provisions for new buildings and other structures, 2009 edition: Federal Emergency Management Agency report P-750. [Also available at https://www.fema.gov/media-librarydata/20130726-1730-25045-1580/femap_750.pdf.]

Campbell, K.W., 2003, Prediction of strong ground motion using the hybrid empirical method and its use in the development of ground motion (attenuation) relations in eastern North America: Bulletin of the Seismological Society of America, v. 93, p. 1,012-1,033, accessed July 2018 at https://doi.org/10.1785/0120020002.

Campbell, K.W., and Bozorgnia, Y., 2014, NGA-West2 ground motion model for the average horizontal components of PGA, PGV, and 5\% damped linear acceleration response spectra: Earthquake Spectra, v. 30, no. 3, p. 1087-1115, accessed July 2018 at https://doi.org/10.1193/062913EQS175M.

Chiou, B.S.J., and Youngs, R.R., 2014, Update of the Chiou and Youngs NGA model for the average horizontal component of peak ground motion and response spectra: Earthquake Spectra, v. 30, no. 3, p. 1117-1153, accessed July 2018 at https://doi. org/10.1193/072813EQS219M.

Frankel, A., Mueller, C., Barnhard, T., Perkins, D., Leyendecker, E.V., Dickman, N., Hanson, S., and Hopper, M., 1996, National seismic hazard maps-Documentation June 1996: U.S. Geological Survey Open-File Report 96-532, 110 p., accessed July 2018 at https://pubs.usgs.gov/of/1996/532/.

Idriss, I.M., 2014, NGA-West2 empirical model for estimating the horizontal spectral values generated by shallow crustal earthquakes: Earthquake Spectra, v. 30, no. 3, p. 1155-1177, accessed July 2018 at https://doi.org/10.1193/070613EQS195M. 
Petersen, M.D., Frankel, A.D., Harmsen, S.C., Mueller, C.S., Haller, K.M., Wheeler, R.L., Wesson, R.L., Zeng, Y., Boyd, O.S., Perkins, D.M., Luco, N., Field, E.H., Wills, C.J., and Rukstales, K.S., 2008, Documentation for the 2008 update of the United States national seismic hazard maps: U.S. Geological Survey Open-File Report 2008-1128, 128 p., accessed July 2018 at https://pubs.usgs.gov/of/2008/1128/.

Petersen, M.D., Moschetti, M.P., Powers, P.M., Mueller, C.S., Haller, K.M., and Frankel, A.D., Zeng, Y., Rezaeian, S., Harmsen, S.C., Boyd, O.S., Field, Ned, Chen, R., Rukstales, K.S., Luco, N., Wheeler, R.L., Williams, R.A., and Olsen, A.H., 2014, Documentation for the 2014 update of the United States National Seismic Hazard Maps: U.S. Geological Survey Open-File Report 2014-1091, 243 p., accessed July 2018 at https://doi.org/10.3133/ofr20141091.

Petersen, M.D., Moschetti, M.P., Powers, P.M., Mueller, C.S., Haller, K.M., and Frankel, A.D., Zeng, Y., Rezaeian, S., Harmsen, S.C., Boyd, O.S., Field, N., Chen, R., Rukstales, K.S., Luco, N., Wheeler, R.L., Williams, R.A., and Olsen, A.H., 2015, The 2014 United States National Seismic Hazard Model: Earthquake Spectra, v. 31, no. S1, p. S1-S30., accessed July 2018 at https://doi.org/10.1193/120814EQS210M.

Pezeshk, S., Zandieh, A., and Tavakoli, B., 2011, Hybrid empirical ground-motion prediction equations for eastern North America using NGA models and updated seismological parameters: Bulletin of the Seismological Society of America, v. 101, p. 1859-1870, accessed July 2018 at https://doi.org/10.1785/0120100144.

Rezaeian, S., Petersen, M.D., and Moschetti, M.P., 2015, Ground motion models used in the 2014 U.S. National Seismic Hazard Maps: Earthquake Spectra, v. 31, no. S1, p. S59-S84, accessed July 2018 at https://doi.org/10.1193/111714EQS194M.

Shumway, A.M., 2018, Data release for additional periods and site class maps for the 2014 National Seismic Hazard Model for the conterminous United States: U.S. Geological Survey data release, https://doi.org/10.5066/P9I6BPX5.

Silva, W., Gregor, N., and Darragh, R., 2002, Development of regional hard rock attenuation relations for central and eastern North America: Pacific Engineering and Analysis Technical Report, 57 p. [Also available at http://www.pacificengineering. org/CEUS/Development of Regional Hard_ABC.pdf.]

Somerville, P., Collins, N., Abrahamson, N., Graves, R., and Saikia, C., 2001, Ground motion attenuation relations for the Central and Eastern United States-Final report, June 30, 2001: Technical report to U.S. Geological Survey, Reston, Va., under Contract 99HQGR0098, 38 p. [Also available at http://www.ce.memphis.edu/7137/PDFs/attenuations/Somerville_Abrahamson_Saikia_1999.pdf.]

Tavakoli, B., and Pezeshk, S., 2005, Empirical-stochastic ground-motion prediction for eastern North America: Bulletin of the Seismological Society of America, v. 95, p. 2283-2296, accessed July 2018 at https://doi.org/10.1785/0120050030.

Toro, G.R., 2002, Modification of the Toro et al. (1997) attenuation equations for large magnitudes and short distances: Risk Engineering, Inc. Technical Report, 10 p. [Also available at http://www.ce.memphis.edu/7137/PDFs/attenuations/Toro_2001_ (modification_1997).pdf.]

Toro, G.R., Abrahamson, N.A., and Schneider, J.F., 1997, Model of strong ground motions from earthquake in central and eastern North America-Best estimates and uncertainties: Seismological Research Letters, v. 68, p. 41-57, accessed July 2018 at https://doi.org/10.1785/gssrl.68.1.41.

Zhao, J.X., Zhang, J., Asano, A., Ohno, Y., Oouchi, T., Takahashi, T., Ogawa, H., Irikura, K., Thio, H.K., Somerville, P.G., Fukushima, Y., and Fukushima, Y., 2006, Attenuation relations of strong ground motion in Japan using site classification based on predominant period: Bulletin of the Seismological Society of America, v. 96, p. 898-913, accessed July 2018 at https://doi. org/10.1785/0120050122. 


\section{Appendix 1. Maps and Data Available for the 2014 National Seismic Hazard Model for the Conterminous United States}

Probabilistic ground motion maps (for 2, 5, and 10 percent probabilities of exceedance in 50 years), 0.1 degree by 0.1 degree gridded ground motion data, and 0.1 degree by 0.1 degree gridded seismic hazard curve data for additional period and uniform site class maps for the 2014 National Seismic Hazard Model for the conterminous United States, described in this report, are available for download at the USGS ScienceBase Catalog (Shumway, 2018). This dataset was calculated using version 1.16 of the nshmp-haz computer code (https://github.com/usgs/nshmp-haz/releases/tag/v1.1.6) and version 4.20 of the nshm-cous-2014 source model (https://github.com/usgs/nshm-cous-2014/releases/tag/v4.2.0).

Table 1.1 List of probabilistic ground motion hazard maps, gridded ground motion data, and seismic hazard curve data available for the 2014 National Seismic Hazard Model.

[SA, spectral acceleration; s, seconds; $\mathrm{V}_{\mathrm{S} 30}$, shear wave velocity in the upper 30 meters; NEHRP, National Earthquake Hazards Reduction Program; CEUS, central and eastern United States; WUS, western United States; conterminous, conterminous United States; PGA, peak ground acceleration; m/s, meters per second; \%, percent; GM, ground motion]

\begin{tabular}{|c|c|c|c|c|c|c|}
\hline \multirow[b]{2}{*}{ Region } & \multirow[b]{2}{*}{ SA } & \multirow{2}{*}{$\begin{array}{l}\text { Probability of } \\
\text { exceedance }\end{array}$} & \multirow[b]{2}{*}{$\mathbf{V}_{\mathrm{s} 30}$} & \multicolumn{3}{|c|}{ Data format } \\
\hline & & & & Maps & Gridded GM data & $\begin{array}{l}\text { Gridded hazard } \\
\text { curves }^{1}\end{array}$ \\
\hline CEUS & PGA & $2,5,10 \%$ in 50 years & $2,000 \mathrm{~m} / \mathrm{s}$ & PDF & Text & Text \\
\hline CEUS & $0.1 \mathrm{~s}$ & $2,5,10 \%$ in 50 years & $2,000 \mathrm{~m} / \mathrm{s}$ & PDF & Text & Text \\
\hline CEUS & $0.5 \mathrm{~s}$ & $2,5,10 \%$ in 50 years & $2,000 \mathrm{~m} / \mathrm{s}$ & PDF & Text & Text \\
\hline CEUS & $1.0 \mathrm{~s}$ & $2,5,10 \%$ in 50 years & $2,000 \mathrm{~m} / \mathrm{s}$ & PDF & Text & Text \\
\hline CEUS & $2.0 \mathrm{~s}$ & $2,5,10 \%$ in 50 years & $2,000 \mathrm{~m} / \mathrm{s}$ & PDF & Text & Text \\
\hline \multicolumn{7}{|c|}{ NEHRP Site Class Boundary A/B } \\
\hline WUS & $0.5 \mathrm{~s}$ & $2,5,10 \%$ in 50 years & $1,500 \mathrm{~m} / \mathrm{s}$ & PDF & Text & Text \\
\hline WUS & $0.75 \mathrm{~s}$ & $2,5,10 \%$ in 50 years & $1,500 \mathrm{~m} / \mathrm{s}$ & PDF & Text & Text \\
\hline WUS & $1.0 \mathrm{~s}$ & $2,5,10 \%$ in 50 years & $1,500 \mathrm{~m} / \mathrm{s}$ & PDF & Text & Text \\
\hline WUS & $2.0 \mathrm{~s}$ & $2,5,10 \%$ in 50 years & $1,500 \mathrm{~m} / \mathrm{s}$ & PDF & Text & Text \\
\hline WUS & $3.0 \mathrm{~s}$ & $2,5,10 \%$ in 50 years & $1,500 \mathrm{~m} / \mathrm{s}$ & PDF & Text & Text \\
\hline WUS & $4.0 \mathrm{~s}$ & $2,5,10 \%$ in 50 years & $1,500 \mathrm{~m} / \mathrm{s}$ & PDF & Text & Text \\
\hline WUS & $5.0 \mathrm{~s}$ & $2,5,10 \%$ in 50 years & $1,500 \mathrm{~m} / \mathrm{s}$ & PDF & Text & Text \\
\hline \multicolumn{7}{|c|}{ NEHRP Site Class B } \\
\hline WUS & PGA & $2,5,10 \%$ in 50 years & $1,080 \mathrm{~m} / \mathrm{s}$ & PDF & Text & Text \\
\hline
\end{tabular}


Table 1.1 List of probabilistic ground motion hazard maps, gridded ground motion data, and seismic hazard curve data available for the 2014 National Seismic Hazard Model.-Continued

[SA, spectral acceleration; s, seconds; $\mathrm{V}_{\mathrm{S} 30}$, shear wave velocity in the upper 30 meters; NEHRP, National Earthquake Hazards Reduction Program; CEUS, central and eastern United States; WUS, western United States; conterminous, conterminous United States; PGA, peak ground acceleration; m/s, meters per second; \%, percent; GM, ground motion]

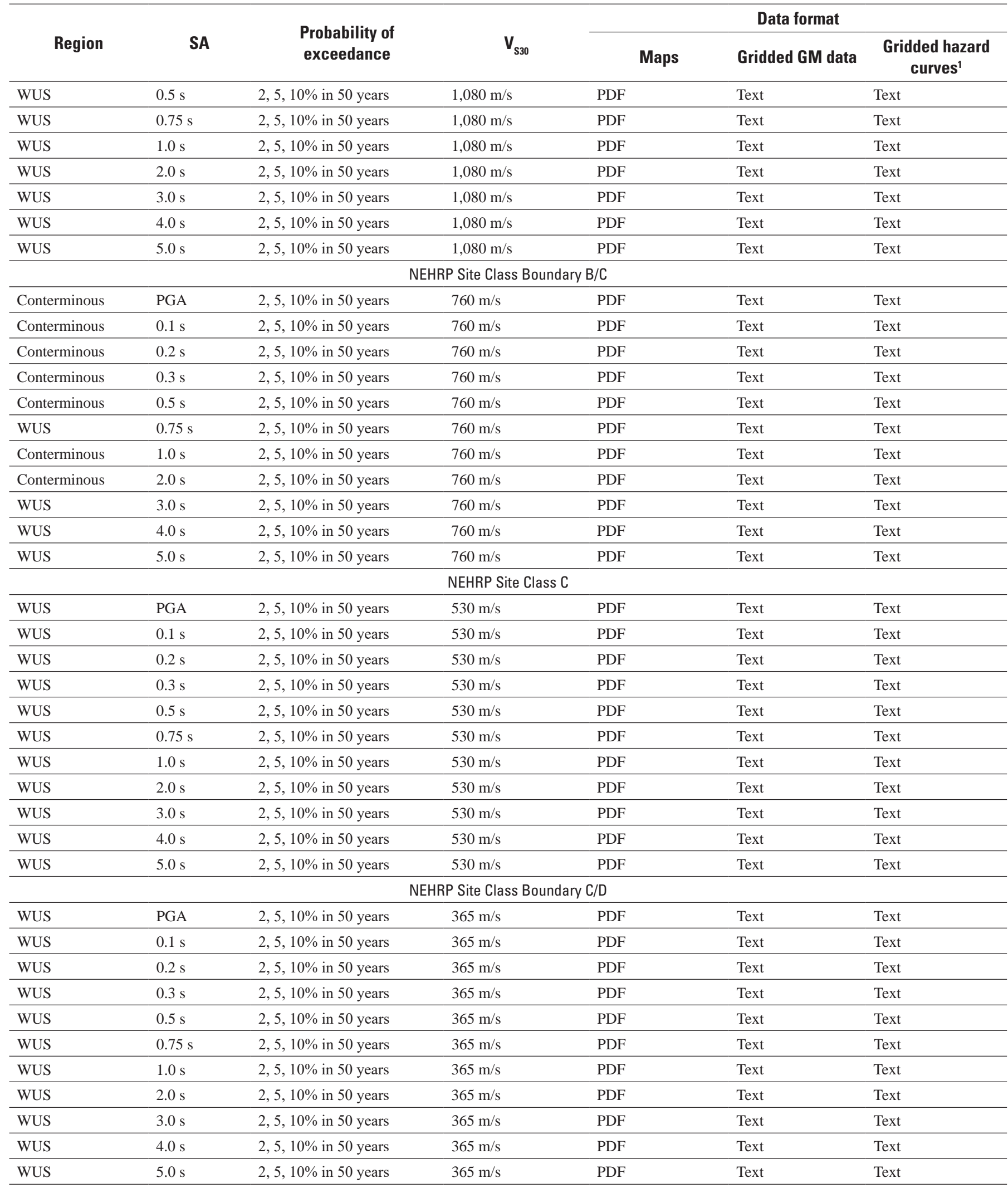


Table 1.1 List of probabilistic ground motion hazard maps, gridded ground motion data, and seismic hazard curve data available for the 2014 National Seismic Hazard Model.-Continued

[SA, spectral acceleration; s, seconds; $\mathrm{V}_{\mathrm{S} 30}$, shear wave velocity in the upper 30 meters; NEHRP, National Earthquake Hazards Reduction Program; CEUS, central and eastern United States; WUS, western United States; conterminous, conterminous United States; PGA, peak ground acceleration; m/s, meters per second; \%, percent; GM, ground motion]

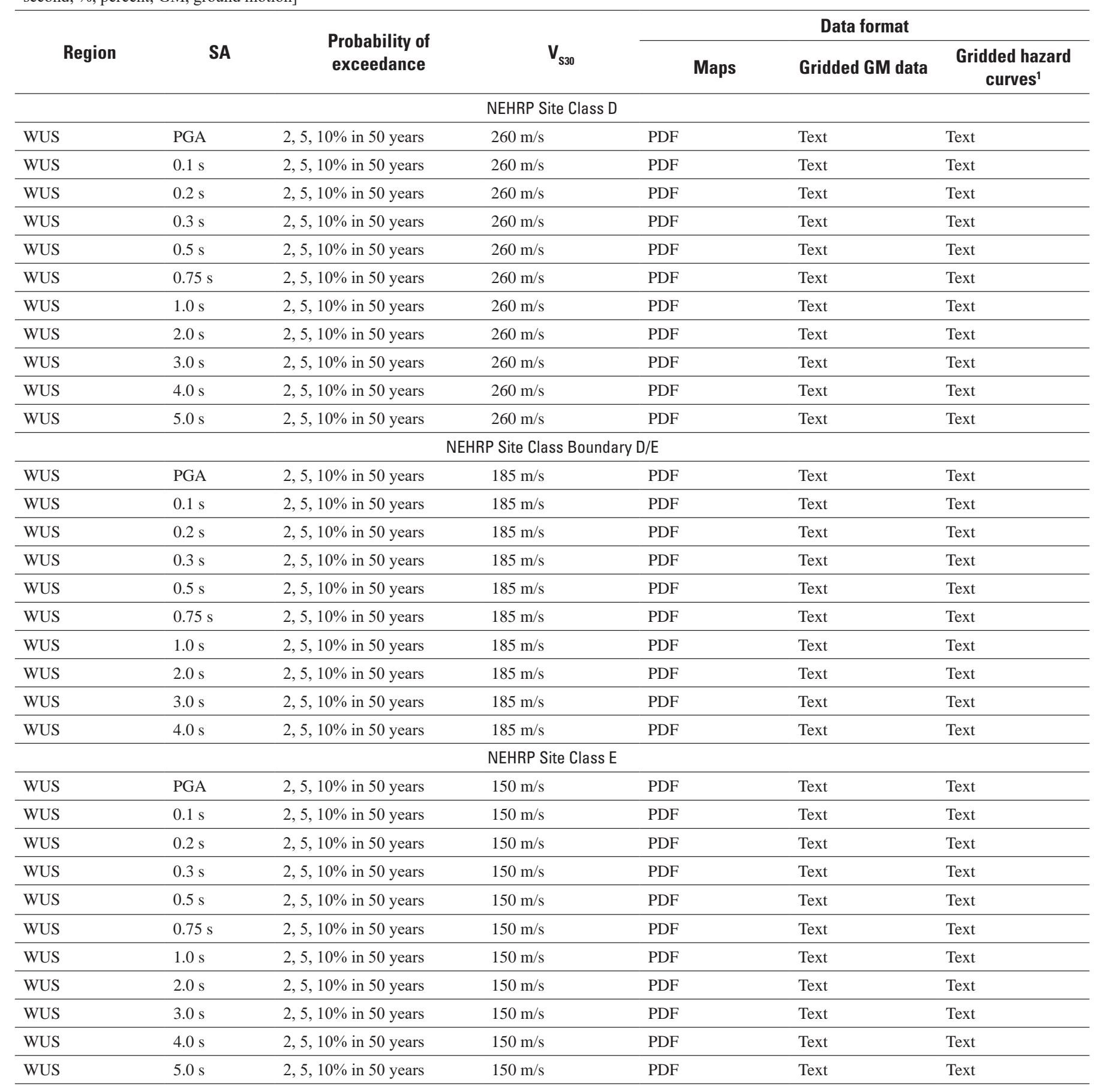

${ }^{1}$ Probability of exceedance is not applicable to hazard curve data. 
Publishing support provided by the Science Publishing Network, West Trenton and Denver Publishing Service Centers

For more information concerning the research in this report, contact the Center Director, USGS Geologic Hazards Science Center

Box 25046, Mail Stop 966

Denver, CO 80225

(303) 273-8579

Or visit Geologic Hazards Science Center website at https://geohazards.cr.usgs.gov/ 
